RICARDO SOEIRO RODRIGUES

\title{
ESTUDO COMPARATIVO DA INTENSIDADE DA FORÇA DE MORDIDA DE PRÓTESES TOTAIS CONVENCIONAIS E OVERDENTURES INFERIORES RETIDAS POR SISTEMA BARRA/CLIP SOBRE IMPLANTE
}




\section{Ricardo Soeiro Rodrigues}

Estudo comparativo da intensidade da força de mordida de próteses totais convencionais e overdentures inferiores retidas por sistema barra/clip sobre implante

Tese apresentada à Faculdade de Odontologia da Universidade de São Paulo, para obter o Título de Doutor pelo Programa de Pós-graduação em Odontologia.

Área de concentração: Prótese Dentária

Orientador : Prof. Dr. Vyto Kiausinis 


\section{FOLHA DE APROVAÇÃO}

Rodrigues R.S. Estudo comparativo da intensidade da força de mordida de próteses totais convencionais e Overdentures inferiores retidas por sistema barra/clip sobre implante [Tese de Doutorado]. São Paulo: Faculdade de Odontologia da USP; 2007.

São Paulo, / /2007

\section{Banca Examinadora}

1) $\operatorname{Prof}(a) . \operatorname{Dr}(a)$

Titulação:

Julgamento:

Assinatura:

2) $\operatorname{Prof}(a) . \operatorname{Dr}(a)$

Titulação:

Julgamento: Assinatura:

3) $\operatorname{Prof}(a) . \operatorname{Dr}(a)$.

Titulação:

Julgamento:

Assinatura:

4) $\operatorname{Prof}(a) . \operatorname{Dr}(a)$.

Titulação:

Julgamento:

Assinatura:

5) $\operatorname{Prof}(a) . \operatorname{Dr}(a)$.

Titulação:

Julgamento:

Assinatura: 


\title{
DEDICATÓRIA
}

\section{Aos meus amados pais RUY E MARIA CECILIA}

Por serem tudo que um filho pode desejar.

Amo vocês

Minhas irmãs MOCA e DEDÉ

As melhores irmãs do mundo.

\section{À FABIOLA}

Pelo amor e alegria sempre presentes.

Te Amo

\author{
À minha avó Hortência \\ Exemplo de vitalidade e alegria.
}

Aos meus tios MARIALICE e BERTINHO

Sempre presentes com carinho em minha vida. 
Ao meu orientador Prof. Dr Vyto Kiausinis,

Grande amigo, colega e professor.

Ao Prof. Dr Roberto Nobuaki Yamada

Pela pessoa maravilhosa que é.

À Profa. Dra. Maria Cecília Milluzi

Pelo exemplo de força e determinação.

Prof. Dr. Atlas Edson Moleros Nakamae

Pela oportunidade de aprendizado e crescimento profissional.

Profa. Dra. Regina Tamaki

Pelo companheirismo e alegria.

Prof. Max Dalla Kiausinis

Amigo e parceiro.

Ao Roger e Ricardo Jun

Amigos que nunca negaram uma ajuda.

Sem vocês está tese não seria possível 
AGRADECIMENTOS ESPECIAIS

À FACULDADE DE ODONTOLOGIA DA UNIVERSIDADE DE SÃO PAULO

Minha escola.

À Deus por me proporcionar uma vida cheia de alegria e sucesso

Grandes amigos

Uma família maravilhosa 


\section{AGRADECIMENTOS}

A Faculdade de Odontologia da Universidade de São Paulo, na pessoa do Prof. Dr. Carlos de Paula Eduardo.

Aos membros da Comissão de Pós-Graduação da Faculdade de Odontologia da USP, presidida pelo Prof. Dr. Reinaldo Brito e Dias.

Aos Professores da Disciplina de Prótese Total da Faculdade de Odontologia da Universidade de São Paulo, Profa. Dra. Maria Cecília Miluzzi, Prof. Dr. Vyto Kiausinis, Prof. Dr. Roberto Nobuaki Yamada, Prof. Dr. Atlas Edson Moleros Nakamae, Prof. Dra. Regina Tamaki, pelo carinho e oportunidade de crescimento profissional.

À Prof Dra. Maria Cecília Milluzi Chefe da Disciplina de Prótese Total da Faculdade de Odontologia da USP.

Ao Prof. Dr. Gerson de Arruda Correa, a Profa. Dra. Maria Luiza Frigério e a Profa. Dra Zlata Victoronova .

Aos meus amigos e colegas da Disciplina de Prótese Total da Faculdade de Odontologia da Usp, em especial ao Eder, Tati, Flavio, Roger, Jun, Karin, Tati e Matheus.

Aos funcionários do Departamento de Prótese Dentária da Faculdade de Odontologia da USP, Sandra, Regina, Coraci, Neizinha, Paula, Zeza, Lena, Marco e Ana, sempre prestativos e carinhosos.

Ao Luis Cláudio, técnico da disciplina de Prótese Total da FOUSP, grande amigo. 
Aos Professores da Disciplina de Prótese Parcial Fixa da Faculdade de Odontologia da USP.

Aos Professores da Disciplina de Prótese Parcial Removível da faculdade de Odontologia da USP.

Ao Prof. Dr. Átônio Sergio Guimarães, pela oportunidade de aprendizado profissional e por abrir as portas de sua casa onde foi possível a realização deste experimento.

Ao Prof. Dr. Lupi da Veiga, grande amigo.

Aos colegas da Pós Graduação, Eder Jun Hatushikano, Tatiana Guarnieri, Flavio Jun Yamaguti, Ricardo Jun, Max Dalla, Andréa Carradori e Paulo Mazzini.

Às funcionárias do Serviço de Pós-Graduação da Faculdade de Odontologia da USP, Catia Tiezzi dos Santos e Nair Natsuko Tanaka.

À Bibliotecária Glauci Elaine Damasio Fidelis e demais funcionários do Serviço de Documentação Odontológica da Faculdade de Odontologia da USP.

À Prof. Dra. Denise Aparecida Botter do Instituto de Matemática e Estatística da universidade de São Paulo.

Aos colegas e amigos Prof. Dr. Sergio Ourike e Prof. Dr. Mario Perito.

Aos meus grandes amigos pessoais, Fernando, Alex, Gil, Leo e Dri, Gisa e Dani, Clau, Lelo e Ro, Lobeira, Pauliho, Boi e XI, André, Cebrian e Max.

Aos meus familiares, amigos e colegas não listados, mas nem por isso esquecidos ou menos importantes. 
Rodrigues RS. Estudo comparativo da intensidade da força de mordida de próteses totais convencionais e Overdentures inferiores retidas por sistema barra/clip sobre implante [Tese de Doutorado]. São Paulo: Faculdade de Odontologia da USP; 2007.

\section{RESUMO}

O objetivo da pesquisa foi comparar a intensidade da força de mordida, utilizando um gnatodinamometro em pacientes edentados que utilizam Próteses Totais superiores e Overdentures inferiores retidas por sistema barra/clipe e avaliar por meio de um questionário a satisfação geral destes pacientes após a reabilitação por próteses sobre implantes. O estudo foi desenvolvido em duas etapas: a primeira parte enfocou a mensuração da intensidade da força de mordida na região dos primeiros molares de ambos os lados, com o paciente utilizando a prótese total superior e a overdenture inferior e a repetição do exame após a remoção da barra sobre implante, tornando-se assim um paciente portador de Próteses Totais bimaxilares convencionais. Em média a intensidade máxima da força de mordida, obtida quando o paciente estava com a barra (overdenture inferior) foi de 8,9 Kgf, e quando a barra era removida (Prótese Total bimaxilar) foi de 4,8 Kgf. Ocorrendo praticamente um aumento de $100 \%$ na intensidade da força com a colocação da prótese sobre implante inferior. Já na segunda parte foi aplicado um questionário com o intuito de comparar a capacidade do paciente de mastigar certos tipos de alimentos com a prótese antiga e com a prótese sobre implante, e avaliar sua satisfação pessoal. Os resultados das respostas dos questionários demonstraram que $100 \%$ dos pacientes relataram dificuldade, com relação à mastigação de Cenoura crua e Amendoim. No entanto, com a prótese sobre implantes, mais de 
91\% afirmaram sentirem-se confortáveis ao mastigar esses alimentos. As porcentagens atingiram 100\% para Pudim, Banana e Maçã. Com a prótese antiga, a capacidade de mastigar era reduzida, visto que notas (0) zero e (4) quatro foram atribuídas por mais de $86 \%$ dos pacientes, já com a prótese sobre implantes, a avaliação da capacidade de mastigar melhorou muito, uma vez que $100 \%$ dos pacientes atribuíram notas iguais ou superiores a 8 (oito). Desta forma pode-se concluir que a reabilitação com próteses sobre implantes em pacientes edentados, proporciona um aumento da intensidade da força de mordida em mais de $100 \%$, ou seja, o dobro em relação a próteses Totais Convencionais. A satisfação geral, com relação ao tratamento envolvendo implantes foi excelente, uma vez que mais de 95\% dos pacientes avaliaram o trabalho com notas iguais a 9 (nove) ou 10 (dez).

Palavras-Chave: Prótese Total - Força de mordida - Overdentures - Reabilitação Oral - Prótese sobre implantes osseointegrados - Prótese Total. 
Rodrigues RS. Comparisions of maximum bite force with mandibular conventional dentures and implant-supported Overdentures [Tese de Doutorado]. São Paulo: Faculdade de Odontologia da USP; 2007.

\begin{abstract}
The objective of the research was to compare the intensity of the bite force, using an gnatodinamometer in edentulous patients that use superior complete denture and inferior Overdentures retained by clip bar system and to evaluate general satisfaction of these patients after the rehabilitation with the prostheses on implants through a questionnaire. The study was developed in two stages: the first part focused the mensuration of the intensity of the bite force in the area of the first molars on both sides, with the patient using the superior complete denture and the inferior overdenture and after the removal of the bar on implant, thus becoming a patient with a complete conventional denture. On average the maximum intensity of the bite force, obtained when the patient was with the bar (inferior overdenture) was of 8,9 Kgf, and when the bar was removed (prosthesis total bimaxilar) it was of $4,8 \mathrm{Kgf}$. notecing an increase of $100 \%$ practically in the intensity of the force with the placement of the prosthesis on inferior implant. In the second part a questionnaire was applied with the intention of comparing the capacity of the patient to chew certain types of foods with the old prosthesis and with the prosthesis on implant, and to evaluate his/her personal satisfaction. The results of the questionnaires demonstrated that $100 \%$ of the patients talked about difficulties regarding the mastication of raw carrot and peanut. However, with the prosthesis on implants, more than $91 \%$ reported to feel comfortable when chewing those foods.
\end{abstract}


The percentages reached $100 \%$ for pudding, banana and apple. With the old prosthesis, the capacity to chew was reduced, as grades (0) zero and (4) four were attributed by more than $86 \%$ of the patients. As regards the prosthesis on implants, the evaluation of the capacity of chewing got much better as $100 \%$ of the patients attributed grades equal or superior to 8 (eight). This way it can be concluded that the rehabilitation with prostheses on implants in edentulous patients, provides an increase of the intensity of the bite force in more than $100 \%$, in other words, the double in relation to conventional complete denture and the general satisfaction, regarding the treatment involving implants was great, as more than $95 \%$ of the patients evaluated the work with grades equal to 9 (nine) or 10 (ten).

Keywords: Complete Denture- Overdenture - Bite Force - Oral Rehabilitation 


\section{LISTA DE ILUSTRAÇÕES}

Figura 4.1 - Gnatodinamometro, marca Kratos, mod. TRCv36A. .52

Figura 4.2 - Paciente executando o teste de mensuração da intensidade da força de mordida .53

Figura 4.3 - Moldagem funcional de transferência. .57

Figura 4.4 - Modelo de trabalho com análogo. .57

Figura 4.5 - Calcinável e barra posicionados. .57

Figura 4.6 - Barra fundida em NiCr. .57

Figura 4.7 - Prova da barra em posição na boca. .57

Figura 4.8 - Clip fixado no laboratório. .57

Gráfico 4.1 - Demonstrativo da conversão dos dados pelo software, de um exame executado por um paciente, lado direito com barra. .53

Gráfico 5.1 - Perfil de médias da variável Força por Tratamento. .78 
Quadro 4.1 - Dados obtidos no primeiro exame do lado direito com barra, paciente $1 .$.

Quadro 4.2 - Demonstração dos dados avaliados durante o exame de mensuração da força de mordida no paciente 1 . 62 


\section{LISTA DE TABELAS}

Tabela 5.1 - Distribuição de freqüências da variável (Queixa principal). 68

Tabela 5.2 - Distribuição de freqüências da variável (Mastigava confortavelmente com a prótese antiga).

Tabela 5.3 - Distribuição de freqüências da variável (Capacidade de mastigar com a prótese antiga).

Tabela 5.4 - Distribuição de freqüências da variável (Gosta da junção entre implante e gengiva).

Tabela 5.5 - Distribuição de freqüências da variável (Sente cheiro ruim na sua prótese sobre implantes) 69

Tabela 5.6- Distribuição de freqüências da variável (Escova seus implantes todas as vezes que se alimenta). 70

Tabela 5.7- Distribuição de freqüências da variável (Acha difícil sua tarefa de limpar os implantes e a barra). .70

Tabela 5.8 - Distribuição de freqüências da variável (Mastiga confortavelmente com a prótese sobre implantes). 70

Tabela 5.9 - Distribuição de freqüências da variável (Capacidade de mastigar com a prótese sobre implantes).

Tabela 5.10- Distribuição de freqüências da variável (Faria implantes novamente). 
Tabela 5.11 - Distribuição de freqüências da variável (Pretende continuar o trabalho de reabilitação). 71

Tabela 5.12 - Distribuição de freqüências da variável ( Indicaria implantes para outras pessoas).

Tabela 5.13 - Distribuição de freqüências da variável (Satisfação geral em relação ao tratamento envolvendo implantes) .72

Tabela 5.14 - Distribuição de freqüências (\%) da variável (Resposta mais freqüente da sensibilidade da mucosa). 75

Tabela 5.15 - Dados dos pacientes (média dos valores máximos obtidos nas três avaliações da variável Força). .77

Tabela 5.16 - Estatísticas descritivas para a variável Força. .78

Tabela 5.17 - Resultados da Análise de Variância .79

Tabela 5.18 - Intervalos de confiança construídos pelo método de Tukey com coeficiente de confiança global igual a 95\% para diferenças entre médias da variável Força. .79

Tabela 5.19 - Distribuição de freqüências conjuntas (\%) das variáveis Lado dominante e Lado mais Forte. 


\section{LISTA DE ABREVIATURAS E SIGLAS}

$\begin{array}{ll}\text { ATM } & \text { Articulação TemporoMandibular } \\ \mathrm{cm} & \text { Centímetros } \\ \text { FUNDECTO } & \text { Fundação para o Desenvolvimento Científico e Tecnológico } \\ \mathrm{Gb} & \text { Giga Bites } \\ \mathrm{HD} & \text { Hard Disc } \\ \text { Kgf } & \text { Quilograma -força }\end{array}$




\section{SUMÁRIO}

p.

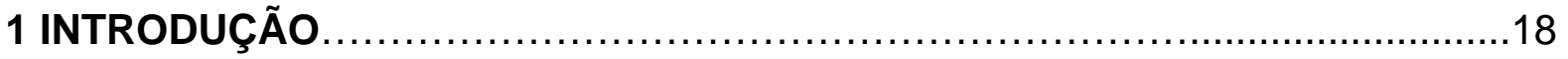

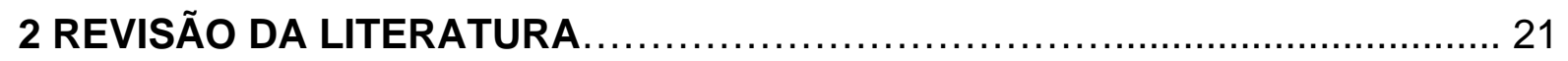

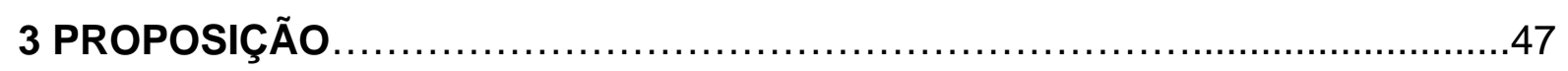

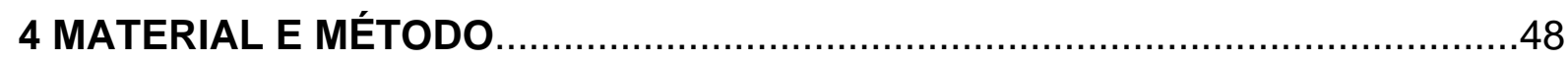

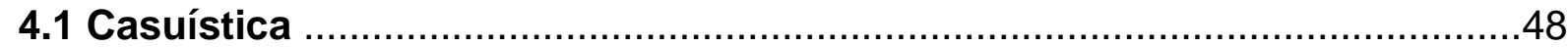

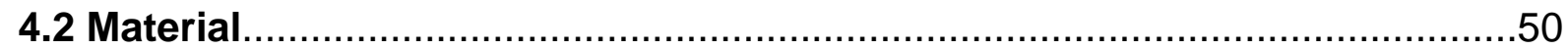

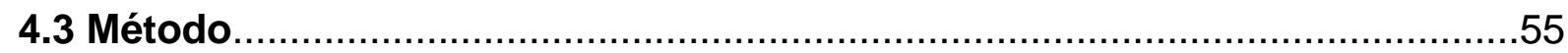

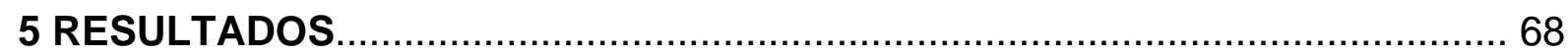

5.1 Análise Estatística das Respostas do Questionário............................... 68

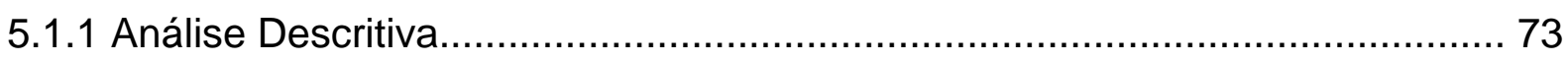

5.2 Análise Estatística da Sensibilidade da Mucosa..................................... 74

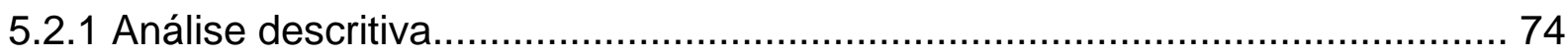

5.3 Análise Estatística da Intensidade da Força de Mordida..........................76

5.3.1 Descrição das Variáveis............................................................... 76

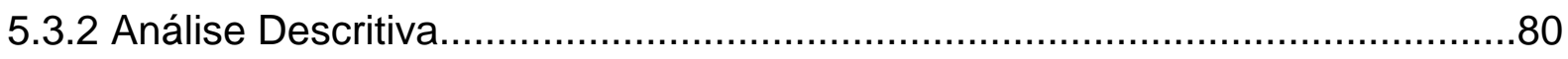

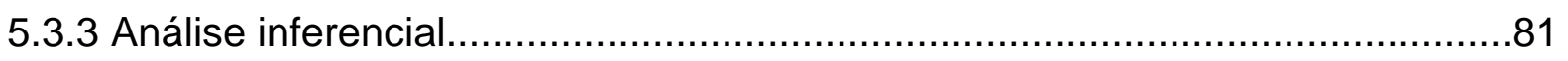

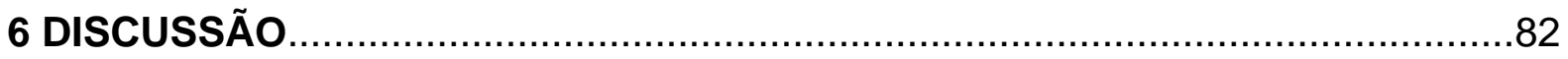

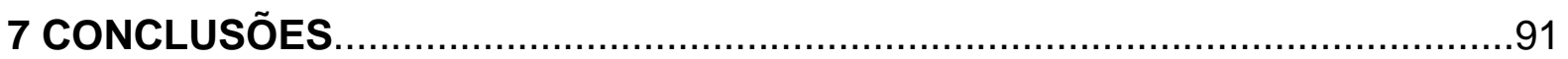

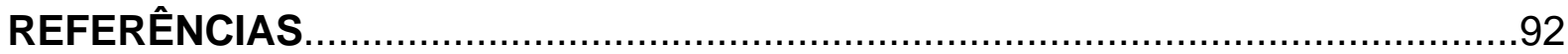

APÊNDICES

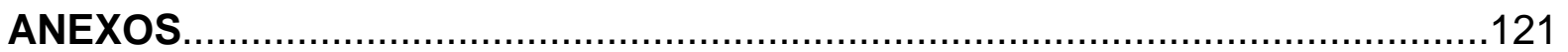




\section{INTRODUÇÃO}

A perda de um ou mais dentes naturais, produz esforços anormais, acarretando uma sobrecarga e diminuição da função, que se caracteriza por distúrbios oclusais, modificando todo o sistema mastigatório. A contínua reabsorção do rebordo alveolar após a extração dos dentes propicia para o sistema uma anatomia que oferece suporte inadequado para as próteses Tallgren (1972).

Reabilitação oral por uma prótese total convencional, mesmo quando bem executada, pode não resolver completamente os problemas funcionais e psicológicos dos pacientes edêntulos, além da redução quantitativa da eficiência mastigatória os pacientes reabilitados por uma prótese convencional também sofrem uma alteração qualitativa da função de mastigação Pêra et al. (1998).

A literatura tem sugerido que a presença de implantes pode melhorar a função oral dos pacientes com rebordo inferior bem reabsorvido, restaurando a função em portadores de próteses totais. Um alto grau de sucesso vem sendo documentado em estudos com próteses suportadas por implantes, obtendo-se maior satisfação, alcançando melhor eficiência mastigatória Jemt, Lindquist e Hedegard (1995), Boerrigter et al. (1993), Benzing (1994), Geertman et al. (1999), Pêra et al (1998), Fontjin-Tekamp et al. (2000), Chen et al. (2002) e Awad et al. ( 2003).

Nesse contexto, uma das formas de solução protética é representada pela overdenture, citada por diferentes autores, por proporcionar maior retenção e estabilidade nos casos de prótese total Branemark, Zarb e Albrektsson (1987), Bortoli Jr. (1996), Chen et al. (2002) e Awad et al. (2003)..

Os resultados de estudos de mastigação com próteses totais apresentam 
determinantes multifatoriais tais como: idade, sexo, anos de edentulismo, condição protética, retenção da prótese e a experiência em usar as próteses Geertman et al. (1999).

A pouca retenção e estabilidade de uma prótese total inferior leva a uma diminuição da eficiência mastigatória, levando os pacientes a optarem por um tratamento com implantes. Quase a totalidade dos pacientes com próteses implantosuportadas em mandíbula descreve uma melhora na função mastigatória e na qualidade de vida Benzing et al (1994).

As forças oriundas do sistema mastigatório resultam da coordenação entre atividade neuro-muscular, óssea e dental. Estas forças denominadas de forças oclusais são dirigidas axialmente à superfície oclusal dos dentes e se dividem em: força máxima de mordida, que equivale à força produzida pelo esforço máximo dos músculos elevadores da mandíbula; e força de mastigação, que é gerada durante o ato mastigatório.

Desse modo, entende-se por força máxima de mordida, a capacidade dos músculos elevadores da mandíbula, exercerem um esforço máximo dos dentes inferiores contra os superiores. E por força de mastigação, entende-se como um ato biomecânico de fragmentação dos alimentos exercido pelos movimentos precisos de várias estruturas incluindo lábios, bochechas, língua e articulação temporomandibular. Estes movimentos são coordenados através de um complexo mecanismo neuro-muscular, permitindo aos dentes triturar eficientemente os alimentos Carlsson (1974) e Bates et al. (1975)

Estudos que visam melhorar o conhecimento das forças oclusais, têm como objetivo, através de várias técnicas de mensuração, verificar a capacidade do indivíduo para detectar ou para discriminar, as forças aplicadas aos dentes naturais 
e ou artificiais Maxifield, Nicholls e Smik (1979), Gunne, Wall (1985) .

Boretti et al. (1995) relatam que entre os testes clínicos de efetividade mastigatória, encontra-se a medida da força de mordida e este é um método indireto baseado na correlação da função mastigatória com a força de mordida.

Fontiin-Tekamp et al. (2001) encontraram em seus estudos uma significante correlação entre a força de mordida e a eficiência mastigatória.

A Disciplina de Prótese Total da Faculdade de Odontologia da USP, sempre se preocupou com as dificuldades inerentes à reabilitação de pacientes desdentados. Com o intuito de aprimorar a especialidade novas linhas de pesquisas foram desenvolvidas, na tentativa de padronização, atualização e desenvolvimento de novas técnicas, tanto do ponto de vista clinico como laboratorial. Dentre estes trabalhos podemos citar Honda (2001), Ribeiro (2002), Rodrigues (2002), Hatushikano (2002 e 2006), Bindo (2003), Rojas (2003), Mazini (2003) e Guarnieri (2006).

Se desenvolve dentro da Disciplina de Prótese Total, um grupo de pesquisa denominado "Clínica de Overdenture" (onde foi desenvolvido este projeto), cuja finalidade é o estudo e desenvolvimento das técnicas de reabilitação de pacientes edentados com próteses sobre implantes osseointegrados. A presente pesquisa avalia a melhora que a reabilitação por prótese sobre implantes em pacientes desdentados pode proporcionar em relação a sua satisfação pessoal e capacidade de mastigar, uma vez que passamos de um aparelho mucoso-suportado para um aparelho mucoso-suportado e implanto-retido. 


\section{REVISÃO DA LITERATURA}

* Forças de mordida e de mastigação, questionários

Estudos relacionados a mensurações de forças resultantes do processo de mastigação, datam de mais de um século. Apresentamos uma revisão dos trabalhos científicos realizados em vários países, que revelou valores e métodos distintos.

Black (1895) apresentou um aparelho denominado gnatodinamômetro destinado a medir as forças de mordidas em pacientes portadores de dentes naturais e artificiais, acrescentando que a força máxima de mordida poderia ser limitada pela inibição do periodonto, e que o bloqueio dos nervos periodontais com anestesia local, resultaria em aumento da força de mordida. Segundo o autor os registros dos esforços mastigatórios por ele obtidos seriam limitados pela capacidade de registro do aparelho e estariam em torno de $125 \mathrm{kgf}$. É também sua a primeira tentativa para avaliar as forças desenvolvidas durante a mastigação em uma série de alimentos em laboratório, pela utilização de um aparelho denominado fagodinamômetro.

Head (1906), estudou as forças desenvolvidas durante a mastigação, através de um aparelho extra-oral por ele desenvolvido, no qual era obtida a trituração ou moagem do alimento. Por este método, ele demonstrou que se requer força consideralvemente menor na trituração dos alimentos, do que a força máxima de mordida. 
Com o objetivo de se determinar a força de mordida estática tanto em dentições naturais, como em pacientes portadores de prótese, Worner (1939), verificou ser difícil comparar estudos, devido às diferentes técnicas utilizadas e à variabilidade presente nos pacientes portadores de diferentes tipos de próteses. $\mathrm{O}$ autor verificou, ainda, que os valores das forças obtidas com os dentes naturais são 4 vezes maiores que os obtidos com próteses totais, desse modo, uma diferença similar foi encontrada nos indivíduos que usam prótese contra dentes naturais.

Boss (1940) foi um dos primeiros que reconheceu a influência dos músculos elevadores da mandíbula durante o registro da dimensão vertical, e introduziu um instrumento de medida denominado "BIMETER" para medir a força de mordida em pacientes edentados. Examinou mais de 300 pacientes em diferentes dimensões verticais. Obteve resultados que variam de 6 a $50 \mathrm{kgf}$, sendo que estes valores foram, em média, de 30 a $32.5 \mathrm{kgf}$ para os homens e 12.5 a $15 \mathrm{kgf}$ para as mulheres. Segundo o autor existe um ponto crítico para cada paciente, no qual a distância da origem com a inserção dos músculos exercem uma força de contração, em nível máximo, próximo da dimensão vertical de repouso, ocasião em que a força de mordida é máxima.

Bekhus et al. (1941), verificaram que uma pessoa raramente registra a mesma força de mordida, e que esta variação pode ser atribuída a fatores fisiológicos e psicológicos. Desse modo, os autores estudaram 128 pessoas divididos em 3 grupos: grupo I - 62 homens, grupo II - 46 homens, grupo III 20 mulheres. A força de mordida média do grupo I foi de 67 kgf e após 9 semanas, a média encontrada foi de 68 kgf. este grupo foi considerado padrão, não sendo 
submetido a nenhum procedimento experimental. A média de força de mordida do grupo II no início da experiência foi de $59 \mathrm{kgf}$. No final da 3 semana a média registrada foi de $60 \mathrm{kgf}$. Após 50 dias consecutivos mastigando cera parafinada por um período de uma hora-dia, outros registros foram obtidos e a média encontrada foi de 71kgf. Posteriormente, duas semanas após a realização da experiência, uma medida final foi realizada no grupo II e a média retornou aos 59 kgf. iniciais, o mesmo foi feito no grupo III . Concluindo os autores afirmaram que a força dos músculos de mastigação é influenciada pelo uso que dela se faz, dentro de limites fisiológicos, e desta forma não diferem dos músculos de qualquer outra parte do corpo.

Howell e Manly (1948), demonstraram que a força de mordida ao nível dos dentes primeiros molares é de 45 a 99kgf e que nas regiões de incisivos centrais é de 14 a 25.5 kgf.

Howell e Brudevold (1950), estudaram as forças de mastigação em pacientes portadores de próteses totais, utilizando um método pelo qual as forças foram medidas diretamente na boca através de transdutores colocados nos dentes. Os resultados obtidos destes estudos indicaram que as forças utilizadas durante a mastigação com próteses são consideravelmente menores do que em pacientes dentados, tendo uma força média de 4kgf e uma máxima de 7kgf.

Segundo Lambrecht (1965), a área das superfícies oclusais dos dentes que fazem contacto durante a oclusão pode ser um fator importante na definição da eficiência mastigatória. E que, esta área de contacto oclusal depende do tamanho e 
forma da superfície oclusal dos dentes, da sua intercuspidação, da forma das cúspides, da quantidade de abrasão ou rotação e da existência de algum tipo de maloclusão.

Algerbeg e Carlsson (1981), observaram que testes de eficiência mastigatória são demorados e usualmente requerem equipamentos de laboratório, o que os tornam inaplicáveis a uma população de número extenso. Desta forma, para avaliar a eficiência e satisfação com a mastigação, usaram como método de pesquisa o envio de um questionário a 1215 pessoas entre 15 e 75 anos de idade escolhidas por amostragem, salientando a subjetividade e aplicabilidade do método.

De acordo com os resultados obtidos, concluíram que as respostas obtidas pelos questionários estavam diretamente relacionadas com o número de dentes remanescentes, ou seja, os pacientes que reclamaram de uma pobre habilidade mastigatória possuíam motivos pertinentes para tal: apresentavam em média um menor número de dentes remanescentes, que estavam freqüentemente distribuídos de maneira desigual nos arcos dentários ou usavam algum tipo de prótese.

Lindquist e Carlsson (1982b) trataram 25 pacientes com problemas na adaptação de suas próteses totais convencionais com próteses novas e depois com overdentures mandibulares. A função mastigatória foi avaliada por três métodos: por quetionário, capacidade de triturar amêndoas e a força de mordida. Nenhuma melhora significativa foi observada após a instalação das próteses novas, porém, após a colocação dos implantes houve um aumento da habilidade e eficiência mastigatória e aumento da intensidade da força de mordida. Oito dos dez alimentos apontados no questionário eram retratados com difíceis ou impossíveis de serem 
mastigados antes da reabilitação, porém, nenhum após a colocação das overdentures. O tempo de mastigação caiu de 49s para 43s com a nova prótese e para 20s com a overdenture. A força de mordida aumentou em 15\% com as próteses novas e em $85 \%$ com a colocação das próteses sobre implantes.

Lindquist e Carlson (1985a), num estudo longitudinal de 3 anos, avaliaram as mudanças na mastigação em 27 pacientes com próteses totais mal adaptadas que foram substituídas inicialmente por próteses novas, a seguir, por próteses fixas totais apoiadas sobre implantes na mandíbula e próteses totais convencionais na maxila.

Para a auto-avliação da habilidade mastigatória pelos pacientes , foi apresentada uma 'escala análoga visual' antes do tratamento, quando eram portadores de prótese convencionais e após a instalação de próteses sobre implantes. As escalas eram formadas de linhas horizontais de $10 \mathrm{~mm}$ de comprimento, marcada do lado esquerdo com um índice suposto 0\% de eficiência e no outro extremo do lado direito um índice de 100\%, que correspondia a um paciente totalmente dentado. Os pacientes marcavam um ponto entre os dois extremos da linha e um valor teórico entre $(0$ 10) era obtido para quantificação, estes valores finais foram todos avaliados em índices.Foi encontrada uma correlação entre o questionário e o resultado das forças de mordida, ou seja, o aumento da força de mordida correspondia ao aumento dos valores marcados nas escalas análogas visuais.

Boerrigter et al. (1985), compararam três tipos de próteses quanto à satisfação e habilidade de mastigação: overdentures, próteses convencionais com 
ou sem cirurgia pré-protética, todas mandibulares. Foram 38 homens e 52 mulheres com altura média do rebordo anterior de $21 \mathrm{~mm}$. Após 1 ano de avaliação com 86 pacientes, 5 dos sete itens do questionário, direcionados para se avaliar a capacidade de mastigar alimentos duros, mostraram significante melhora para os dois grupos que fizeram cirurgia. O mesmo foi encontrado para o grau de satisfação e todos ficaram satisfeitos com a estética.

Para os autores, primeiro as próteses suportadas por implantes e depois as confeccionadas após vestíbuloplastia e aprofundamento do assoalho promovem uma maior satisfação no geral, que as próteses convencionais.

Lassila, Holmulund e Koivumaa (1985), estudaram a relação entre a máxima força de mordida em medições intra-orais e os diferentes tipos de arcadas dentárias em 89 pacientes divididos em 3 grupos: (a) portadores de próteses totais bimaxilares; (b) portadores de próteses totais superiores e próteses parciais inferiores; (c) dentição natural superior, ou prótese parciais dento-suporadas com arco antagonista prótese parciais com extremidade livre. Os autores concluíram que quanto maior suporte mucoso menor a força de mordida.

Fields, Proffit e Case (1986), avaliaram as variáveis que poderiam afetar a tomada de medidas verticais de forças oclusais. Os fatores testados foram: separação entre os maxilares ; oclusão com e sem suporte contralateral; postura e também a amplitude de abertura bucal que esses pacientes apresentavam enquanto sua carga mastigatória era registrada.

Os autores concluíram que a posição da cabeça do paciente não deve ser flexionada ou estendida, pois apesar das alterações serem pequenas, com a cabeça 
flertida nas medições de máxima força de mordida "as diferenças estavam sendo significativas". Quanto ao apoio contralateral nas tomadas de da carga mastigatória, a conclusão a que chegaram foi que, independentemente da presença ou não de um apoio do lado oposto, os valores das medidas não se alteraram. No que se referiu a amplitude de abertura, os autores relataram que, em pacientes adultos, aberturas de grande amplitude alteram a força oclusal máxima e portanto deveriam ser controladas.

Vervoorn (1988) relatou que a reabsorção óssea afeta mais a mandíbula que a maxila gerando uma menor área de suporte e consequentemente, pouca distribuição de carga levando a uma menor eficiência mastigatória e maior sensibilidade da fibromucosa da área basal. O autor utilizou uma escala analógica de 1 10 para verificar a satisfação dos pacientes em relação a suas Próteses Totais.

Engquist et al. (1988), publicaram um estudo no qual participaram onze centros suecos de reabilitação oral, treinados na técnica de implantes Branemark. O estudo retrospectivo avaliou 89 pacientes portadores de sobredentaduras suportadas por implantes osseointegrados, foi aplicado um questionário composto de 6 perguntas, levando em conta suas experiências com o uso das próteses.

Como resultados, os pesquisadores consideraram as reações dos pacientes como sendo positivas, no que se refere à função e conforto. Foi relatado que $81 \%$ dos pacientes sentiam suas próteses melhores que as prévias e a maioria dos pacientes nunca, ou raramente, removiam suas prótese por conta de desconforto sentido com ausência das mesmas. 
Bakke et al. (1989), avaliaram o significado clínico da força de mordida máxima, a medida foi feita com um transdutor de tensão montado em placas pequenas de metal conectadas a um amplificador. Os autores concluíram que a força de mordida unilateral registrada na região dos primeiros molares era significantemente maior do que a bilateral, quando comparada com valores médios obtidos com registros simultâneos. A força de mordida máxima unilateral pode ser usada clinicamente como um indicador da força de mordida da mandibula como um todo,e como um método confiável de acompanhamento de alterações na força induzida durante o desenvolvimento ou causadas por tratamento ou perdas dentais.

Através de medidas eletrognatográficas Setz et al. (1989), comparou em 18 pacientes o ciclo mastigatório com as próteses convencionais originais e após colocação de barras sobre os implantes mandibulares. Encontrou ciclos mais largos e com movimentos mais estáveis com as overdentures; a área do ciclo mastigatório sem fixação de implantes foi $56 \%$ da área com suporte de implantes. A média de duração da abertura foi maior com o a próteses suportada por implantes. Observou através de medidas de força que os implantes recebiam stress durante o ciclo e até durante a fixação da barra e deglutição.

Para Korioth e Hannam (1990) o valor absoluto da mordida pode ser diferente entre os pacientes e no mesmo paciente, porque não é somente uma função de uma situação anatômica particular, mas também do ponto de aplicação da força de mordida.

Van Eijden (1990), verificou que a maior força de mordida voluntária é 
desenvolvida na direção vertical. Na direção obliqua, a maior força é exercida com esforço dirigido posteriormente, correspondendo em torno de 90\% da força máxima de mordida perpendicular ao plano oclusal dos dentes maxilares.

Zarb e Schimitt (1990), num estudo longitudinal dos efeitos clínicos dos implantes osseointegrados, avaliaram os resultados obtidos em 46 pacientes que demonstravam incapacidade crônica para uso de próteses totais. Para a análise subjetiva dos resultados obtidos, os pacientes foram requisitados a julgar como sendo bom, razoável ou ruim seis itens relacionados á experiência pessoal de uso de próteses totais e implantes. Esses itens consideravam conforto, eficiência mastigatória, estética, articulação, dor e eficiência ao corte de alimentos através de um questionário aplicado pelo mesmo examinador.

Os autores relataram que todos os pacientes conseguiram usar suas próteses implanto-suportadas com sucesso durante pelo menos 4 anos de controle, concluindo que a osseintegração consiste num recurso valioso na reabilitação de pacientes edêntulos.

Mericske-Stern e Zarb (1993), em um estudo que se estendeu por cinco anos, avaliaram 59 idosos edêntulos, todos tratados com overdentures e previamente divididos em dois grupos, um deles instalado em Toronto (Canadá) e o outro em Berna (Suíça). O grupo canadense reuniu 25 pacientes, com idade média de 62,2 anos; 0 grupo suíço, 34 pacientes, com idade média de 68,9 anos. Apresentando condições gerais de saúde altamente comprometidas, os componentes de ambos os grupos receberam tratamento entre 1984 e início de 1987 e, a partir daí, passaram a usar regularmente suas respectivas overdentures. Em Toronto, optou-se pelo sistema 
Branemark; em Berna, pelo ITI. Na maioria das overdentures executadas, a retenção foi feita por apenas dois implantes. O acompanhamento de cada caso foi feito por dois pesquisadores, que, em todas as avaliações efetuadas, seguiram parâmetros periodontais e radiográficos. Os resultados finais do estudo demonstraram um alto índice de sucesso, superior a 90\%, nos dois grupos, apontando as overdentures como um bom tratamento alternativo, benéfico para a saúde geral do paciente.

Diaz (1993) utilizaram um gnatodinamômetro em pacientes com oclusão normal e encontrou uma média de 21.2 kgf na força máxima de mordida na região interincisal; entretanto, em pacientes com disfunção têmporo-mandibular, a média foi de 7 kgf..

Benzing et al. (1994), avaliaram a eficiência de mastigatória de 15 pacientes edentados totais que foram reabilitados com overdentures inferiores retidas por sistema barra/clip. Os autores concluíram que a pouca retenção e estabilidade de uma prótese total inferior leva a uma diminuição da eficiência mastigatória, levando os pacientes a optarem por um tratamento com implantes. Quase a totalidade dos pacientes com próteses implanto-suportadas em mandíbula descreve uma melhora na função mastigatória e na qualidade de vida.

Segundo Fine et al. (1994), estudos têm demonstrado que próteses implantosuportadas são mais satisfatórias e eficientes para os pacientes desdentados do que as próteses convencionais. A investigação comparou os diferentes tipos de prótese implanto-suportadas, verificando que a eficiência mastigatória é ligeiramente maior com as próteses fixas. 
Boretti Bickel e Geering (1995), em um estudo epidemiológico aplicado em 1106 pacientes, revisando a habilidade e eficiência mastigatória, afirmaram que a função mastigatória pode ser avaliada por intermédio de testes de mastigação e entrevistas pessoais. De acordo com os autores, os testes de mastigação avaliam com objetividade a função e os questionários de auto-avaliação ajudam a mensurar as respostas subjetivas fornecidas pelos pacientes sobre sua habilidade em mastigar. Os autores concluíram que, apesar de podermos traçar somente correlações fracas entre os dois testes de função, é razoável obter informações sobre a qualidade da função mastigatória usando-se questionários e exames clínicos. No caso de pacientes portadores de próteses totais, o critério é objetivo, pois o paciente tem possibilidade de se comunicar e expressar seus sentimentos sobre sua função.

Burns et al. (1995), apresentaram uma avaliação clínica sobre satisfação e preferência de pacientes portadores de prótese totais que foram reabilitados com overdentures sobre implantes mandibulares. Foram instalados encaixes tipo 0'ring, depois substituídos por magnetos, posteriormente, a preferência dos pacientes foi investigada através de um questionário de oito perguntas relacionadas a estética , estabilidade, eficiência e satisfação das próteses antigas e novas.

Das conclusões, os autores relataram que os dois sistemas demonstraram um aumento significante na satisfação do paciente, quando comparadas as próteses totais, existindo uma forte preferência pelo encaixe tipo O'ring.

Ogata e Satoh (1995), utilizaram próteses totais para medir as forças durante a mastigação, através de transdutores de força colocados nas regiões 
correspondentes aos primeiros pré-molares e segundo molar de ambos os lados da base da prótese. As forças foram registradas durante a mastigação de amendoim e uva passa; sendo registrado o valor médio de forças entre 6.5 e $11 \mathrm{kgf}$.

Na mesma linha de raciocínio, Jemt, Lindquist e Hedegarb (1995), analisaram possíveis mudanças que poderiam ocorrer no ciclo mastigatório entre pacientes edentados com próteses convencionais adequadas e após reabilitação com overdentures. Os registros foram feitos em três oportunidades: no primeiro exame, 2 meses após instalação das próteses convencionais e 2 meses após a colocação dos implantes; mas , apenas os dois últimos foram usados para análise. Os pacientes com próteses convencionais mostraram uma grande variação individual do ciclo mastigatório. Após a reabilitação com implantes, o ciclo mastigatório dos pacientes reabilitados se assemelhou ao padrão dos pacientes dentados; mesmo esses pacientes tendo próteses superiores convencionais. Conclui que reabilitação inferior com overdentures resulta em uma melhora funcional.

Maciel (1996) explicou que: (a) As forças oclusais, nas posições excêntricas, também são importantes e que, embora apresentem nível e duração inferiores aos da força gerada em máxima intercuspidação (MIC), podem ter participação significante no trauma periodontal e nas alterações musculares e articulares; (b) As forças horizontais, exercidas na parafunção, são potencialmente muito superiores do que as observadas durante a mastigação, possuindo a capacidade de promover adaptações e, associada a outros fatores, de causar lesões; (c) As cargas mais altas ocorrem em MIC; (d) Nos movimentos mastigatórios, são usados, em média, 40\% desta capacidade de carga. 
Morimoto et al. (1996) estudaram a força de mordida e a atividade dos músculos elevadores da mandíbula, variando em sete posições verticais diferentes, próximo da dimensão vertical de oclusão D.V.O. em pacientes desdentados. A força de mordida aumentou em proporção ao aumento da dimensão vertical. Estes resultados indicam que a D.V.O. não é a posição na qual se obtém a maior força mastigatória.

Geertman et al. (1996a), em seu estudo, objetivaram estudar os efeitos do tratamento de overdentures e próteses totais convencionais em rebordos alveolares bem reabsorvidos em 151 pacientes, 91 pacientes receberam uma overdenture e 60 uma prótese total convencional. Idade, sexo, período de edentulismo, número de próteses anteriores, tempo de uso da prótese atual e altura do rebordo foram critérios usados a título de comparação dos grupos estudados. Os resultados foram avaliados antes e 1 ano depois do tratamento. Antes do tratamento os grupos de pacientes estavam insatisfeitos com suas próteses mandibulares pela dificuldade de mastigar alimentos duros. Após 1 ano de instalação o grupo de overdentures estava satisfeito com o resultado; porém, o outro grupo tinha apenas um terço de satisfação. Quanto à habilidade de mastigação o grupo de overdentures obteve um resultado bem melhor que o grupo de próteses convencionais.

Bruyin et al. (1997) avaliaram através de um questionário 61 pacientes reabilitados com próteses sobre implantes. A habilidade mastigatória foi avaliada perguntando se os pacientes eram capazes de mastigar certos tipos de alimentos, os resultados referentes a estética, higiene, satisfação geral e conforto foram obtidos através de uma escala de 6 pontos. 
Cibirka, Razzog e Lang (1997), avaliaram a resposta de 26 pacientes portadores de próteses sobre implantes, usando para isto questionários que abordavam itens envolvendo conforto, função, estética, fonação, auto-estima e satisfação com a saúde dental, comparando os resultados das próteses previamente existentes (próteses totais convencionais), com as próteses novas sobre implantes.

Os questionários foram especialmente desenvolvidos pelos autores para esta pesquisa, utilizaram como método de avaliação escalas análogas visuais nomeadas como " qualidade de vida relacionada a saúde" , e aplicados em dois momentos distintos: antes da colocação dos implantes e um no após a instalação das prótese sobre implantes.

Hildebrandt et al. (1997) entrevistaram 602 pacientes com mais de 60 anos de idade, e estes relataram dificuldades de mastigação, evitavam alimentos fibrosos, alimentos duros (inclusive vegetais), alimentos sólidos e secos (inclusive pães) e alimentos pegajosos com dificuldade de deglutição.

Garret et al. (1998) conduziram um estudo clínico para comparar a efetividade na função mastigatória de overdentures e próteses totais convencionais inferiores em pacientes com diabetes mellitus, 89 pacientes completaram o tratamento, sendo que 37 foram reabilitados com prótese convencional e 52 com overdentures retidas a barra sobre dois implantes. Testes mastigatórios foram aplicados antes do tratamento, e após 6 e 24 meses do fim do tratamento. Os dois grupos foram comparáveis em termos de idade, qualidade das próteses originais, tecido de suporte e próteses anteriores. Nenhuma diferença foi encontrada para pacientes 
tratados com ou sem insulina. Os testes com as próteses anteriores foram mais positivos para o grupo de próteses convencionais que para o das overdentures. Porém, os testes posteriores foram similares pelos benefícios que o grupo das overdentures obtiveram. Por fim, pacientes que tiveram baixos índices nos testes iniciais tiveram melhoras depois do tratamento tanto com prótese convencional quanto com overdenture.

Também numa análise a longo prazo da eficiência mastigatória, ciclo mastigatório e grau de satisfação, Pera et al. (1998), analisaram antes e 12 meses depois da reabilitação de 12 pacientes com média de 66 anos com overdentures inferiores com rebordo extremamente reabsorvido. A avaliação foi feita com a confecção de uma prótese convencional e posterior colocação de dois implantes. Encontraram que a eficiência mastigatória aumentou significantemente e os ciclos mastigatórios tiveram sua amplitude aumentada após o suporte da prótese sobre implantes. O aumento do grau de satisfação dos pacientes foi relacionado com o aumento da eficiência mastigatória .

Brunello e Mandikos (1998), avaliou um grupo de 100 pacientes portadores de próteses totais, com a finalidade de identificar quais são as principais queixas relacionadas as suas próteses e suas causas. As queixas mais freqüentes foram desconforto e sensibilidade na fibromucosa durante a mastigação. Concluiu que a idade, sexo e medicação utilizada não apresentaram relação com as queixas, e a principal causa esta relacionada em falhas na confecção das próteses como subextensão erro de dimensão e falta de estabilidade e retenção. 
Vieira (1998), através de uma pesquisa clínica avaliou e comparou a força da mordida de indivíduos dentados naturais, edentados reabilitados com próteses convencionais e implanto-suportadas através de um método direto de mensuração da força de mordida, utilizando um gnatodinamômetro. Dos resultados foi possível concluir que a força de mordida dos dentados naturais é superior à dos demais indivíduos reabilitados proteticamente, sendo a região dos molares a que apresentou a maior força e a região dos incisivos, a menor. Os portadores de próteses totais convencionais apresentaram menor força de mordida quando comparados aos dentados naturais e aos reabilitados com próteses fixas sobre implantes. Os indivíduos reabilitados com próteses fixas sobre implantes desenvolveram maior força de mordida que os portadores de overdenture na reabilitação dos edentados completos, sendo as próteses fixas implanto-suportadas uma boa opção no restabelecimento da função oral.

Geertman et al. (1999), avaliaram a satisfação dos pacientes reabilitados com implantes mandibulares e overdentures com sistema barra-clipe e com próteses totais bimaxilares convencionais, através de uma escala analógica de $\underline{1}$ 10. Encontrando em média valores de 8.4 para as overdentures e 6.4 para os portadores de próteses totais.

Tang et al. (1999) constataram que com a colocação de somente dois implantes se obtém um resultado satisfatório em relação a retenção em pacientes com rebordos extremamente reabsorvidos. 
Meijer et al. (1999) compararam overdentures mandibulares com próteses totais convencionais, verificando aspectos clínicos e a satisfação dos pacientes, não apenas durante o primeiro ano pós-tratamento, mas também nos quatro anos seguintes. Os pacientes foram divididos em dois grupos: um deles, com 61 componentes, recebeu uma overdenture sobre dois implantes; o outro, com 60, uma prótese total convencional. Após um ano, 14 pacientes, descontentes com a prótese total, tiveram a oportunidade de receber implantes. No grupo tratado com a overdenture, quatro implantes foram perdidos no primeiro ano e quatro outros, no decorrer dos quatro anos seguintes. Com isso, o índice de sucesso alcançado com a overdenture chegou 93\%. Os pacientes com overdenture mostraram-se, após um ano, significativamente mais satisfeitos do que aqueles com prótese total. As conclusões dos autores, cinco anos depois de iniciada a pesquisa, foram as seguintes: (1) Dois implantes-suporte para overdenture podem atingir alto índice de sucesso (93\%); (2) A overdenture satisfaz mais do que prótese total; (3) A colocação de implantes na mandíbula não afetam a prótese superior; (4) A satisfação com a overdenture diminui com tempo - isso, talvez pelo fato de os pacientes se acostumarem a uma situação melhor.

Geertamn et al. (1999), estudaram clinicamente a relação de um teste artificial de comida na eficiência mastigatória e o ciclo mastigatório subjetivo. O exame constou da comparação entre overdentures retidas a barra e próteses totais convencionais mandibulares num total de 84 pacientes (64 mulheres e 20 homens) com média de 57 anos. A eficiência e o ciclo mastigatório foram substancialmente melhores para as próteses retidas por implantes comparados ao grupo com próteses convencionais. 
Sheiman et al (1999), em conjunto com Instituto Britânico de Pesquisa em Dietas Nutrição estudaram a habilidade de pacientes com idade igual ou superior a 65 anos de comer certos tipos de alimentos. Dos pacientes estudados grande percentagem relatou dificuldade em comer 16 tipos de alimentos estudados, e dependendo da situação oclusal (dentes remanescentes ou presença de próteses), não conseguir comer 4 tipos (cenouras cruas, amendoim e castanhas,maçãs, carne bem passada). Concluíram que a escolha da dieta está associada a condição dental e sua capacidade de mastigação.

Misch (2000) expôs algumas das qualidades das overdentures implantosuportadas em relação às overdentures tradicionais. Lembrou que essas overdentures tradicionais dependem do suporte de dentes remanescentes e que, além da localização desses pilares naturais ser altamente variável, em geral, eles já estão comprometidos devido a uma perda óssea prévia, associada a doença periodontal. Em contrapartida, em uma overdenture mandibular implanto-suportada, os implantes podem ser inseridos em locais específicos, planejados; sua quantidade é determinada pelo dentista restaurador e pelo paciente. Além disso - afirmou -, os abutments do implante da overdenture são saudáveis, rígidos e fornecem um excelente sistema de suporte; assim, os riscos e benefícios podem ser avaliados previamente em cada caso.

Zistmann e Marinello (2000) compararam os resultados obtidos com próteses fixas e removíveis apoiadas sobre implantes osseintegrados, com ênfase no ponto de vista do paciente. Para isso, examinaram 20 pacientes divididos em dois grupos iguais, portadores dos dois tipos de próteses e aplicaram um questionário considerando seu bem estar psicológico e satisfação com o trabalho, antes do 
mesmo ser executado e seis meses depois de instalado. Os autores consideraram conforto, função, estética, sensibilidade ao sabor, fonética e auto-estima. Usaram para a avaliação desses itens a Escala Análoga Visual.

Como conclusão, os autores mostraram que os dois grupos estão igualmente satisfeitos com as próteses aplicadas, sejam elas fixas ou removíveis.

Fontjin-Tekamp et al. (2000), mediram força de mordida e eficiência mastigatória com métodos iguais para pacientes com overdentures, prótese total convencional e suportadas por raízes. Observaram que a força de mordida encontrada nos pacientes com overdentures está entre a encontrada com prótese total e os dentes naturais usado como controle. A eficiência mastigatória das overdentures foi maior que em rebordos reabsorvidos, mas, menor que em rebordos altos ou sobre raízes. Para todos os grupos uma significante correlação foi encontrada entre a força de mordida e a eficiência mastigatória. Concluíram que o uso de implantes não é a solução para todos os problemas em pacientes desdentados.

Outro autor que comparou a eficiência mastigatória de overdentures, próteses híbridas e próteses totais convencionais foi Chen et al. (2002). Os grupos em número de 14 cada foram avaliados quanto à eficiência mastigatória com alimentos duros e os resultados avaliados com traçados mandibulares e eletromiografia dos músculos masseter e temporal. Concluíram que os pacientes com overdentures obtiveram os melhores graus de eficiência, logo acompanhados pelos pacientes com próteses híbridas e por fim os com próteses convencionais. Essa seqüência se repetiu com relação aos traçados do ciclo mastigatório. 
Fontijn-Tekamp et al. (2001), compararam a sensibilidade da fibromucosa, a estabilidade, e força de mordida de pacientes edentados totais e portadores de próteses sobre implantes (overdentures) inferiores. Concluíram que a presença de implantes nas próteses inferiores permite ao paciente exercer uma maior força de mordida e menor sensibilidade na fibromucosa,devido a uma maior estabilização da mesma pelos implantes.

Bonachella e Rossetti (2002), enfatizando que as principais queixas dos portadores de próteses dentais estão relacionadas com a impossibilidade de retenção dessa prótese durante atividades simples, tais como falar ou triturar alimentos fibrosos e/ou de consistência não pastosa, apontaram uma solução para o problema. Segundo eles, para contornar a falta de estabilidade, seja ela decorrente da inabilidade no uso da prótese, sobretudo no caso das próteses mandibulares, seja ela resultante da perda de osso alveolar, deve-se posicionar implantes ou selecionar raízes estratégicas, para manter a homeostasia dos tecidos mucosos, dos rebordos alveolares e dos pilares.

Hollanda (2002) analisou a evolução da força de mordida em pacientes que possuíam indicação de instalação de próteses parciais implanto suportadas e comparou os resultados com as respostas obtidas por meio de um questionário aplicado, que avaliou o grau de satisfação geral, estética, habilidade em mastigar e higiene após três meses de conclusão do trabalho protético instalado sobre os implantes. As forças de mordida foram medidas com um gnatodinamômetro digital no local da prótese instalada, simulando a máxima força de mordida e mastigação. 
Os resultados alcançados com os testes de força de mordida no momento de instalação das próteses foram confrontados e analisados estatisticamente com os obtidos três meses após o término do tratamento, de forma que se observou um aumento da força de mordida máxima em todas as situações avaliadas, sendo que as forças simulando mastigação diminuíram na região de molares em situação de pouco estresse. Foi encontrada uma clara correlação entre aumento de força de mordida máxima, facilidade de higienização do trabalho e satisfação geral nos trabalhos protéticos localizados na região posterior da boca, sendo que nos pacientes com trabalhos localizados na região de dentes anteriores, a estética prevaleceu como o fator mais relacionado com a aceitação do trabalho já pronto, independente do aumento de força.

Bakke, Holm e Gofredsen (2002), estudaram a satisfação, intensidade da força de mordida e ciclo mastigatório de pacientes portadores de prótese totais com pouca retenção, onde foram confeccionadas novas próteses e após 3 meses colocados dois implantes na região anterior da mandíbula e após 6 meses fixados os sistema de retenção,os exame foram feitos lano e 5 anos após a fixação dos encaixes. Houve um aumento significativo na intensidade e na duração da força de mordida com as overdentures, chegando aos seguintes valores em média 11,5 Kgf para prótese antes dos implantes, 20 Kgf 3 meses após a colocação dos implantes.

Van Kapen, Kune e Bosman (2002) compararam a intensidade da força de mordida em diferentes sistemas de retenção de overdentures (encaixe tipo bola, barra-clipe e magnetos). O autor relatou um aumento significativo na força de mordida após a colocação dos implantes e uma equivalência nos resultados 
referentes aos três sistemas de retenção, sendo o menor valor obtido no sistema de magnetos, resultado este que o autor atribuiu a menor retenção e estabilidade que o sistema de magnetos apresenta.

Walton, Macentee e Glick (2002), analisaram a satisfação dos pacientes portadores de dois implantes na região anterior da mandíbula. Através de uma escala analógica (VAS) que foi aplicada antes da cirurgia, 1 semana após a instalação da overdenture inferior, e um ano após esta data. Verificaram que os pacientes se monstraram bem satisfeitos, com a melhora na eficiência mastigatória,conforto e aparência que suas Prótese Totais antigas, e que as próteses com sistema bola tiveram 8 x mais retornos para ajuste que o sistema barra/clipe.

Awad et al. (2003), quiseram comparar a eficiência de overdentures mandibulares retidas por dois implantes e uma barra e próteses convencionais em pacientes de 35-65 anos. 48 pacientes receberam próteses convencionais e 54 overdentures. Foram analisados quanto ao conforto, habilidade de mastigação, limpeza, fala e estabilidade antes da reabilitação e 2 meses após a instalação. Foi encontrada uma satisfação significantemente maior no grupo das overdentures que no das próteses convencionais cuja facilidade de mastigar alimentos não alterou significantemente. Idade, sexo, renda não foram associados com o grau de satisfação. Além disso, o grupo das overdentures obteve maiores marcas em relação ao conforto, estabilidade e facilidade em mastigar. Porém, não diferiram quanto à estética, habilidade de fala ou de limpeza da prótese. Concluiu que uma overdenture mandibular com uma prótese convencional maxilar é um tratamento mais satisfatório 
que apenas próteses convencionais.

Doudoulakis et al. (2003) em uma revisão da literatura, analisaram os benefícios e os riscos das reabilitações em pacientes edentados com Overdentures e Próteses Totais. $\mathrm{Na}$ opinião dos mesmos, as desvantagens das próteses convencionais são: a limitação da retenção e estabilidade, contínua reabsorção óssea, função mastigatória diminuída e comprometimento estético com o uso. Já as overdentures apresentam vantagens como: requerer pequeno número de implantes, boa retenção e estabilidade do aparelho através dos encaixes e diminuição da reabsorção óssea. Concluíram que a alta taxa de sucesso na colocação de implantes na região anterior aos forames mentonianos (95\%) indica resultados previsíveis na superioridade da overdenture quanto à retenção, estabilidade, função e satisfação do paciente em comparação a uma prótese convencional.

Para Klemetti et al. (2003), um dos maiores objetivos da implantodontia é melhorar a retenção das próteses totais que são freqüentemente associadas à insatisfação em pacientes com rebordos reabsorvidos. Os autores afirmaram que a taxa de sucesso na colocação de implantes na região anterior da mandíbula é muito alta. Por esse fator e pelo baixo custo é comum tratar pacientes edentulos com a colocação de dois implantes e uma barra de retenção da prótese ao invés de quatro implantes e uma barra. Foram reabilitados 30 pacientes com overdenture mandibular e prótese total superior convencional e 30 pacientes com prótese total bimaxilar convencional. A estabilidade das overdentures foi excelente e a extensão da região lingual da prótese foi levada apenas até a linha milo-hióidea proporcionando maior conforto a língua. As visitas de controle posterior no primeiro ano à instalação foram 
em menor número para as overdentures que para as próteses convencionais.

Roumanas et al. (2003), avaliou a dificuldade de mastigar alimentos em pacientes reabilitados com próteses totais convencionais e overdentures, estes foram submetidos a uma dieta onde foram atribuídos valores de 1 a 10 para grupos de alimentos, e através de um questionário concluiu que para certos tipos de alimentos considerados difíceis de mastigar ( granola, castanhas, files de carne vermelha) houve uma diferença significativa de freqüência capacidade de mastigar para as overdentures. O autor associou o resultado a menor sensibilidade na fribomucosa nos pacientes portadores de overdentures.

Bortolli Jr. (2004) analisou , com o auxílio do método fotoelástico, as tensões geradas nas estruturas ao redor de implantes-suporte de overdentures, com sistema de encaixe Bola O'Ring e Barra Clip, variando as cargas e os movimentos, em lateralidade esquerda e direita, protrusiva e máxima intercuspidação (MIC). Para isso, foi confeccionado um modelo inferior de resina fotoelástica, contendo três implantes rosqueados do tipo osseointegrado na região anterior, e, sobre esse modelo, foram confeccionadas duas overdentures: uma com encaixe Bola O’Ring; a outra com Barra Clip. Os corpos de prova foram colocados em articulador e, sobre o seu ramo superior, foram aplicadas as variáveis cargas na seguinte ordem: cinco e dez quilogramas, em MIC; dois e quatro quilogramas, em lateralidade esquerda (Bola O'Ring), lateralidade direita (Barra Clip) e protrusiva. Os resultados permitiram concluir que: (1) O sistema de encaixe Bola O’Ring parece transmitir menos tensões aos implantes do que ao rebordo; (2) O sistema de encaixe Barra Clip parece transmitir mais tensões aos implantes do que ao rebordo; (3) As tensões 
transmitidas aos implantes são menos intensas no seu entorno, direcionando-se mais para as regiões apical e cortical; (4) Em movimentos de lateralidade, as tensões no rebordo se concentram mais no lado do movimento; (5) Em movimento protrusivo, as maiores tensões concentram-se nos implantes; (6) Em MIC, houve uma distribuição mais eqüitativa das tensões entre os implantes e o rebordo.

Tanaka et al. (2004), analisou o limiar de dor de pacientes edentulos em diferentes áreas do rebordo correlacionando com a intensidade da força de mordida, o autor concluiu que o limiar de dor era menor em algumas áreas e inversamente proporcional a intensidade da força de mordida devido ao trauma provocado pelas próteses.

Ozcan et al. (2005), estudou a utilização de um adesivo para próteses relacionando com a intensidade da força de mordida. Encontrou melhora significativa nos resultados para as próteses com adesivos, justificou o resultado ao conforto e a maior estabilidade proporcionada pela utilização do adesivo.

Stelligsma, Slagter e Stegenga (2005) compararam a eficiência mastigatória em pacientes portadores de overdentures mandibulares com rebordos extremamente reabsorvidos, com as suas próteses antes da colocação dos implantes. Utilizaram um questionário aplicado antes e após a osseointegração seguido de uma entrevista. Os autores utilizaram a mesma prótese para os exames, através dos resultados obtidos concluíram que as próteses sobre implantes 
apresentaram resultados melhores que as próteses convencionais, fato que se deve a maior retenção proporcionada pelos sistemas de retenção das overdentures.

Visser et al. (2005) avaliaram o sucesso e a satisfação do tratamento com overdenturtes mandibulares retidas por dois ou três implantes e sistema barra-clip de retenção em 60 pacientes edentados através de um questionário e consultas de retorno durante um período de 5 anos. A satisfação com relação a nova condição protética foi positiva e se manteve estável durante os 5 anos. O grupo com dois implantes apresentou maior manutenção protética e o grupo com 3 implantes maior problema perimplantar. 


\section{PROPOSIÇÃO}

Em vista dos poucos trabalhos relacionados ao assunto encontrados na literatura, terem demonstrado que existe um aumento significativo da força de mordida em pacientes que se beneficiam do uso de overdentures, quando comparadas as suas próteses antigas e ausência de uma metodologia de pesquisa padronizada, nos propomos a :

- Quantificar e comparar os valores de intensidade da força de mordida quando os pacientes utilizam Próteses Totais Convencionais Bimaxilares, e quando os mesmos utilizam Próteses Totais Convencionais Superiores com arco antagonista reabilitado com Overdenture retida a barra/clipe sobre implante.

- Comparar a eficiência mastigatória das próteses antes dos implantes com as próteses sobre implantes.

- Avaliar a satisfação geral do paciente em relação a sua nova condição protética. 


\section{MATERIAL E MÉTODOS}

\subsection{Casuística}

Foram avaliados 23 pacientes edentados, reabilitados no Curso de Implantodontia Sistema ITI, na Fundação para Desenvolvimento Científico e Tecnológico da FOUSP.

Dos pacientes, 14 eram do sexo feminino e 9 do sexo masculino, não houve escolha preferencial de sexo e a idade variou entre 45 e 65 anos.

Através do exame clínico e da documentação radiográfica necessária, foi avaliada a possibilidade de colocação em cada paciente, na região compreendida entre os forames mentonianos, dois implantes marca ITI (Synocta) 4.8 de diâmetro.

Após período de osseointegração (6 meses), estes foram reabilitados com prótese total superior e e overdenture inferior retida por sistema barra/clip.

Com a aprovação do Comitê de Ética, protocolo 102/05 (Anexo A) e após um período de adaptação das próteses de no mínimo 4 meses, foram executados os exames de mensuração da intensidade da força de mordida e aplicados os questionários.

Os exames foram desenvolvido nos equipamentos da clínica de dor Orofacial do Departamento de Neurofisiologia da Faculdade de Medicina da Universidade Federal de São Paulo coordenado pela profa. Dra.Sueili Marrie responsável pelo departamento e co-orientado pelo Prof. Dr. Antônio Sergio Guimarães.

Os pacientes que participaram da pesquisa após consulta e por vontade própria assinaram um termo de consentimento (Apêndice A). 


\subsection{Material}

4.2.1 Material e instrumental para confecção das próteses totais

O material, instrumental e aparelhos utilizados na confecção das próteses totais deste trabalho são os mesmos empregados, na disciplina de Prótese Total da FOUSP, segundo técnica descrita por Tamaki (1984).

4.2.2 Material específico utilizado para confecção das Overdentures

- Implantes ITI SLA (Sand-Blasted, Large-grit, Acid-etched, superfície tratada por jato de areia e ataque ácido de 4,8 mm de diâmetro Sistema Synocta (Instituto Straumann- Waldenburg, Suíça)

- Tampas de cicatrização para implantes (Instituto Straumann-Waldenburg Suíça)

- Transfer parafusado para sistema Synocta (Instituto Straumann-Waldenburg Suíça)

- Análogo para sistema Synocta (Instituto Straumann-Waldenburg Suíça)

- Barra de plástico calcinável tipo Dolder perfil oval standard, regular de altura de 3,0mm (Instituto Straumann-Waldenburg Suíça)

- Clip de titânio para barra tipo Dolder de altura 4,5mm (Instituto StraumannWaldenburg Suíça)

- Ucla plástico calcinável (Instituto Straumann-Waldenburg Suíça) 
- Parafuso oclusal SCS comprimento 4,4mm de titânio (Instituto StraumannWaldenburg Suíça)

- Chave de parafuso SCS (Instituto Straumann-Waldenburg Suíça)

- Catraca e dispositivo de controle de torque (Instituto Straumann-Waldenburg Suíça)

4.2.3 Equipamentos utilizados para os registros da intensidade da força de mordida:

- Gnatodinamometro, modelo TRCv36A fabricado pela Kratos-Cas Balanças Eletrônicas LTDA.

- Câmera fotográfica Digital Sony Cyber-shot DSC-P50 2.1 mega pixel.

- Microcomputador pessoal de mesa com processador Intel Pentium 4, HD de 60GB, 1.2 GB de memória RAM, com monitor de 19 polegadas.

Software utilizados

- Excel for Windows ;

- Microsoft Word;

- Minitab 14.0 for Windows; 
4.2.3.1 descrição do Gnatodinamometro:

Para o registro da intensidade da força de mordida utilizou-se um "Gnatodinamômetro", que segundo Bernardes (2002) dispositivo amplamente utilizado nos estudos científicos descritos na literatura, conectado a um Microcomputador, aparelhos estes presentes nas instalações da clínica de Dor Orofacial .

a) Identificação:

Este aparelho é um instrumento de medição de força, fabricado pela KratosCas Balanças Eletrônicas LTDA, modelo TRCv36A, com calibração automática e precisão de $0,1 \%$ e certificado de calibração. Utiliza um software para armazenar as leituras obtidas pela célula de carga de alta precisão.

Constitui-se de uma empunhadura de borracha, que permite a apreensão do operador no momento do ensaio, apresentando um braço transdutor de metal protegido por duas superfícies plásticas, onde o paciente posiciona os dentes e executa a pressão na região que vai ser estudada (figura 4.1 ). 


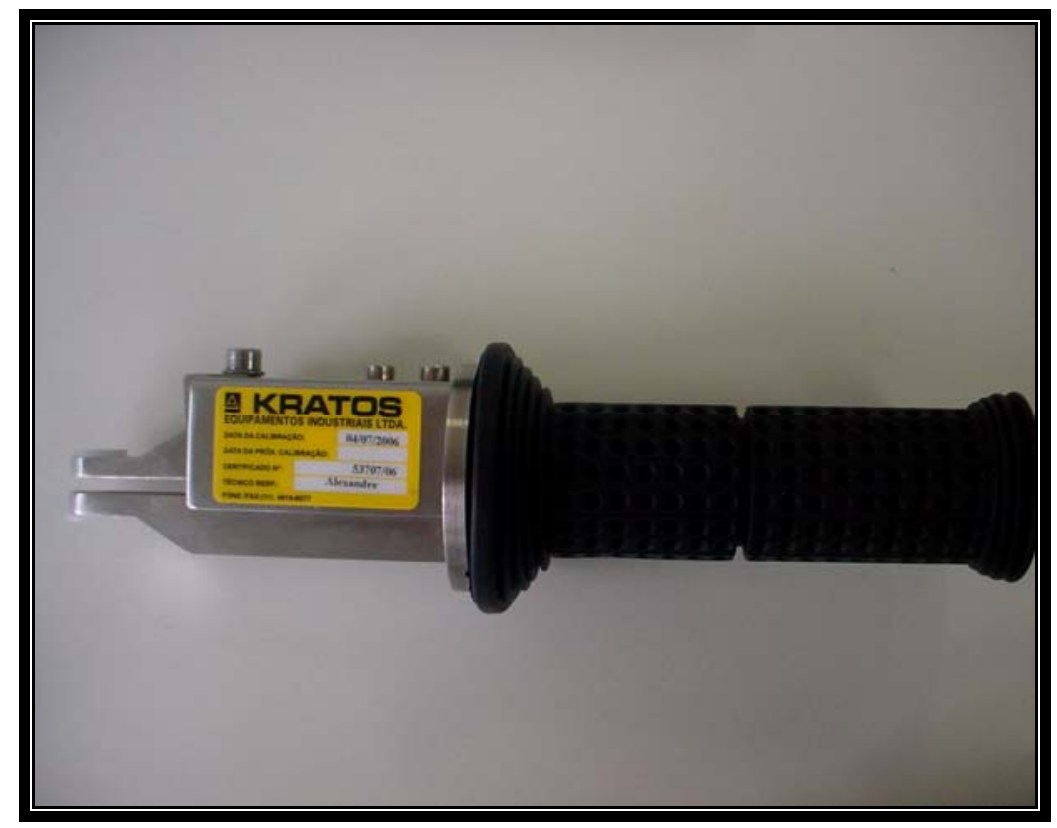

Figura 4.1 - Gnatodinamometro, marca Kratos, mod. TRCv36A

b) Princípio de funcionamento

As hastes do transdutor de força (comercialmente chamado de célula de carga) se encontram separadas, e conforme é aplicada carga, elas sofrem uma deformação, e uma microrresistencia elétrica suportada por uma película de material isolante, acompanha as microdeformações das hastes que são diretamente proporcionais à força aplicada. Um indicador traduz esta deformação em unidade de força, que é transmitida para o software no microcomputador (Figura 4.2). 


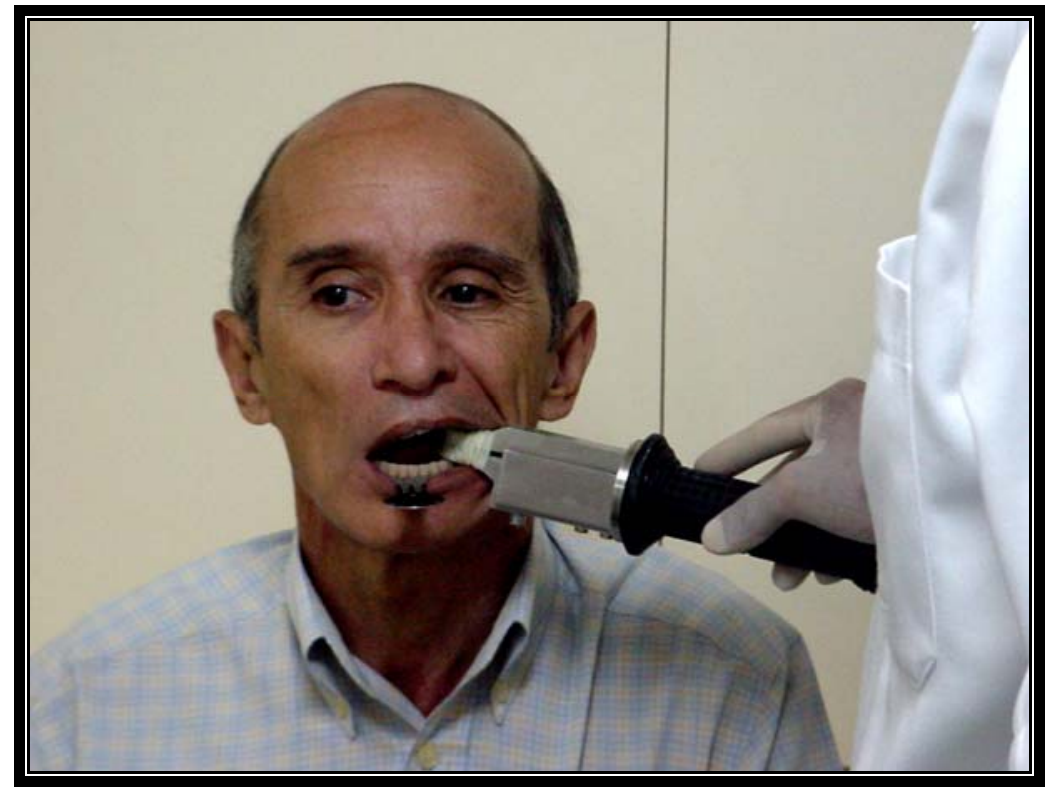

Figura 4.2 - Paciente executando o teste de mensuração da intensidade da força de mordida

O software é capaz de converter os dados (quadro 1) a seguir, em uma função gráfica (gráfico 4.1) abaixo, que registra o início do esforço mastigatório até o seu pico, fornecendo também o tempo total do ensaio.

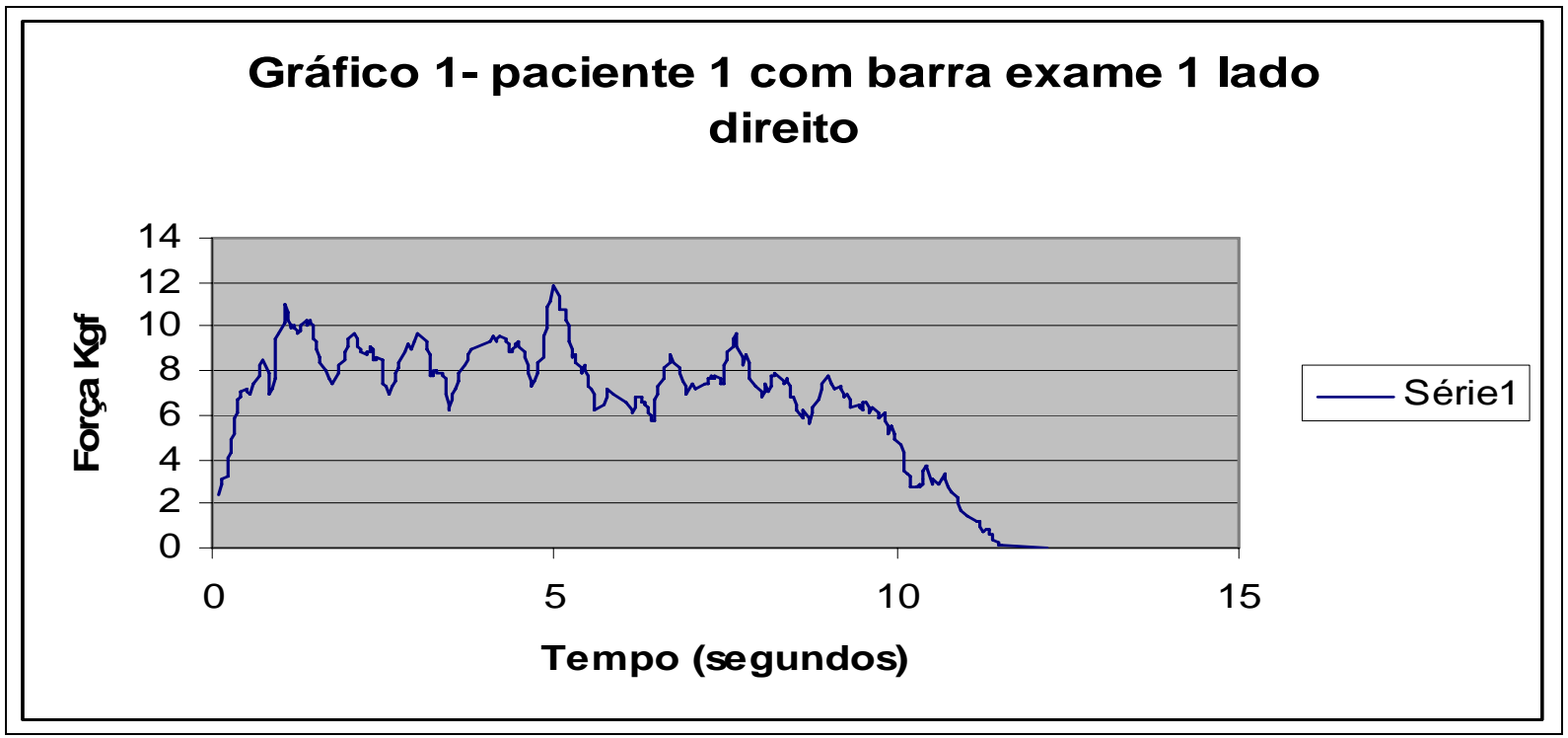

Gráfico 4.1 - Demonstrativo da conversão dos dados pelo software, de um exame executado por um paciente, lado direito com barra 


\begin{tabular}{|c|c|c|c|c|c|c|c|c|c|}
\hline Tempo (s) & Carga (kgf) & Tempo (s) & Carga (kgf) & Tempo (s) & Carga (kgf) & Tempo (s) & Carga (kgf) & Tempo (s) & Carga (kgf) \\
\hline 0 & 1 & 0,82 & 7,5 & 1,48 & 9,75 & 2,47 & 8,45 & 3,46 & 6,45 \\
\hline$-1,75 \mathrm{E}-12$ & 1,25 & 0,82 & 6,9 & 1,48 & 9,5 & 2,47 & 8,15 & 3,46 & 6,25 \\
\hline 5,00E-02 & 1,5 & 0,87 & 7,15 & 1,53 & 9,3 & 2,47 & 7,75 & 3,46 & 6,25 \\
\hline 5,00E-02 & 1,75 & 0,93 & 7,65 & 1,53 & 9 & 2,47 & 7,45 & 3,46 & 6,4 \\
\hline $5,00 \mathrm{E}-02$ & 2 & 0,93 & 8,35 & 1,59 & 8,6 & 2,52 & 7,25 & 3,51 & 6,65 \\
\hline 0,11 & 2,4 & 0,93 & 8,95 & 1,59 & 8,35 & 2,58 & 7 & 3,51 & 6,95 \\
\hline 0,16 & 2,85 & 0,93 & 9,45 & 1,64 & 8,05 & 2,63 & 7,25 & 3,57 & 7,2 \\
\hline 0,16 & 3 & 0,98 & 9,7 & 1,7 & 7,65 & 2,69 & 7,5 & 3,62 & 7,55 \\
\hline 0,16 & 3,1 & 1,04 & 10,2 & 1,75 & 7,4 & 2,69 & 7,9 & 3,62 & 7,9 \\
\hline 0,22 & 3,25 & 1,04 & 10,7 & 1,86 & 7,9 & 2,74 & 8,15 & 3,68 & 8,2 \\
\hline 0,22 & 3,45 & 1,04 & 11,05 & 1,86 & 8,25 & 2,74 & 8,4 & 3,73 & 8,45 \\
\hline 0,22 & 3,7 & 1,09 & 10,7 & 1,92 & 8,5 & 2,8 & 8,9 & 3,73 & 8,7 \\
\hline 0,22 & 4,05 & 1,09 & 10,25 & 1,92 & 8,8 & 2,85 & 9,25 & 3,79 & 8,95 \\
\hline 0,27 & 4,35 & 1,15 & 10 & 1,97 & 9,15 & 2,91 & 9 & 4,06 & 9,3 \\
\hline 0,27 & 4,65 & 1,15 & 9,95 & 1,97 & 9,45 & 2,96 & 9,3 & 4,11 & 9,55 \\
\hline 0,27 & 4,9 & 1,15 & 9,95 & 2,08 & 9,7 & 3,02 & 9,65 & 4,17 & 9,35 \\
\hline 0,32 & 5,15 & 1,15 & 10 & 2,14 & 9,4 & 3,13 & 9,3 & 4,17 & 9,35 \\
\hline 0,32 & 5,4 & 1,2 & 10 & 2,14 & 9,15 & 3,13 & 9 & 4,17 & 9,35 \\
\hline 0,32 & 5,65 & 1,2 & 9,95 & 2,19 & 8,95 & 3,18 & 8,75 & 4,17 & 9,45 \\
\hline 0,32 & 5,85 & 1,2 & 9,9 & 2,19 & 9 & 3,18 & 8,45 & 4,22 & 9,55 \\
\hline 0,38 & 6,1 & 1,26 & 9,85 & 2,19 & 8,95 & 3,18 & 8,15 & 4,22 & 9,6 \\
\hline 0,38 & 6,35 & 1,26 & 9,75 & 2,19 & 8,8 & 3,18 & 7,8 & 4,22 & 9,6 \\
\hline 0,38 & 6,55 & 1,26 & 9,7 & 2,25 & 8,7 & 3,24 & 7,75 & 4,22 & 9,6 \\
\hline 0,38 & 6,75 & 1,26 & 9,7 & 2,25 & 8,75 & 3,24 & 7,85 & 4,28 & 9,5 \\
\hline 0,43 & 6,85 & 1,31 & 9,8 & 2,25 & 8,8 & 3,24 & 8 & 4,28 & 9,4 \\
\hline 0,43 & 6,95 & 1,31 & 9,95 & 2,3 & 8,9 & 3,24 & 8,05 & 4,28 & 9,35 \\
\hline 0,43 & 7,1 & 1,31 & 10,05 & 2,3 & 9,05 & 3,29 & 8,05 & 4,33 & 9,2 \\
\hline 0,49 & 7,15 & 1,37 & 10,25 & 2,3 & 9,15 & 3,29 & 7,95 & 4,33 & 9,05 \\
\hline 0,49 & 7,15 & 1,37 & 10,3 & 2,3 & 9,15 & 3,29 & 7,9 & 4,33 & 8,9 \\
\hline 0,49 & 7,15 & 1,37 & 10,2 & 2,36 & 9 & 3,35 & 7,95 & 4,33 & 8,8 \\
\hline 0,49 & 7,1 & 1,37 & 10,1 & 2,36 & 8,75 & 3,35 & 7,9 & 4,39 & 8,8 \\
\hline 0,54 & 7 & 1,42 & 10,15 & 2,36 & 8,55 & 3,35 & 7,85 & 4,39 & 8,85 \\
\hline 0,6 & 7,4 & 1,42 & 10,25 & 2,41 & 8,5 & 3,35 & 7,8 & 4,39 & 8,9 \\
\hline 0,71 & 7,75 & 1,42 & 10,3 & 2,41 & 8,55 & 3,4 & 7,6 & 4,39 & 9 \\
\hline 0,71 & 8,2 & 1,42 & 10,2 & 2,41 & 8,6 & 3,4 & 7,3 & 4,44 & 9,05 \\
\hline 0,76 & 8,5 & 1,48 & 10 & 2,41 & 8,6 & 3,4 & 6,9 & 4,44 & 9,15 \\
\hline
\end{tabular}

Quadro 4.1- Dados obtidos no primeiro exame do lado direito com barra, paciente 1 


\subsection{Métodos}

\subsubsection{Seleção dos pacientes}

Os pacientes selecionados gozam de boa saúde geral e a faixa etária gira entre 40 a 65 anos de idade. Já utilizam estas prótese por um período de mais de 6 meses, apresentando perfeita harmonia do Sistema Estomatognático, fibromucosa, A.T.M. e musculatura em condições de normalidade e correta oclusão, pois segundo Diaz (1993) tais alterações podem levar a uma diminuição de até 1/3 da intensidade da força de mordida..

Para avaliarmos possíveis problemas relacionados com disfunção de A.T.M., os pacientes se submeteram a uma avaliação clínica (Apêndice A), caso apresentassem qualquer sintoma de Disfunção-Temporo-Mandibular seus dados eram descartados.

\subsubsection{Confecção das próteses}

Cada paciente recebeu dois implantes ITI na região anterior da Mandíbula, após o processo de osseointegração (6 meses), estes foram reabilitados com Prótese total superior e Overdenture inferior.

As Próteses foram executadas segundo técnica descrita por (TAMAKI 1984) para confecção de Próteses Totais Bimaxilares Convencionais. 
Somente na confecção das Overdentures empregamos as seguintes variações na técnica:

- Moldagem funcional de transferência com moldeiras individuais abertas e transfer parafusado (figura .4.3).

- Obtenção do modelo de trabalho (modelo funcional), com análogos corretamente transferidos (figura. 4.4).

- UCLAS calcináveis parafusados sobre os análogos, a barra plástica fixada com duralay e posterior fundição da barra em níquel-cromo (figura 4.5).

- Após fundição, a barra foi provada em posição na boca do paciente e feita uma radiografia para se conferir a correta adaptação da mesma sobre os implantes (figura. 4.6).

- O clip de metal foi fixado a base da prótese no laboratório durante o processo de acrilização (figura. 4.7). 


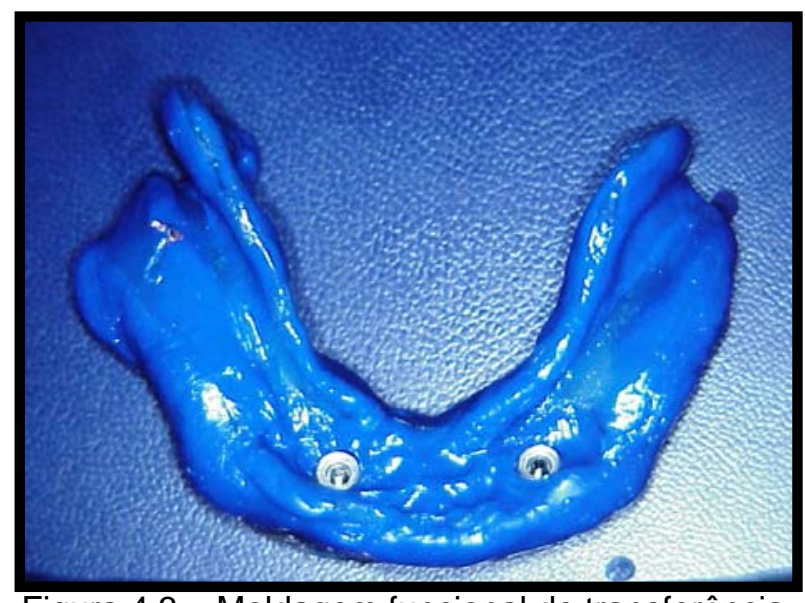

Figura 4.3 - Moldagem funcional de transferência

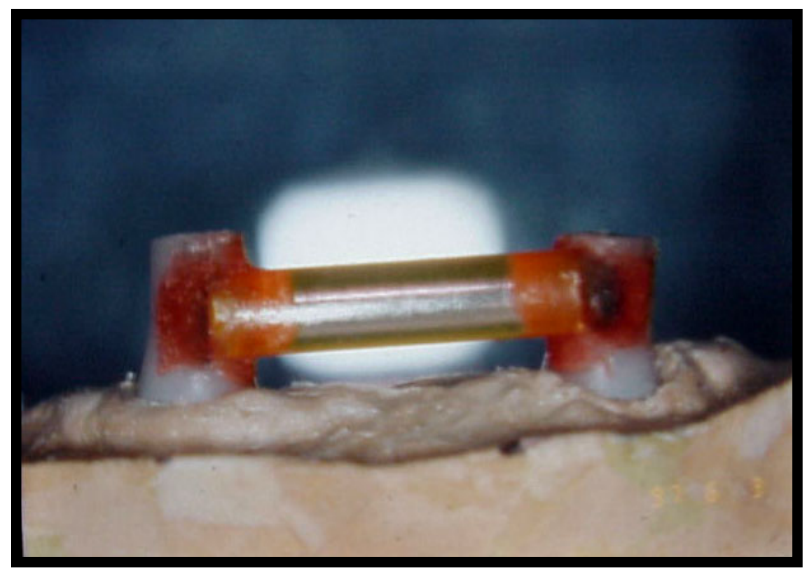

Figura 4.5 - Calcinável e barra posicionados

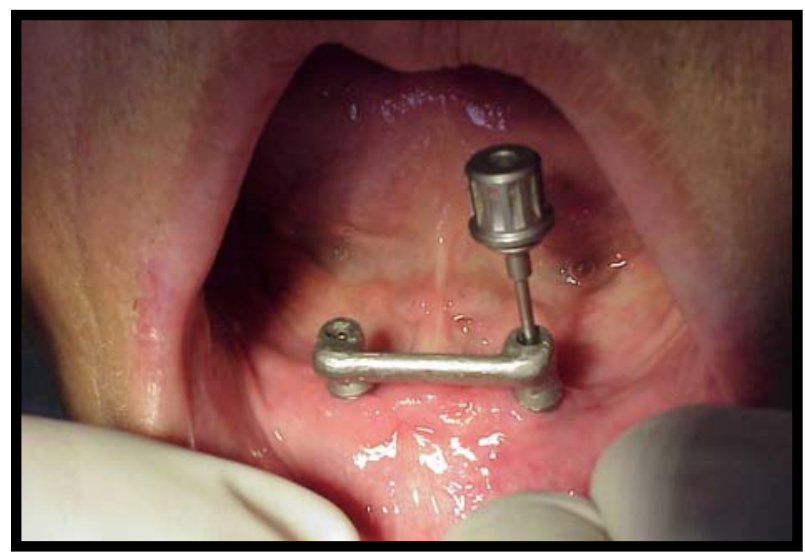

Figura 4.7 - Prova da barra em posição na boca

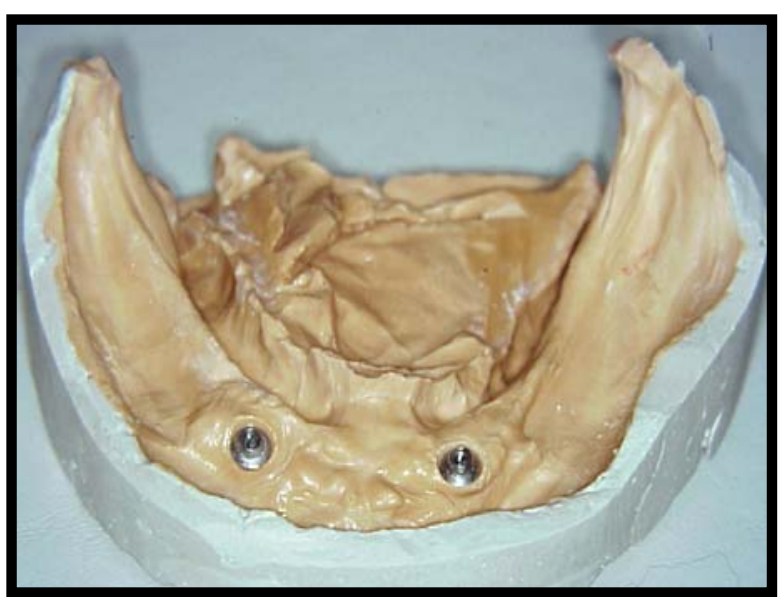

Figura 4.4 - Modelo de trabalho com análogo

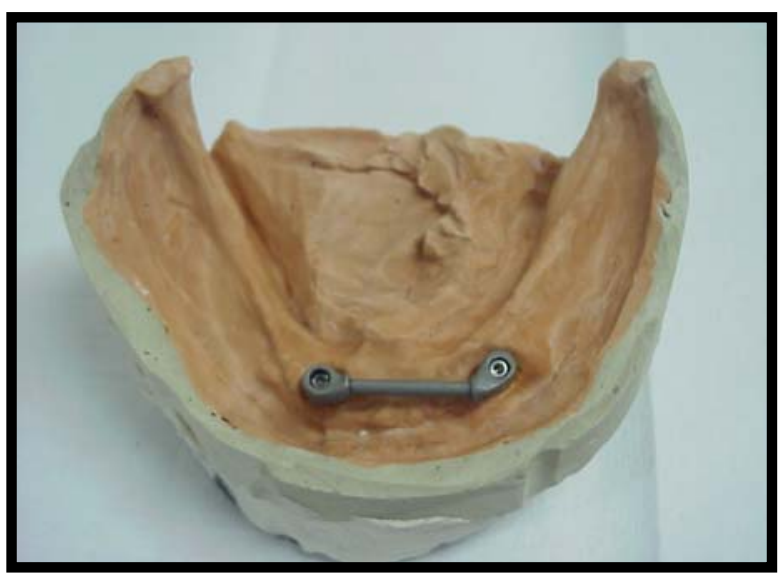

Figura 4.6 - Barra fundida em $\mathrm{NiCr}$

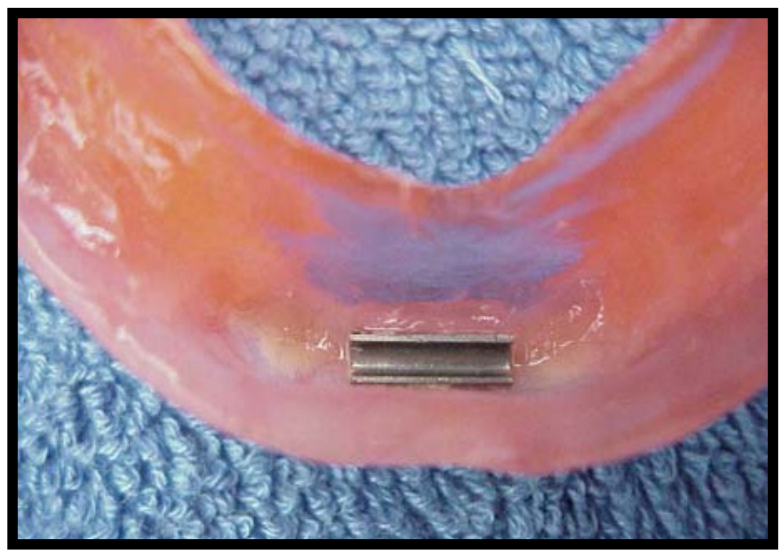

Figura 4.8 - Clip fixado no laboratório 


\subsubsection{Preparo do paciente}

Os pacientes passaram por um exame clínico minucioso, para verificação da correta adaptação da prótese, e a presença de alguma alteração na fibromucosa (lesões), que como descrito por Korioth e Hannam (1990) possdem de alguma forma interferir ou alterar o resultado do ensaio .

Receberam verbalmente a devida orientação de posicionamento e treinamento de como manusear o aparelho, como proceder durante o ensaio e por escrito as informações relacionadas ao objetivo do trabalho, justificativa da pesquisa, possível desconforto e risco esperado, benefício etc. e assinaram o termo de consentimento (Apêndice A).

\subsubsection{Preparo do aparelho}

O aparelho foi devidamente higienizado e desinfetado com uma solução bactericida, e as hastes que entram em contato com a cavidade oral do paciente envoltas com barreiras (filme de PVC) para se evitar qualquer problema de infecção cruzada seguindo as norma de Biossegurança do Ministério da Saúde

Antes do ensaio foi conferida a calibração e o correto funcionamento do aparelho.

O paciente foi devidamente identificado e cadastrado no software de armazenamento dos dados do aparelho e os exames foram executados. 


\subsubsection{Regiões avaliadas}

As mensurações foram executadas com a cabeça do paciente na Posição Ortostática (plano oclusal paralelo ao plano horizontal), pois segundo Fields, Proffite e Case (1986) posições flertadas da cabeça alteram os resultados das mensurações da intensidade da força de mordida.

Com o auxílio do operador, foi posicionada a face oclusal do dente inferior, da região de interesse, no centro da superfície plástica de proteção da haste do aparelho, não existiu apoio contralateral, pois segundo Fields, Proffit e Case (1986) não altera o resultado das medições de força de mordida.

As mensurações foram efetuadas nas seguintes regiões:

- Região posterior do lado direito: sobre o centro da face oclusal do primeiro molar inferior direito.

- Região posterior do lado esquerdo: sobre o centro da face oclusal do primeiro molar inferior esquerdo. 


\subsubsection{Mensurações}

Os dados foram obtidos em uma única sessão clínica, pois segundo Hannam (1990) e Bakke, Holm e Gofredsen (2002) podem ocorrer diferenças nos resultados quando os exames são executados em dias diferentes.

Inicialmente as próteses foram removidas e higienizadas com auxílio de um ultra-som, logo após, checados os contatos oclusais, com papel carbono para articulação.

O exame foi executado em duas fases distintas:

1ㅡㅗ Fase: o paciente posicionado na cadeira odontológica sempre com plano oclusal paralelo ao plano horizontal (FIELDS, 1986). Com a Prótese Total superior e a Overdenture inferior em posição, este executa a pressão oclusal no aparelho até atingir a sua força máxima permanecendo nesta pressão até que se canse ou intervalo de 1 minuto (foram executadas 3 mensurações de cada lado com intervalos de 1 minuto de descanso, para correta análise estatística).

2 ${ }^{\mathbf{a}}$ Fase: as barras sobre implante foram removidas e devidamente higienizadas, e as próteses recolocadas na cavidade oral, sem a presença da barra tornando-se esta uma prótese Total Bimaxilar Convencional, da mesma maneira que na $1^{a}$ fase o paciente efetuou a pressão oclusal no aparelho nas áreas já mencionadas. 
4.3.6 Avaliação da sensibilidade da fibromucosa da área basal

Durante o ensaio foram avaliados alguns dados referentes à sensibilidade da fibromucosa mucosa, pois segundo Tanaka et al. (2004), o limiar da dor diminui quando aumenta a força de mordida e esta relação tende a ser maior nas regiões posteriores da mandíbula.

Logo após, cada exame que o paciente executou, as seguintes perguntas foram feitas:

- Parou de pressionar, por que doeu a mucosa da região superior ?

- Parou de pressionar, por que doeu a mucosa da região inferior ?

- Parou de pressionar, por que cansou ?

4.3.7 Determinação do lado do ciclo mastigatório do paciente.

Após o exame uma cenoura crua cortada no formato de um $1 \mathrm{~cm}^{3}$ foi fornecida ao paciente para que este mastigasse e desta forma foi possível determinar qual o lado de preferência da mastigação (ciclo mastigatório) do paciente.

O quadro 4.2 a seguir exemplifica as respostas de um paciente e o resultado dos outros pacientes pode ser encontrado no Apêndice C. 


\begin{tabular}{|c|c|c|c|}
\hline Paciente & \multicolumn{3}{|c|}{ Com Barra } \\
\hline $\begin{array}{l}\text { Nome } \\
1\end{array}$ & $\frac{\text { Ciclo }}{\text { Mastigatório }}$ & $\begin{array}{l}\text { Força de mordida Lado } \\
\text { Esquerdo }\end{array}$ & $\begin{array}{l}\text { Forca de mordida Lado } \\
\text { Direito }\end{array}$ \\
\hline 1 & & 1.deslocou lado oposto & 1.dor mucosa sup \\
\hline 2 & lado direito & 2.dor mucosa sup. & 2.cansou \\
\hline 3 & & 3.dor mucosa superior & 3.cansou \\
\hline Paciente & \multicolumn{3}{|c|}{ Sem Barra } \\
\hline $\begin{array}{c}\text { Nome } \\
1\end{array}$ & $\begin{array}{l}\text { Ciclo } \\
\text { Mastigatório } \\
\end{array}$ & $\begin{array}{l}\text { Forca de mordida Lado } \\
\text { Esquerdo }\end{array}$ & $\begin{array}{l}\text { Forca de mordida Lado } \\
\text { Direito } \\
\end{array}$ \\
\hline 1 & lado direito & 1.dor mucosa inf esq & 1.dor mucosa inf dir \\
\hline 2 & & 2.dor mucosa inf esq & 2.dor mucosa inf dir \\
\hline 3 & & 3.dor mucosa sup & 3.dor mucosainf. Dir \\
\hline
\end{tabular}

Quadro 4.2 - Demonstração dos dados avaliados durante o exame de mensuração da força de mordida no paciente 1

\subsubsection{Questionário}

Após os testes o paciente respondeu a um questionário simples e direto, que tem por finalidade:

- Comparar eficiência mastigatória das próteses antes dos implantes com as próteses sobre implantes estudados.

- Avaliar a satisfação pessoal do paciente em relação a sua nova condição protética. 


\subsubsection{1 questionário}

O objetivo deste questionário é obter informações referentes a melhora na qualidade de vida e satisfação pessoal dos pacientes reabilitados com Overdentures (próteses sobre implantes) inferiores associadas a Próteses Totais Convencionais Superiores.

Nenhum dado fornecido será divulgado publicamente, servindo somente como informação para estudos científicos, com a finalidade de melhorar cada vez mais o resultado final dos trabalhos protéticos.

Ficando você no direito de não responder a qualquer pergunta que não achar pertinente.

\section{DADOS PESSOAIS:}

Nome:

Idade:

Sexo:

End:

Bairro:

Cep:

Fone: 


\section{ANTES DOS IMPLANTES:}

Você usava algum tipo de prótese antes dos implantes ?

$\operatorname{Sim}($ ) Não ( )

Se usava, qual era

$\begin{array}{ccc}\begin{array}{c}\text { Ponte Fixa ( ) } \\ \text { Prótese P. Fixa }\end{array} & \begin{array}{c}\text { Ponte Móvel ( }) \\ \text { Prótese P. Móvel }\end{array} & \begin{array}{c}\text { Dentadura ( }) \\ \text { Prótese Total }\end{array}\end{array}$

Há quanto tempo você usava sua ultima prótese ? anos e meses

Porque, você procurou um tratamento com implantes, o que mais the incomodava na sua prótese antiga?

Estética ( ) Fixação ( ) Mastigação ( ) Conforto ( )

Você mastigava com conforto:

Banana ou pudim

Maçã

Amendoim

Cenoura crua

$\begin{array}{ll}\operatorname{Sim}(\text { ) } & \text { Não( ) } \\ \operatorname{Sim}(\text { ) } & \text { Não( ) } \\ \operatorname{Sim}(\text { ) } & \text { Não( ) } \\ \operatorname{Sim}(\text { ) } & \text { Não( ) }\end{array}$


Avalie a capacidade de mastigar com sua prótese antiga, marcando um ponto na linha ou atribuindo uma nota de 0 a 10

Insatisfeito Muito satisfeito

(Nota0)

(Nota 10)

Nota:

3. AGORA QUE VOCÊ JÁ APRESENTA PRÓTESES SOBRE IMPLANTES:

Você gosta da junção entre implante e gengiva ?

$\operatorname{Sim}($ ) Não( )

Você sente cheiro ruim na sua prótese sobre implante?

$\operatorname{Sim}(\quad) \quad$ Não( )

Você escova seus implantes toda as vezes que se alimenta?

$\operatorname{Sim}($ ) Não( )

Você acha difícil sua tarefa de limpar os implantes e a barra ?

$\operatorname{Sim}($ ) Não( ) 
Você mastiga com conforto:

Banana ou pudim

Maçã

Amendoim

Cenoura crua
$\operatorname{Sim}()$

Não ( )

$\operatorname{Sim}($ )

$\operatorname{Sim}($ )

$\operatorname{Sim}($ )
Não ( )

Não ( )

Não ( )

Avalie a capacidade de mastigar com sua prótese sobre implante, marcando um ponto na linha ou atribuindo uma nota de 0 a 10

Insatisfeito Muito satisfeito (Nota 0) (Nota 10)

Nota:

Estando reabilitado e totalmente adaptado você faria novamente implantes ? $\operatorname{Sim}(\quad)$ Não( )

Você pretende continuar o trabalho de reabilitação?

$\operatorname{Sim}(\quad)$ Não( )

Você vai indicar implantes para outras pessoas ?

$\operatorname{Sim}(\quad)$ Não( ) 
Avalie a satisfação geral do seu trabalho envolvendo implantes, marcando um ponto na linha, ou atribuindo uma nota de 0 a 10

Insatisfeito muito satisfeito

(Nota 0)

(Nota 10)

Nota: 


\section{RESULTADOS}

\subsection{Análise estatística das respostas dos questionários}

O questionário foi aplicado a 23 pacientes usuários de próteses totais bimaxilares após a reabilitação com overdentures inferiores sobre implantes.

Os resultados referentes às respostas fornecidas pelos pacientes são encontrados nas (Tabelas de 5.1 a 5.13 ) apresentadas a seguir.

Tabela 5.1 - Distribuição de freqüências da variável (Queixa principal)

\begin{tabular}{c|c|c}
\hline Queixa principal & No. de pacientes (\%) & Total de pacientes (\%) \\
Estética & $1(4,35)$ & $23(100)$ \\
Fixação & $22(95,65)$ & $23(100)$ \\
Mastigação & $15(65,22)$ & $23(100)$ \\
Conforto & $15(65,22)$ & $23(100)$
\end{tabular}

Tabela 5.2 - Distribuição de freqüências da variável (Mastigava confortavelmente com a prótese antiga)

\begin{tabular}{c|c|c|c}
\hline Tipo de alimento & \multicolumn{2}{|c|}{$\begin{array}{c}\text { Número de pacientes } \\
\text { (\%) }\end{array}$} & $\begin{array}{c}\text { Total de pacientes } \\
\text { Sim }\end{array}$ \\
Pudim e Banana & $6(26,09)$ & $17(73,91)$ & $23(100)$ \\
Cenoura crua & $0(0,00)$ & $23(100,00)$ & $23(100)$ \\
Maçã & $5(21,74)$ & $18(78,26)$ & $23(100)$ \\
Amendoim & $0(0,00)$ & $23(100,00)$ & $23(100)$
\end{tabular}


Tabela 5.3 - Distribuição de freqüências da variável (Capacidade de mastigar com a prótese antiga)

\begin{tabular}{c|c}
\hline Nota & $\begin{array}{c}\text { No. de pacientes } \\
(\%)\end{array}$ \\
0 & $10(43,48)$ \\
4 & $10(43,48)$ \\
5 & $3(13,04)$ \\
Total & $23(100,00)$
\end{tabular}

Tabela 5.4 - Distribuição de freqüências da variável (Gosta da junção entre implante e gengiva)

\begin{tabular}{c|c}
\hline Categorias da variável & $\begin{array}{c}\text { Número de pacientes } \\
\mathbf{( \% )}\end{array}$ \\
Sim & $20(86,96)$ \\
Não & $3(13,04)$ \\
Total & $23(100,00)$
\end{tabular}

Tabela 5.5 - Distribuição de freqüências da variável (Sente cheiro ruim na sua prótese sobre implantes)

\begin{tabular}{c|c}
\hline Categorias da variável & $\begin{array}{c}\text { Número de pacientes } \\
(\%)\end{array}$ \\
Sim & $1(4,35)$ \\
Não & $22(95,65)$ \\
Total & $23(100,00)$
\end{tabular}


Tabela 5.6 - Distribuição de freqüências da variável (Escova seus implantes todas as vezes que se alimenta)

\begin{tabular}{c|c}
\hline Categorias da variável & $\begin{array}{c}\text { Número de pacientes } \\
(\%)\end{array}$ \\
Sim & $22(95,65)$ \\
Não & $1(4,35)$ \\
Total & $23(100,00)$
\end{tabular}

Tabela 5.7 - Distribuição de freqüências da variável (Acha difícil sua tarefa de limpar os implantes e a barra)

\begin{tabular}{c|c}
\hline Categorias da variável & $\begin{array}{c}\text { Número de pacientes } \\
(\%)\end{array}$ \\
Sim & $3(13,04)$ \\
Não & $20(86,96)$ \\
Total & $23(100,00)$
\end{tabular}

Tabela 5.8 - Distribuição de freqüências da variável (Mastiga confortavelmente com a prótese sobre implantes)

\begin{tabular}{c|c|c|c}
\hline Tipo de alimento & \multicolumn{2}{|c|}{$\begin{array}{c}\text { Número de pacientes } \\
\text { (\%) }\end{array}$} & $\begin{array}{c}\text { Total de pacientes } \\
\text { (\%) }\end{array}$ \\
& \multicolumn{2}{|c|}{ Sim } & Não \\
Pudim e Banana & $23(100,00)$ & $0(0,00)$ & $23(100)$ \\
Cenoura crua & $21(91,30)$ & $2(8,70)$ & $23(100)$ \\
Maçã & $23(100,00)$ & $0(0,00)$ & $23(100)$ \\
Amendoim & $22(95,65)$ & $1(4,35)$ & $23(100)$
\end{tabular}


Tabela 5.9 - Distribuição de freqüências da variável (Capacidade de mastigar com a prótese sobre implantes)

\begin{tabular}{c|c}
\hline Nota & No. de pacientes \\
& $\mathbf{( \% )}$ \\
8 & $3(13,05)$ \\
9 & $15(65,22)$ \\
10 & $5(21)$ \\
Total & $23(100)$
\end{tabular}

Tabela 5.10 - Distribuição de freqüências da variável (Faria implantes novamente)

\begin{tabular}{c|c}
\hline Categorias da variável & $\begin{array}{c}\text { Número de pacientes } \\
(\%)\end{array}$ \\
Sim & $22(95,65)$ \\
Não & $1(4,35)$ \\
Total & $23(100,00)$
\end{tabular}

Tabela 5.11 - Distribuição de freqüências da variável (Pretende continuar o trabalho de reabilitação)

\begin{tabular}{c|c}
\hline Categorias da variável & $\begin{array}{c}\text { Número de pacientes } \\
\text { (\%) }\end{array}$ \\
Sim & $3(13,04)$ \\
Não & $20(86,96)$ \\
Total & $23(100,00)$
\end{tabular}


Tabela 5.12 - Distribuição de freqüências da variável (Indicaria implantes para outras pessoas)

\begin{tabular}{c|c}
\hline Categorias da variável & $\begin{array}{c}\text { Número de pacientes } \\
(\%)\end{array}$ \\
Sim & $23(100,00)$ \\
Não & $0(0,00)$ \\
Total & $23(100,00)$
\end{tabular}

Tabela 5.13 - Distribuição de freqüências da variável (Satisfação geral em relação ao tratamento envolvendo implantes)

\begin{tabular}{c|c}
\hline Nota & No. de pacientes \\
& $(\%)$ \\
8 & $1(4,35)$ \\
9 & $7(30,43)$ \\
10 & $15(65,22)$ \\
Total & $23(100,00)$
\end{tabular}




\subsubsection{Análise Descritiva}

Pela Tabela 5.1, nota-se que o motivo principal pelo qual $95,65 \%$ dos pacientes procuraram um tratamento com implantes foi a fixação da prótese antiga. Por outro lado, houve pacientes que relataram mais de um problema, uma vez que $65,22 \%$ deles disseram ter problemas de mastigação, 65,22\% mencionaram problemas de conforto e apenas 4,35\% queixaram-se de problemas estéticos.

A Tabelas 5.2 e 5.8 mostram que, com a prótese antiga, uma grande porcentagem de pacientes (mais de 73\%) relataram não ter mastigação confortável ao comer Pudim, Banana, Maçã, Cenoura Crua e Amendoim. Vale ressaltar que essa porcentagem chegou a 100\% com relação à mastigação de Cenoura crua e Amendoim. No entanto, com a prótese sobre implantes, mais de 91\% afirmaram sentirem-se confortáveis ao mastigar esses alimentos. As porcentagens atingiram 100\% para Pudim, Banana e Maçã.

A análise das Tabelas 5.3 e 5.9 mostra que, com a prótese antiga, a capacidade de mastigar era reduzida, visto que as notas zero e quatro foram atribuídas por mais de $86 \%$ dos pacientes; já, com a prótese sobre implantes, a avaliação da capacidade de mastigar melhorou muito, uma vez que 100\% dos pacientes atribuíram notas iguais ou superiores a 8.

As Tabelas 5.4 a 5.7 e 5.10 a 5.12 mostram que os pacientes fizeram uma avaliação excelente da prótese sobre implantes visto que, aproximadamente $87 \%$ deles disseram:

- Gostar da junção entre o implante e a gengiva;

- Não ter dificuldade em limpar os implantes e a barra;

- Não querer continuar o trabalho de reabilitação. 
Além disto, 95,65\% dos pacientes relataram:

- Escovar seus implantes toda vez que ingerem alimentos;

- Não sentir cheiro ruim na prótese sobre implante;

- Que fariam implantes novamente.

Finalmente, todos os pacientes afirmaram que indicariam os implantes a outras pessoas.

A Tabela 5.13 mostra que a satisfação geral com o tratamento envolvendo implantes é ótima, pois mais de $95 \%$ dos pacientes avaliaram o trabalho com notas iguais a 9 (nove) ou 10 (dez).

\subsection{Análise estatística da sensibilidade da fibromucosa}

\subsubsection{Análise Descritiva}

Cada um dos 23 pacientes teve a sensibilidade da fibromucosa avaliada durante o teste de intensidade da força de mordida do lado esquerdo e do lado direito, com barra e sem barra, em três exames para cada lado (Quadro 4.2). Foi criada, então, a variável (Sensibilidade da mucosa) que, em cada momento, apresentou os seguintes resultados: sentiu dor e cansou ou não sentiu dor.

Para resumir os resultados dos três testes, criou-se a variável (Resposta mais freqüente da sensibilidade da mucosa. Considerou-se como resultado desta variável, o resultado da variável Sensibilidade da mucosa que apareceu com maior freqüência dentre os três exames considerados. 
Tabela 5.14 - Distribuição de freqüências (\%) da variável (Resposta mais freqüente da sensibilidade da mucosa)

\begin{tabular}{c|l|c|c|c}
\hline & \multicolumn{2}{|c|}{ Lado esquerdo } & \multicolumn{2}{c}{ Lado direito } \\
& Sentiu & Cansou/Não sentiu & Sentiu & Cansou/Não sentiu \\
dor & $2(8,7 \%)$ & dor & dor & dor \\
barra & $21(91,3 \%)$ & $0(0,00 \%)$ & $23(100,0 \%)$ \\
Sem & $23(100,0)$ & $0(0,0 \%)$ & $23(100,0)$ & $0(0,0 \%)$ \\
barra & & & & \\
\hline
\end{tabular}

A análise da Tabela 5.14 mostra que todos os pacientes sentiram dor durante o teste da mensuração da força de mordida em ambos os lados quando não estavam com a barra tornando-se esta uma Prótese Total Bimaxilar. Usando a barra, todos os pacientes cansaram ou não sentiram dor do lado direito, enquanto que do lado esquerdo 91,3\% apresentaram este resultado. Nota-se, então, que com o uso da barra, a sensibilidade na fibormucosa parece ser amenizada ou demorar muito a aparecer. 


\subsection{Análise Estatística da Intensidade da Força De Mordida}

\subsubsection{Descrição das variáveis}

- Variáveis independentes

1. Barra: Sem (S) e Com (C)

2. Lado: Esquerdo (E) e Direito (D);

3. Tratamento: combinações das categorias das variáveis Barra e Lado (Sem-D, Sem-E, Com-D e Com-E);

4. Lado do ciclo mastigatório: Esquerdo (E) e Direito (D);

5. Lado mais forte: Esquerdo (E) e Direito (D);

- Variáveis dependentes

1. Força (Kgf) 
Tabela 5.15 - Dados dos pacientes (média dos valores máximos obtidos nas três avaliações da variável Força)

\begin{tabular}{c|c|c|c|c}
\hline Paciente & Sem barra -E & Sem barra -D & Com barra - E & Com barra -D \\
1 & 4,33 & 3,43 & 6,67 & 4,65 \\
2 & 1,30 & 1,60 & 5,60 & 7,10 \\
3 & 7,93 & 5,10 & 12,77 & 11,88 \\
4 & 8,13 & 2,77 & 12,77 & 11,88 \\
5 & 4,75 & 3,48 & 12,03 & 10,72 \\
6 & 6,28 & 6,58 & 10,72 & 10,33 \\
7 & 2,07 & 3,97 & 8,08 & 9,57 \\
8 & 8,40 & 12,07 & 23,08 & 20,17 \\
9 & 2,12 & 1,78 & 6,63 & 4,65 \\
10 & 2,92 & 4,58 & 12,77 & 11,88 \\
11 & 6,63 & 4,65 & 7,58 & 5,80 \\
12 & 8,22 & 5,03 & 12,77 & 11,88 \\
13 & 4,33 & 3,43 & 6,63 & 4,65 \\
14 & 5,85 & 2,53 & 10,20 & 4,50 \\
15 & 2,13 & 1,67 & 2,82 & 1,87 \\
16 & 6,85 & 3,38 & 8,08 & 9,57 \\
17 & 4,33 & 3,43 & 7,22 & 3,05 \\
18 & 4,52 & 4,30 & 6,00 & 9,63 \\
19 & 4,57 & 8,50 & 15,70 & 14,03 \\
20 & 8,05 & 5,67 & 9,23 & 4,28 \\
21 & 5,10 & 4,30 & 7,58 & 6,53 \\
22 & 4,80 & 7,42 & 7,22 & 3,05 \\
23 & 4,78 & 6,85 & 8,08 & 9,57 \\
\hline
\end{tabular}


Tabela 5.16 - Estatísticas descritivas para a variável Força

\begin{tabular}{c|c|c|c|c}
\hline \multirow{2}{*}{ Lado } & \multicolumn{4}{|c}{ Barra } \\
& \multicolumn{2}{|c|}{ Sem } & \multicolumn{2}{c}{ Com } \\
Média & D & E & D & E \\
Desvio padrão & 4,631 & 5,147 & 8,315 & 9,575 \\
& 2,432 & 2,160 & 4,366 & 4,234 \\
\hline
\end{tabular}

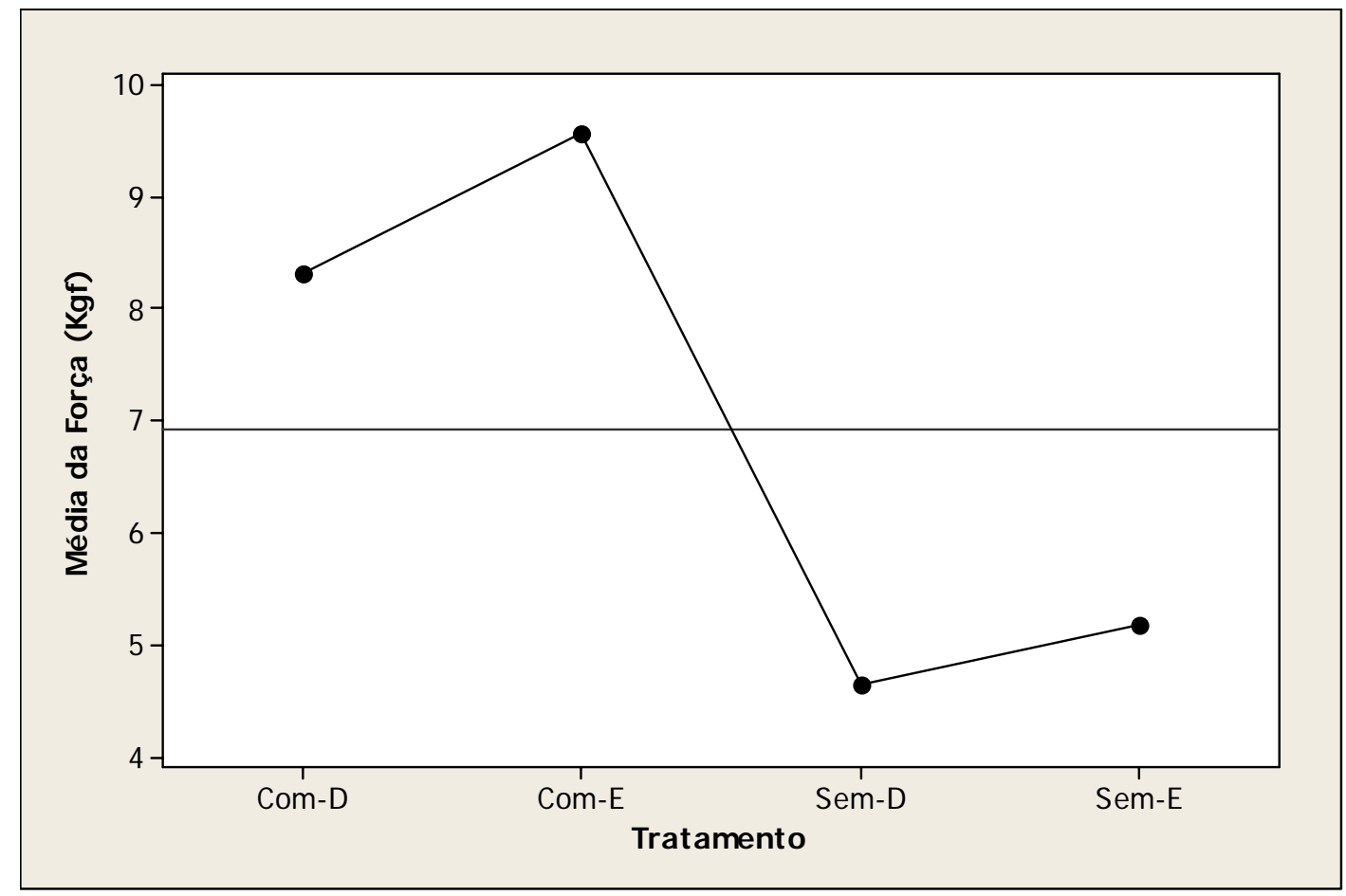

Gráfico 5.1 - Perfil de médias da variável Força por Tratamento 
Tabela 5.17 - Resultados da Análise de Variância

\begin{tabular}{c|c|c|c|c|c}
\hline Fonte de & $\begin{array}{c}\text { Grau de } \\
\text { liberdade }\end{array}$ & $\begin{array}{c}\text { Soma de } \\
\text { quadrados }\end{array}$ & $\begin{array}{c}\text { Quadrado } \\
\text { médio }\end{array}$ & $\mathbf{F}$ & $\boldsymbol{P}$ \\
variação & 22 & 719,872 & 32,745 & 6,63 & 0,000 \\
Indivíduo & 3 & 400,280 & 133,427 & 27,01 & 0,000 \\
Tratamento & 66 & 325,975 & 4,939 & - & - \\
Resíduo & 91 & 1446,127 & - & - & - \\
Total & & -
\end{tabular}

Tabela 5.18 - Intervalos de confiança construídos pelo método de Tukey com coeficiente de confiança global igual a 95\% para diferenças entre médias da variável Força

\begin{tabular}{c|c}
\hline Diferença & Intervalo de confiança \\
Média sob Sem-D - Média sob Sem-E & {$[-2,322 ; 1,175]$} \\
Média sob Com-D - Média sob Com-E & {$[-2,989 ; 0,468]$} \\
Média sob Com-D - Média sob Sem-D & {$[1,985 ; 5,414]$} \\
Média sob Com-E - Média sob Sem-E & {$[2,634 ; 6,140]$} \\
\hline
\end{tabular}

Tabela 5.19 - Distribuição de freqüências conjuntas (\%) das variáveis Lado do ciclo mastigatório e Lado mais Forte

\begin{tabular}{c|c|c|c}
\hline Lado do ciclo mastigatório & \multicolumn{2}{|c|}{ Lado mais forte } & Total \\
& D & E & \\
D & $4(17,39)$ & $6(26,09)$ & $10(43,48)$ \\
E & $1(4,35)$ & $12(52,17)$ & $13(56,52)$ \\
Total & $5(21,74)$ & $18(78,26)$ & $23(100,00)$ \\
\hline
\end{tabular}




\subsubsection{Análise Descritiva}

A Tabela 5.16 apresenta a média e o desvio padrão da variável Força para cada um dos quatro tratamentos.

No Gráfico 5.1 apresentamos o perfil de médias da variável Força sob os quatro tratamentos.

A análise da Tabela 5.16 e do Gráfico 5.1 mostra que não parece haver diferença entre as médias da variável Força sob os lados $D$ e $E$, tanto Sem quanto Com o uso da barra. No entanto, o valor da média da variável Força Com o uso da barra é quase o dobro do valor da média Sem o uso da barra, para ambos os lados.

A Tabela 5.19 mostra a distribuição de freqüências conjuntas das variáveis Lado do ciclo mastigatório e Lado mais forte. O lado de preferência do ciclo mastigatório do paciente é aquele usado com mais freqüência para mastigar; o lado mais forte é aquele que apresentou numericamente o maior valor da variável Força sob a situação Com barra (notar que, em geral, a diferença entre os valores da força de ambos os lados é muito pequena).

A análise da Tabela 5.19 mostra que o lado mais forte é $E$, pois aparece em 78,26\% dos pacientes; por outro lado, não há predominância de um lado como dominante, já que o lado $E$ é apresentado por apenas $56,52 \%$ dos pacientes, ou seja, não existiu correlação entre o lado de preferência da mastigação ser o lado onde se obteve maior intensidade da força da mordida. 


\subsubsection{Análise Inferencial}

O objetivo da análise inferencial é verificar o efeito das variáveis Barra e Lado sobre a média da variável Força. Como cada paciente foi avaliado nos quatro tratamentos, utilizou-se um modelo de análise de variância com medidas repetidas (NETER et al., 1996).

A Tabela 5.17 exibe os resultados da análise de variância. Pode-se concluir, ao nível de significância de 5\%, que os valores das médias da variável Força sob os quatro tratamentos não são iguais (nível descritivo $P=0,000<5 \%$ ). Utilizando o método de TUKEY para comparações múltiplas (NETER et al., 1996) com coeficiente de confiança global igual a 95\% (ver intervalos de confiança apresentados na Tabela 5.18 ), temos que, tanto para Sem barra como para Com barra, a média da Força sob o lado $D$ é igual à do lado E. Já, a média da Força sob o tratamento Com barra é maior do que a média sob o tratamento Sem barra, em ambos os lados.

Para verificar se há associação entre o Lado do ciclo mastigatório e o Lado mais forte foi realizado um teste exato de Fisher (AGRESTI, 2002). O nível descritivo $P$ do teste foi igual a 0,127 , indicando, ao nível de significância de 5\%, indicando que as variáveis Lado do de preferência do ciclo mastigatório e Lado mais forte não estão associadas $(P>5 \%)$. 


\section{DISCUSSÃO}

A literatura tem demonstrado que existe um aumento da força de mordida em pacientes edentados totais, que se beneficiam do uso de próteses sobre implantes (overdentures), quando comparadas as sua próteses antigas Boretti, Bickel e Geering (1995), Burns et al. (1995), Koivumaa (1985), Lassila, Homulund e Hollanda (2002) e Lindquist e Carlsson (1985).

Como as próteses antigas na maioria dos casos apresentam-se com vários anos de uso, mal adaptadas, desgastadas e com sua dimensão vertical de oclusão alterada, foi de extrema importância, se obter um padrão de comparação real entre a condição pregressa do paciente (quando este se apresentava sem elementos dentários), e sua atual situação (sendo este portador de implantes osseointegrados e usuário de uma prótese sobre implante, no caso uma Overdenture, mucoso suportada e implanto retida).

Para não induzir variáveis na metodologia e ser possível comparar os resultados dos testes de mensuração da intensidade da força de mordida, foi utilizada a mesma prótese inferior que quando na presença da barra sobre os implantes e retida com o clip, se torna uma Overdenture e a partir do momento em que esta barra é desparafusada e removida dos implantes, esta prótese se torna uma Prótese Total Convencional .

Assim sendo, como descrito por Ozcan et al (2005), qualquer variável relacionada a uma possível diferença existente entre duas próteses diferentes, referente à: extensão da área basal, oclusão, dimensão vertical etc., que possam ser questionadas ficam eliminadas. 
Nos trabalhos citados na revisão da literatura, encontramos autores que em suas pesquisas, compararam próteses antigas com próteses novas ou compararam grupos de pacientes portadores de Próteses Totais Bimaxilares com grupos de pacientes portadores de Overdentures Awad et al. (2003), Bakke, Holm e Godfrendsen (2002), Boerrigter et al (1985), Chen et al.(2002), Cibirka, Razzog e Lang (1997), Gertman et al. (1996), Gertman et al. (1999), Meijer et al (1999), Morimoto et al. (1996), Pêra et al. (1998) e Walton, Macentee e Glick (2002) Somente Stelligsman, Sglater e Stegenga (2005) e o presente estudo utilizaram a mesma prótese em seu trabalho.

Lundgren et al. (1975) validaram o uso de questionários como método subjetivo de avaliação de função, e como método complementar, para avaliação da intensidade da força de mordida. Já Baer, Elias e Reynolds (1992) concluíram que o emprego de questionários, fornece informações valiosas para se avaliar a função em pacientes usuários de próteses. Cibirka, Razzog e Lang (1997), Hollanda (2002) afirmaram que os questionários aplicados em suas pesquisas forneceram evidencias científicas da melhora da qualidade de vida de pacientes portadores de próteses sobre implantes.

Apesar de todos os autores mencionados concluírem após análise das respostas de seus questionários, que os pacientes reabilitados com próteses sobre implantes demonstraram-se satisfeitos, resultado que corrobora nossa pesquisa, tornou-se difícil fazer uma comparação dos nossos resultados com os encontrados na literatura, pois não existia um questionário padronizado com metodologia definida. 
Para uma possível comparação com os resultados descritos na revisão bibliográfica, nosso questionário foi montado com itens que eram relevantes e comuns aos questionários descritos por Burns et al. (1995), Cibirka, Razzog e Lang (1997), Egquist et al. (1998), Haraldson e Zarb (1988), Hollanda (2002), Lindqvist e Haraldson (1992) Winsmeijer et a. (1992) e Zarg et al.(1990). Aplicamos aos pacientes um questionário com perguntas objetivas e respostas simples, na forma de "sim" e "não".

Através dos resultados obtidos no questionário aplicado aos pacientes, notase que o motivo principal pelo quais $95,65 \%$ dos pacientes procuraram um tratamento com implantes foi a fixação da prótese antiga (Tabela 5.1). Por outro lado, houve pacientes que relataram mais de um problema, uma vez que 65,22\% deles disseram ter problemas de mastigação, $65,22 \%$ mencionaram problemas de conforto e apenas 4,35\% queixaram-se de problemas estéticos. Resultados semelhantes foram descritos por, Brunello (1998) que descreveu como queixa principal dos pacientes portadores de prótese total, consistia em desconforto e sensibilidade da fibromucosa durante a mastigação.

Quanto ao limiar de dor Tanaka et al. (2004) relatou que este diminui quando aumenta a força de mordida e esta relação tende a ser maior nas regiões posteriores da mandíbula, Vervoorn (1988) relatou que a reabsorção óssea afeta mais a mandíbula que a maxila, gerando uma menor área de suporte e conseqüentemente, pouca distribuição de carga, levando a uma menor eficiência mastigatória e maior sensibilidade da fibromucosa da área basal. Bakke, Holm e Godfredsen (2002) constataram que a menor sensibilidade da mucosa levou o paciente a exercer uma maior atividade muscular detectada no seu estudo, através de eletro-miografia 
durante a atividade dos músculos Masseter e Temporal.

Constatamos nos resultados da Tabela 5.14 que todos os pacientes sentiram dor durante o exame da mensuração da força de mordida, em ambos os lados quando não usavam a barra (Prótese Total Bimaxilar). Usando a barra, todos os pacientes cansaram ou não sentiram dor do lado direito, enquanto que do lado esquerdo 91,3\% apresentaram este resultado. Nota-se, então, que com o uso da barra, a dor parece ser eliminada ou demorar muito a aparecer.

Uma hipótese para explicar esta diminuição foi descrita por Geertman et al (1999), Fontinji-Tekamp et al. (2000), Van Kapen, Cune e Bosman (2002) e Stelligsman, Slagter e Stegenga (2005) que determinaram em seus estudos como uma das causas da melhora da sensibilidade na mucosa da área basal em pacientes reabilitados com overdentures inferiores, se deve ao aumento da retenção e estabilidade proporcionado pela presença do sistema barra/clipe, pois estas próteses são classificadas pelos autores com mucoso suportadas e implanto retidas.

Segundo Stelligsman, Slagter e Stegenga (2005), Ozcan et al. (2005), Tanaka et al. (2004), Roumanas et al. (2003), Fontinji et al. (2000), Geertman et al. (1999), Brunello e Mandikos (1998), Mericske-Stern e Zarb (1993), Slagter (1992), Vervoorn (1988) e Haraldson et al. (1988) a limitação de se conseguir triturar os alimentos se deve a vários fatores como: habilidade de controlar a força de mordida em termos de intensidade e direção, a sensibilidade da fibromucosa que se localiza na área basal aonde a prótese vai se apoiar e a pouca retenção e estabilidade que apresentam as próteses totais sobre rebordos extremamente reabsorvidos. 
Sheiman et al (1999), relataram que grande porcentagem dos pacientes portadores de próteses totais estudados não conseguia se alimentar de cenouras cruas, amendoim , castanhas, maçãs e carne bem passada.

Roumanas et al. (2003) através de seu estudo, classificou grupos de alimentos segundo a dificuldade dos pacientes portadores de próteses mastigar em: fáceis (pudim,pão macio, bolo, espaguete), moderados( maioria dos vegetais cozidos, frango assado, cheeseburger, maioria das frutas), difíceis (maçã, granola, castanha e amendoim, carnes vermelhas).

Podemos observar nas Tabelas 5.2 e 5.8 que com a prótese antiga, uma grande porcentagem de pacientes (mais de $73 \%$ ) relatou não ter mastigação confortável ao comer Pudim, Banana, Maçã, Cenoura Crua e Amendoim. Vale ressaltar que essa porcentagem chegou a 100\% com relação à mastigação de Cenoura crua e Amendoim.

No entanto, com a prótese sobre implantes, mais de 91\% afirmaram sentiremse confortáveis ao mastigar esses alimentos. As porcentagens atingiram 100\% para Pudim, Banana e Maçã.

Uma hipótese para explicar este fato foi descrita por Geertman et al (1999), Fontinji-Tekamp et al. (2000), Van Kapen, Cune e Bosman (2002) e Stelligsman, Slagter e Stegenga (2005) que determinaram em seus estudos como uma das causas da melhora da eficiência mastigatória e da intensidade da força de mordida em pacientes reabilitados com overdentures inferiores, se deve a diminuição da sensibilidade na fibromucosa da área basal durante os testes de mastigação e aumento da retenção.

Bakke, Holm e Godfredsen (2002), Walton (2002), Roumanas et al. (2003), Ozcan et al. (2005) e Fontinji- Tekamp et al (2001) também relacionaram o 
aumento da eficiência mastigatória dos pacientes reabilitados com overdentures inferiores com um melhor conforto e confiança durante a mastigação.

Para a auto-a valiação dos pacientes como descrito por Awad et al. (2003), Bakke et al. (2002), Carlsson e Lindqvist (1994), Cibirka, Razzog e Lang (1997), Geertman et al (1999) Haralson et al. (1988), Hollanda (2002), Lundqvist e Carlsson (1985), Macentee e Glick (2002), Walton (2005), Ozcan et al. (2005), Roumanas et al. (2003), Stelligsman, Sglater e Stengenga (2005), Zarb e Schimit (1990) e Zistman e Marinello (2002), utilizamos as denominadas "Escalas Análogas Visuais " .Entretanto todos os pacientes optaram em ler e preencher as respostas por eles mesmos, ao invés de serem verbalmente entrevistados. No momento de preencher as escalas análogo visuais dos itens (capacidade de mastigar com a prótese antiga, capacidade de mastigar com a prótese sobre implante, satisfação geral do tratamento com próteses sobre-implantes), preferiram graduar de zero a dez os itens de avaliação, ao invés de marcar um ponto na linha da escala, fato semelhante descrito por Hollanda (2002).

A análise das Tabelas 5.3 e 5.9 mostra que, com a prótese antiga, a capacidade de mastigar era reduzida, visto que as notas zero e quatro foram atribuídas por mais de $86 \%$ dos pacientes; já, com a prótese sobre implantes, a avaliação da capacidade de mastigar melhorou muito, uma vez que $100 \%$ dos pacientes atribuíram notas iguais ou superiores a 8.

As Tabelas 5.4 a $5 . .7$ e $5 . .10$ a $5 . .12$ mostram que os pacientes fizeram uma avaliação excelente da prótese sobre implantes visto que, aproximadamente 87\% deles, não apresentaram dificuldades durante a higienização das próteses e da junção entre implante e gengiva, e não tem intenção de fazer outro tipo de 
tratamento. Todos os pacientes afirmaram que indicariam tratamento com implantes para outras pessoas, e 96,65 \% fariam implantes novamente se necessário.

Observa-se na Tabela 5.13 que a satisfação geral com o tratamento envolvendo implantes é ótima, pois mais de 95\% dos pacientes avaliaram o trabalho com notas iguais a 9 ou 10. Geertman e Splagter (1999), avaliaram a satisfação dos pacientes reabilitados com implantes mandibulares e overdentures com sistema barra-clipe e com próteses totais bimaxilares convencionais, encontrando em média notas de 8.4 para os pacientes reabilitados com overdentures. Engquist et al. (1988) relataram que $81 \%$ dos pacientes sentiam suas próteses melhores que as prévias, Mericske-Stern e Zarb (1993) obtiveram um índice de satisfação em relação às overdentures inferiores, superior a $90 \%$.

Meijer et al (1999), conlcuiram que: (1) Dois implantes-suporte para overdenture podem atingir alto índice de sucesso (93\%); (2) A overdenture proporciona um grau de satisfação melhor que a prótese total; (3) A colocação de implantes na mandíbula não afeta a prótese superior; (4) A satisfação pessoal obtida com a overdenture diminui com tempo - isso, talvez pelo fato de os pacientes se acostumarem a uma situação melhor.

Com relação à intensidade da força de mordida, as observações da análise descritiva foram confirmadas na análise inferencial, ou seja, há evidência de diferença entre as médias da variável Força apenas nas situações Com barra e Sem Barra, sendo que a média sob Com Barra é maior do que sob Sem barra.

Não foi encontrada associação entre o Lado mais forte e o Lado de preferência do ciclo mastigatório. 
Os valores em média encontrados para a intensidade da força de mordida foram de 4,88 Kgf Sem barra e 8,98 Kgf Com barra, praticamente o dobro de aumento da intensidade da força quando os pacientes utilizavam suas próteses sobre implantes.

Nossos resultados são corroborados pelos de Howell e Brudevold (1950) que estudaram as forças de mastigação em pacientes portadores de próteses totais, obtendo uma força média de mordida de 4kgf. Já Ogata e Satoh (1995) encontraram valores médios de 6,5Kgf.

Vieira (1998), encontrou valores médios para força máxima de mordida na região de primeiros molares de $11.5 \mathrm{Kgf}$ em pacientes portadores de Próteses Totais superiores e Overdentures inferiores e de $5 \mathrm{Kgf}$ para pacientes edentados totais.

Lindquist e Carlson (1982a) descreveram que a intensidade da força de mordida aumentou em 85\% com a colocação das overdentures.

Bakke, Holm e Godfredsen (2002) relatam um aumento significativo na intensidade e na duração da força de mordida com as overdentures, chegando aos seguintes valores em média :11,5Kgf para prótese antes dos implantes, 20Kgf 3 meses após a colocação dos implantes. Segundo os mesmos este aumento se deve a uma maior segurança por parte do paciente devido à prótese apresentar uma maior retenção e estabilidade proporcionada pelos sistemas de retenção sobre implantes. Pode-se ver no quadro 5.15 que somente o paciente número 8 atingiu valores semelhantes aos descritos por estes autores.

Lindquist e Carlson (1985b) encontraram correlação entre o questionário e o resultado das forças de mordida, ou seja, o aumento da força de mordida correspondia ao aumento dos valores marcados nas escalas análogas visuais. 
Boretti et al. (1995) relatam que entre os testes clínicos de efetividade mastigatória, encontra-se a medida da força de mordida e este é um método indireto baseado na correlação da função mastigatória com a força de mordida.

Fontiin-Tekamp et al. (2001) encontraram em seus estudos uma significante correlação entre a força de mordida e a eficiência mastigatória.

$\mathrm{Na}$ tentativa de relacionar as respostas do questionário ao resultado obtido na comparação da intensidade da força de mordida dos pacientes, encontramos correlação positiva como Hollanda (2002), Boretti, Bickel e Geering (1995), Burns et al. (1995), Lindquist e Carlsson (1985) e Lassila, Homulund e Koivumaa (1985).

O aumento da força pode ser relacionado ao conforto, habilidade de mastigar e a satisfação geral proporcionada pela reabilitação com próteses sobre implantes, pois a simples mudança de um aparelho mucoso suportado (Prótese Total) para um aparelho mucoso suportado e implanto retido proporciona uma maior retenção e estabilidade que são as grandes dificuldades a serem superadas na confecção de próteses em pacientes com rebordos extremamente reabsorvidos. 


\section{CONCLUSÕES}

Através da metodologia aplicada e com base na análise dos dados obtidos, parece lícito concluir que:

- Há diferença entre os valores médios da variável Força nas situações Com barra e Sem Barra, sendo que a média sob Com Barra é maior do que sob Sem barra.

- A capacidade de mastigar se mostrou mais eficiente após a reabilitação com Overdentures inferiores e este fato se deve a um melhor conforto e confiança durante a mastigação proporcionado pela melhor retenção e estabilidade que o sistema barra/clip sobre implantes oferece.

- A Overdenture demonstrou um alto índice de sucesso e proporciona um grau de satisfação melhor que relatado pelas Próteses Totais. 


\section{REFERÊNCIAS ${ }^{1}$}

Adell RÇ, Lekholm U, Branemark PI. A 15 year study of osseointegrated implants in the tratment of edentulous jaw. Int. J Oral Surg 1981;10(15): 387-416.

Agberg G, Carlsson GE. Chewing ability in relation to dental and genaral health. Analysis of data obtainned from a questionnaire. Acta Odontol Scand 1981;39(10):147-53.

Agresti A. Categorical Data Analysis. 2a edição. New York: Wiley; 2002.

Awad MA, Lund JP, Dufresne E, Feine JS. Comparing the efficacy of mandibular implant-retained overdentures and convencional dentures among middle-aged edentulous patients: satisfaction and functional assessment. Int J Prosth 2003;16(2):117-22.

Baer M L, Elias SA. Reynolds, MA. The use of psycological measures in predicting patient satisfication with complete dentures. Int J Prosthodont 1992; 5(22):221-6.

Batess JF, Stafford GD. Harisson. A. Masticatoryfunction: a review of the literature II. Speed of movement of the mandible, rate of chewing and forces developed inchewing. J. Oral Rehabil 1975; 2(4):349-61.

Bakke M, Michler L, Han K, Moller E. Clinical significance of isometric bite force versus eletrical activity in temporal and masseter muscles. Scand J Dent 1989;97( $6): 539-51$.

Bakke M, Holm B, Gofredsen K. Masticatory function patient satisfaction withimplant supported mandibular overdentures :A prospective 5- year study. Int J Prosthodontics 2002;15(6):575-81.

Benzing $\mathrm{U}$, Weber $\mathrm{H}$, Simonis A, Engel E. Changes in chewing patterns implantation in the edentulous mandible. Int J Oralmaxillofac Implants 1994; 9(2): 207-13.

\footnotetext{
${ }^{1}$ De acordo com o estilo Vancouver. Abreviatura de periódicos segundo base de dados Medline.
} 
Bernardes NJ. Avaliação da força máxima de mordida, revisão dos métodos utilizados. [Dissertação de Mestrado]. São Paulo: Escola Paulista de Medicina;2002.

Beumer IJ, Lewis SG. Sistema de Implantes Branemark: procedimentos clínicos e laboratoriais. Trad. de Vilma Simões Gomes. São Paulo: Pancast; 1993.

Bindo MF. Estudo da dureza e do modulo de elasticidade na superfície de resinas acrílicas para base de prótese total [Tese Doutorado]. São Paulo : Faculdade de Odontologia da USP; 2003.

Black GV. An investigation of the physical characters of the human teeth in relation to their diseases, and to pratical dental operations, together with the physical characters of the filingmaterials. Dent Cosmos 1895;37(6):469-84.

Boerrigter EM, Gerrtman M E, Van'Tof M A, Van Wass MAJ, Van Hort RP, Boering $\mathrm{G}$,et al. Patient satisfactionwih implant-retained mandibular overdenures. A comparision with a new complete dentures not retaned by implants a muticentre randomized clinical trial. J. Oral Maxilalfacial Surgery 1995; 33: 282-288.

Boerrigter E M, Stegenga B, Raghoebar G M, Boering G. Patient satisfaction and chewing ability with implant-retained mandibular overdentures: a comparison with new complete dentures with or without preprosthetic surgery. J Oral Maxillofac Surg 1995;53(10):1167-73.

Bonachella WC, Rossettl, PHO. Overdentures . São Paulo: Santos; 2002.

Boretti G, Bickel M, Geering AH. A review of mastigatory ability and efficiency. J Proshet 1995;74(4):400-3.

Bortoli Jr N. Complicações biomecânicas das overdentures. Rev Bras Implant 1996;8(10): 59-65.

Bortoli Jr. N. Análise fotoelástica da distribuição das tensões nos rebordos e na região de implantes-suporte de Overdentures com sistema de encaixe Bola O'ring e Barra Clipe, [Tese de Doutorado\}. São Paulo:Faculdade de Odontologia da USP;2004.

Boss $\mathrm{RH}$. Intermaxilary relation estabilished by biting power. J Am Dent Assc 1940;27(8):1192-9. 
Brunello DL, Mandikos N. Construction faults, age, gender, and relative medical health: Factors associated with complaints in complete dentures patients. J Prosthetic Dentistry 1998; 79(5):545-54.

Branemark P, Zarb GA, Albrektsson T. Protesis tejido integradas: la osseointegração em la odontologia clínica. Trad. de Jaime A. Gil. Los Angeles: Quintessence Books; 1987.

Beckhus PI, Armstrong WD, Simon WJ. Stimulation of the muscles of mastication. J Dent Res 1941;20(2):87-92.

Brudevold F, Rochester NY. A baic study of the cheing forces of a denture wearer. J Am Dent Assoc 1951;43(1):45-51.

Bruyin $\mathrm{H}$, Collaert $\mathrm{B}$, Linden $\mathrm{U}$, Bjorn AL.Patients opinion of treatment Outcome of fixed rehabilitation on Branermarck implants. Clin Oral implants Res 1997;8(4):265-71.

Burns DR, Unger JW, Elswick RK, Giglio JA. Prospective clinical evaluation of mandibular implant overdentures: Part II-patient satisfaction and preference. J. Prosthet Dent 1995;73(4):364-9.

Bussab WOE, Morettin PA. Estatística Básica. 5ª ed São Paulo: Saraiva: 2005.

Carlssson GE. Bite force and efficiency chewing. In: KAWAMURA Y Frontiers of oral physiology. Basel: Karger, 1974.

Carlsson GE, Lindquist LW. Ten year longitudinal studyof masticatory function in edentulous pacients treated with fixed complet denhtures on osseointegrated implants. Int J Prosthodont 1994;7(25):448-53.

Chen L XIE Q, Feng H, Lin Y, Li J. The masticatory efficiency of mandibular implant-supported overdentures as compared with tooth-supported overdentures and complete dentures. J Oral Implantol 2002;28(5):238-43.

Cibirka RM, Razzog MA, Lang BR. Critical evaluation of patitent responsesto dental implant therapy. J Prosthet Dent 1997;78(6):574-81.

Dario LJ. How oclusal forces change in implant patients. A clinical research 
report. J Am Dent Assoc 1995;126( 8):1130 -61.

Cune MS, Putter C, Hoogstraten J. Treatment outcome with implant-retained overdentures; part II - patient satifaction and predictability of subject treatment outcome. J Prosth Dent 1994;72(2)152-8.

Diaz SEA. Estudo comparativo do espaço interoclusal em relação centrica com a técnica do desprogramador anterior em função do tempo e a força de mordida. [Dissertação de Mestrado]. São Paulo: Faculdade de Odontologia da USP; 1993.

Doudonlakis JH, Eckert SE, Lindquist CC, Jeaffcoat MK. The implant-supported overdenture as an alternative to the complete mandibular denture. J Am Dent Assoc 2003; 134(11):1455-8.

Engquist B, Bergental $\mathrm{T}$, Kallus $\mathrm{T}$, Lnden $\mathrm{U}$. A retrospective multicenter evaluation of osseointegrated implanhts supporting overdentures. Int J Oral Maxillofac.

Implants 1988;3(2):129 -34.

Fields HW, Proffit WR, Case JC. Variables affcting menssuraments of vertical occlusal force. J Dent Res 1986;5(2):135-8.

Fine JS, Grandmont P, Boudrias P, Brien N, La Marche C, Tache R et al. Within subject comparisions of implant-supported mandibular prostheses : choice of prosthesis. J. Dent Res 1994;73(5):1105-11.

GunneHSJ. Masticatory efficiency a new method for determination of the breakdowm of masticated test material. Acta odontol Scand 1983;41(5):271-276.

Fontijin-Tekamp FA, Slagter A P, Van Der Bilt A, Vant Hof MA, Witter DJ. Bitting and chewing in overdentures, full dentures and natural dentitions. J Dent Res 2000;79(7):1519-24.

Fontijin-Tekamp FA, Slagter AP, Vant Hof MA, Kalk W, Jansen JA. Pain and instability during biting with mandibular inplantretained overdentures. Clin. Oral Implants Res 2001;12(1):46-51.

Garret NR, Kapur KK, Hamada MO, Roumanas ED, Freymiller E, Han T, et al. A 
randomized clinical trial comparing the efficacy of mandibular implant-supported overdentures and conventional dentures in diabetic patients. Part II. Comparisons of masticatory performance. J Prosth Dent 1998;79(6):632-40.

Geertman ME, Boerrigter EM, Van'Tof MA, Van Wass MAJ, Van Oort RP, Boering G, et al. Two-center clinical trial of implant-retained mandibular overdentures versus complete dentures - chewing ability. Commun Dent Oral Epidem 1996 ;24(1):79-84.

Geertman ME, Boerrigter EM, Van'Tof MA, Van Wass MAJ, Van Oort RP. Boering G.; Kalk W. Clinical aspects of a muticenter clinical trial of implantretanined mandibular overdentures in patiets with severely resorbed mandibles. J. of Prosthet Dent 1996; 75(2): 75-80.

Geertman ME, Splagter AP, Van'Tof MA, Van Wass MAJ, Kalk W. Masticatory performance and chewing experience with implant-retained mandibular overdentures. J Oral Rehabil 1999;26(1):7-13.

Guarnieri TC. Avaliação in vitro das variações posicionais da cabeça da mandíbula na fossa articular decorrentes da alteração dimensional de resinas acrílicas para base de prótese total submetidas a diferentes técnicas de processsamento [Tese Doutorado]. São Paulo : Faculdade de Odontologia da USP; 2006

Gunne HSJ, Wall AK. The effect of new complete dentures on mastication and dietary intake. Acta Odontol Scand 1985;43(5):257-68.

Haroldson T, Jemt T, Stalblad P, Lekholm U. Oral function in subjects with overdentures supported by osseointegrated implants. Scand J Dent Res 1988; 96(3):235-42.

Hatushikano EJ. Influencia da estimulação elétrica neural transcutânea (TENS) nos registros maxilomandibulares horizontais em edentados completos [Dissertação de Mestrado]. São Paulo : Faculdade de odontologia da USP; 2002.

Hatushikano EJ. Análise da Laterotrusão condilar nos movimentos de lateralidade centrífuga e de Bennett em edentados completos [Tese de Doutorado]. São Paulo : Faculdade de odontologia da USP; 2006

Head J. The human skull used as gnathodynamometer, to determine the vvalue of trituration in the mastication of food. Dent Cosmos 1906;48(11):189-92. 
Hildebrandt GH, Doiminguez BL, Schork MA, Loesche WJ. Functionalunits, chewing, swallowing, and food avoidance among elderly. J. Prosthet Dent 1997; 77(6):588-595.

Hollanda RF. Evolução da carga mastigatória em pacientes portadores de próteses parciais sobre implantes osseointegrados, satisfação auto-avaliada por meio de questionário. [Dissertação Mestrado]. São Paulo Faculdade de Odontologia da Universidade de são Paulo; 2002.

Honda MO. Estudo da união entre a base da resina acrílica termicamente ativada e o dente de resina acrílica com modificação em sua interface.[Dissertação Mestrado]. São Paulo: Faculdade de odontologia da USP;2001.

Howell Ah, Brudevold F. Vertical forces used during chewing of food. J. Dent Res 1950; 27(2):133-136.

Howell Ah, Manly RS. An eletronic strin gauge for mensuring oral forces. J Dent Res 1948;27(6):705-12.

Jemt $T$, Lindquist $L$, Hedegard B. Changes in chewing patterns of patients with complete dentures after placement of osseointegrated implants in the mandible. $\mathrm{J}$ Prosth Dent 1995;53(4):578-83.

Klemetti E, Chedade A, Takanashi Y, Fine JS. Two-implant mandibular overdenture: simple to fabricateand easy to wear. J Can Dent Assoc 2003; 69(1):29-33.

Korioth TW, Hannam AG. Effect of bilateral asymmetric tooth clenching on load distribution hat the menmdibular condyles. J.Prosth Dent 1990;64(1):62-73.

Lambrecht JR. the influence of oclusal contact area on chewing performance. J. Prosthet Dent 1965;15(3):444-50.

Lassila V, Holmulund I, Koivumaa KK. Bite force and its correlations in different denture types. Acta Odntol Scand 1985;43(3):127-32.

Lindquist LW, Carlsson GE. Long term effects on chewing with mandibular fixed prostheses on osseointegrated implants, Acta odontol Scand,1985;43(3):39-45. 
Lindquist LW, Carlsson GE. Changes masticatory function in complet dentures wearers after insertion of bridges on osseointegrated implants in thelawer jaw. In:

Lee AJC, Albrektson T, Branemark PI. Clinical applications of biomaterials. $1^{\text {st }} \mathrm{ed}$. New York : John Wiley \&Sons, 1982:151-5.

Lundgren D, Nyman S, Heijl L, Carlsson GE. Functional anlysis of fixed brigdges on abutment teeth with reduced periodontal support. J. Oral Rehabil 1975; 2(1): 105-16.

Maciel RN. Oclusão e ATM - procedimentos clínicos. São Paulo: Santos; 1996.

Mazini P. Avaliação da área de contato dos dentes artificiais em função da forma das arcadas [Dissertação de Mestrado]. São Paulo : Faculdade de odontologia da USP; 2003.

Maxfield JB, Nicholls JI, Smith DE. The mensurament of forces transmitted to abutment teeth of removable partial dentures. J Prosthet Dent 1979;41(2):134-42.

Meijer HJA, Raghoebar GM, Van't Hof MA, Geertman ME, Vanhort RP. Clin Oral Impl Res 1999;10(1):238-44.

Mericske-Stern R, Zarb GA. Overdentures: an alternative implant methodology for edentulous patients. Int J Prosthodont 1993;6(2):203-8.

Misch LE. Implantes dentários contemporâneos. São Paulo: Santos; 2000.

Morimoto $\mathrm{T}$, Abekura $\mathrm{H}$, Tokuyama $\mathrm{H}$, Hamada $\mathrm{T}$. Alternation in the bite force and E.M.G. activity with changes in the vertical dimension of edentulous subjects. J Oral Rehabil 1996;23(5):336-41.

Neter J, Kutner MH, Nachtshein CJE, Wasserman W. Applied Linear Statistical Models. 4th ed. Irwin;1996.

Ogata K, Satoh M. Centre and magnitude of vertical forces in complete denture. J.Oral Rehabil 1995;22(2):113-9.

Ozcan M, Kulak Y, Baat G, Arikan A. The effect of a new denture adhesive on bite force until denture dislodegement. J Prosthod 2005;14(2):122-6. 
Pera P, Bassi F, Schierano G, Appendino P, Preti G. Implant anchored complete mandibular denture: evaluation of masticatory efficiency, oral function and degree of satisfaction. J Oral Rehabil 1998;25(6):462-7.

Ribeiro MS. Análise do efeito da repulsão magnética em usuários de próteses totais e portadores de distúrbios têmporo mandibulares [Tese de Doutorado]. São Paulo: Faculdade de Odontologia da USP;2002.

Rodrigues RS. Estudo da alteração da posição dos dentes artificiais durante a fase de acrilização da prótese total em função do tipo de muralha de contenção utilizada .[Dissertação Mestrado]. São Paulo: Faculdade de Odontologia da USP;2002.

Rojas Cabrera WI. Avaliação da magnitude das discrepâncias na dimensão vertical do eixo terminal de rotação [Tese Doutorado]. São Paulo : Faculdade de Odontologia da USP; 2003

Roumanas ED, Garret NN, Hamada MO, Kapur KK. Comparision of chewing difficulty of consumed foods with mandibular conventional dentures and implantsupported overdentures in diabetic denture weares. Int $\mathrm{J}$ of Prosthodonticis 2003;16(6):609-15.

Setz J, Kramer A, Benzing U, Heber H. Complete dentures fixed on dental implants: chewing patterns and implant stress. Int J Oral Maxillofac Impl 1989;4(2):107-11.

Sheihan A, Steele JG, Marcenes W, Finch S, Walls AWG., The impact of oral health on stated ability to eat certain foods; Findings from the National Diet and Nutrition Survey of older people in great Britain. The Gerondotology Assoc 1999;16(1):11-20.

Sglater AP, Bosman F, Van der Glas HW, Van der Bilt A. Humanjaw elevator mucle activity and food communition in the dentate and edentulous state. Arch Oral Biol 1993;38:195-205.

Stellingsma K, Slagater AP, Stegenga B. Mastigatory function in patients with mandibular implante-retaned overdentures: comparision of three types of treatment protocols. J Oral Rehabilitation 2005;32(1):403-10.

Tallgren A. The continuing reduction of the residual alveolar ridges in complete denture wearers: a mixed-longitudinal study covering 25 years. J Prosth Dent 
1972;27(2):120-31.

Tamaki T. Dentaduras Completas. $3^{\mathrm{a}}$ ed, São Paulo: Savier, 1984.

Tanaka M, Ogimoto T, Koyano K, Ogawa T. Denture wearing and strong bite force reduce pressure pain threshold of edentulous oral mucosa. J. of Oral Rehabil 2003;31(2):873-8.

Tang L, Lund JP, Tache R, Clokie CM, Feine JS. Awithim-subject comparision of mandiularong-bar and hybrid implant supported protheses : Evaluation of masticatory function. J.Dent Res 1999;78:1544-53.

Van Eijden TM. Jaw muscleactive in relation to the direction and point of application of bite force. J. Dent. Res.1990;69(5):901-5.

Van Kapen FMC, Cune MS, Bosman F. The Influence of Various Attachment types in mandibular implant-retained overdentures on maximum Bite Force and EMG.J. Dent Research 2002;81(3):170-3.

Vieira LP. Estudo longitudinal da força de mordida de indivíduos dentados com próteses convencionais e implanto-suportadas. [Dissertação de Mestrado]. São Paulo, Faculdade de Odontologia da USP;1998.

Visser A, Raghoerbar GM, Meijer HJA, Batenburg RHK, Vissink A. mandibular overdentures supported by tow or four endosseous implants. A 5-year prospective study. Clin Oral Implants Res 2005;16(1):19-25.

Walton JN, Macentee Mi, Glick N. One-Year Prosthetic outcomes with Implant Overdentures :A Randomized Clinical Trial. Int J Oral Maxilofacial Implants 2002;17(3):391-8.

Worner HKM. Gnathodinamics, the mensurament of biting forces with a new desing of gnathodinamometer. Aust J Dent 1939;43(3):381-93.

Zarb GA, Schimitt A. The longitudinal clinical effectiveness of osseointegrated dental implants. The Toronto study. Part II: the prosthetic resuls. J Prosthet Dent 1990;64(1): 53-61. 
Zistzman NU, Marinello CP. Treatment outcomes of fixed or removable implantsupported prostheses in the edntuolous maxilla. J Prosthet Dent. 2000;83(4): 42433. 
APÊNDICE A - Informações e consentimento pós-informação para pesquisa clínica

As informações contidas neste documento foram fornecidas pelo C.D. Ricardo Soeiro Rodrigues, objetivando, firmar acordo por escrito, pelo qual o paciente envolvido no estudo, autoriza sua participação, com pleno conhecimento da natureza dos procedimentos e riscos ao qual se submeterá, com a capacidade de livre arbítrio e sem qualquer tipo de coação.

Título preliminar do projeto: Estudo comparativo da intensidade da força de mordida entre Próteses Totais convencionais e Overdentures inferiores retidas por barra-clip sobre implantes.

Objetivo do estudo: Quantificar e comparar a força de mastigação em pacientes desdentados usuários de Próteses Totais Convencionais (dentaduras) superiores e inferiores e comparar quando os mesmos utilizam as mesmas próteses sendo as inferiores overdentures sobre implantes (mucoso suportadas e implanto retidas sobre sistemas barra clipe)

Justificativa: A literatura tem demonstrado que existe um aumento da força de mastigação em pacientes que se beneficiam do uso de próteses sobre implantes (overdentures), quando comparadas as suas próteses antigas. Uma vez que estas próteses antigas na maioria dos casos estão velhas e mal adaptadas, é de extrema importância, obter-se, um padrão de comparação real entre a condição pregressa do paciente, quando este se apresentava sem elementos dentários, e a atual situação, sendo este usuário de implantes, uma vez que a mesma prótese será utilizada no 
exame.

Procedimentos: Através de um eletrognatodinamometro (aparelho este capaz de quantificar a força de mordida em humanos), será registrada a força máxima de mordida .

Este procedimento será realizado após a instalação das overdentures em um tempo suficiente para que os pacientes tenham a devida adaptação a sua nova condição.

Em cada indivíduo serão realizadas três medições com intervalos de 1 min. na região de $1^{0}$ molar esquerdo e direito respectivamente, estando o paciente com a prótese inferior retida pelo sistema barra-clip sobre implante. Logo após, com a remoção da barra, esta setornara uma prótese convencional.

O paciente responderá também a um questionário simples, com a finalidade de avaliar a satisfação e adaptação ao novo trabalho protético.

Desconforto ou risco esperado: Extremamente improvável, mas se ocorrer algum dano a prótese e/ou implante durante a realização dos exames, a peça danificada será substituída sem nenhum gasto para o paciente, passando somente pelo desconforto dos procedimentos clínicos normais na confecção de um novo trabalho.

Benefícios para o voluntário: As próteses e os implantes passarão por um controle posterior onde serão feitos os devidos ajustes e aumento de retenção do clip de fixação se necessário, higienização dos mesmos, e controle de higiene dos implantes. A participação dos pacientes proporcionará desenvolvimento das técnicas 
e planejamento das futuras próteses sobre, implantes que tanto ele como a comunidade desfrutarão.

Obrigações do voluntário: Comparecer nos dias agendados para os exames e responder com veracidade aos questionários, uma vez, que sem dados completos, fica impossível concluir o estudo.

Informações e sigilo: Fica garantido que os voluntários serão esclarecidos de suas dúvidas e perguntas sobre o andamento da pesquisa .

Suas identidades e dados serão mantidas em sigilo absoluto, mesmo no momento da publicação do trabalho.

Anulação do consentimento: os voluntários têm toda liberdade de se retirarem da pesquisa a qualquer momento por questões de foro intimo ou não. 


\section{CONSENTIMENTO PÓS-INFORMAÇÃO}

$\mathrm{Eu}$, certifico que, tendo lido as informações prévias e tendo sido suficientemente esclarecido pelo C.D. Ricardo Soerio Rodrigues, estou plenamente de acordo com a realização deste estudo, autorizo a realização dos procedimentos descritos.

São Paulo, de 200

Nome legível do Paciente:

R.G.:

Ass:

Nome legível da testemunha:

R.G.:

Ass:

Elaborado com base na resolução 196 do Conselho Nacional de Saúde do Ministério da Saúde, publicada no Diário Oficial de 10/10/1996. 


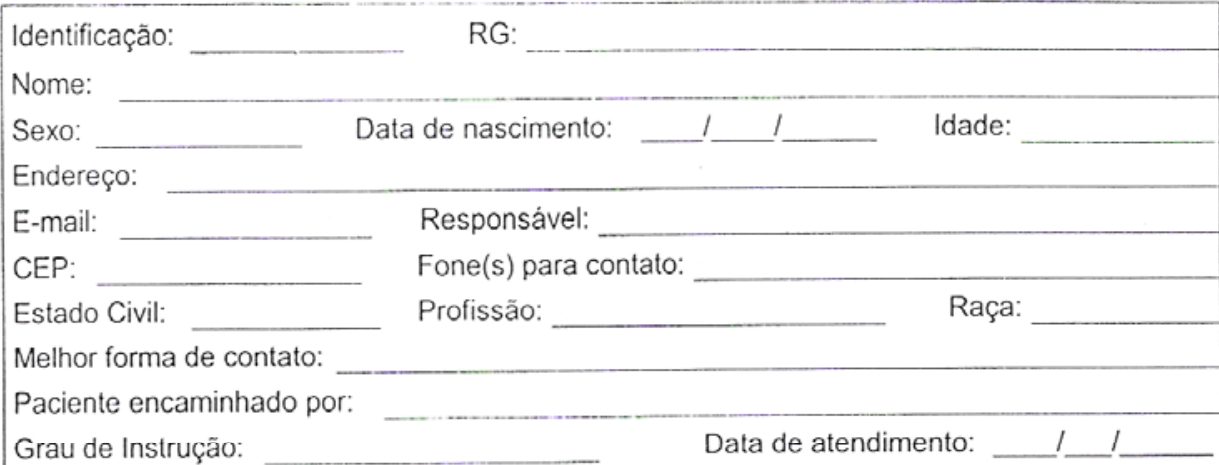

Equipe de atendimento (nomes legiveis)

Queixa(s) e duração(ões) (QD) (de modo resumido relacione o(s) motivo(s) pelo(s) qual(is) o paciente procurou o atendimento)

\begin{tabular}{|l|l|l|l|l|l|l|l|l|l|l|l|l|l|l|l|l|l|l|}
\hline Piorou & & & & & & & & & & & & & & & & & & \\
\hline Inalterado & & & & & & & & & & & & & & & & & & \\
\hline Pouco melhor & & & & & & & & & & & & & & & & & & \\
\hline Melhor & & & & & & & & & & & & & & & & & & \\
\hline Muito melhor & & & & & & & & & & & & & & & & & & \\
\hline Sem sintomas & & & & & & & & & & & & & & & & & & \\
\hline DATAS
\end{tabular}

1. Você tem dor no lado direito da sua face, lado esquerdo ou ambos os lados? (Se o paciente indicar dor na linha média circule ambos)
nenhum (0)
direito (1)
esquerdo (2)
ambos (3)

2. Você poderia apontar as áreas aonde você sente dor?

\begin{tabular}{|l|l|l|l|}
\hline \multicolumn{1}{|c|}{ Direito } & \multicolumn{2}{c|}{ Esquerdo } \\
\hline Nenhuma & 0 & Nenhuma & 0 \\
Articulação & 1 & Articulação & 1 \\
Músculos & 2 & Músculos & 2 \\
Ambos & 3 & Ambos & 3 \\
\hline
\end{tabular}

Examinador apalpa a área apontada pelo paciente, caso não esteja claro se é dor muscular ou articular, pressione levemente para identificar corretamente a região anatômica) 
História pregressa da moléstia atual (HPMA) (caracterize os fatos que se relacionam à(s) queixa(s) atual(is) em ordem cronológica de ocorrência, detalhando cada aspecto diretamente relacionado à queixa. Se houver mais de uma queixa, faça esta cronologia para uma delas. Utilize o roteiro para dados minimos de anamnese para tentar ser mais completo)
Hábitos
( ) Apertar os dentes
( ) Diurno
( ) Noturno
( ) Ranger os dentes
( ) Diurno
( ) Noturno

Outros: 
3. Padrão de Abertura (Por favor, posicione sua boca o mais confortavelmente possivel, com os dentes se tocando levemente, agora eu gostaria que você abrisse sua boca o máximo que puder, mesmo que sinta um pouco de dor).

Reto

Desvio lateral direito (não corrigido)

Desvio lateral direito corrigido ("S")

Desvio lateral esquerdo (näo corrigido)

Desvio lateral corrigido ("S")

Outro

Tipo

(especifique)

4. Extensão de movimento vertical dos incisivos maxilares utilizados (por exemplo: 11 e 21)

a. Abertura sem auxílio sem dor mm ("Eu g̣ostaria que vocõ abrisse a boca o mais amplamente possivel sem sentir dor")

b. Abertura máxima sem auxilio _ـ $\mathrm{mm}$ ("Eu gostaria que vocè abrisse a boca o mais amplamente possivel, mesmo que você sinta um poucu de desconforto")

c. Abertura máxima com auxílio ___ $\mathrm{mm}$ ("Eu estou checando ; ara ver se você pode abrir a boca um pouco mais longe, se você sentir dor levante a mão que eu paro")

d. Trespasse incisal vertical $\mathrm{mm}$

Tabela abaixo: Para os itens "b" e "c" somente

\begin{tabular}{|c|c|c|c|c|c|c|c|}
\hline \multicolumn{3}{|c|}{ DOR MUSCULAR } & \multicolumn{4}{c|}{ DOR ARTICULAR } \\
\hline nenhuma & direito & esquerdo & ambos & nenhuma & direito & esquerdo & ambos \\
\hline 0 & 1 & 2 & 3 & 0 & 1 & 2 & 3 \\
\hline 0 & 1 & 2 & 3 & 0 & 1 & 2 & 3 \\
\hline
\end{tabular}

5. Ruidos articulares (palpação) ("Enquanto eu posiciono m eus dedos n a s ua a rticulação, eu g ostaria que você abrisse a boca vagarosamente, o máximo que puder, e fechasse vagarosamente até seus dentes estarem completamente juntos". Peça ao paciente para abrir e fechar três vezes.)

\section{a. Abertura}

Nenhum

Estalido

Crepitação grosseira

Crepitaçāo fina

$\begin{array}{cc}\text { Direito } & \text { Esquerdo } \\ 0 & 0 \\ 1 & 1 \\ 2 & 2 \\ 3 & 3\end{array}$

Medida do estalido na abertura $\mathrm{mm}$ $\mathrm{mm}$

\section{b. Fechamento}

Nenhum

Estalido

Crepitação grosseira

Crepitação fina

$\begin{array}{cc}\text { Direito } & \text { Esquerdo } \\ 0 & 0 \\ 1 & 1 \\ 2 & 2 \\ 3 & 3\end{array}$

Medida do estalido na abertura $\mathrm{mm}$

$\mathrm{mm}$

\section{c. Estalido reciproco eliminado durante abertura protrusiva}

Sim

Não

Direito

0

1

Esquerdo

NA

0

1 
Paciente Desenha

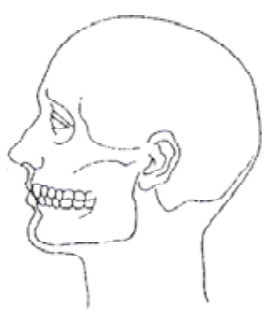

Lado Esquerdo

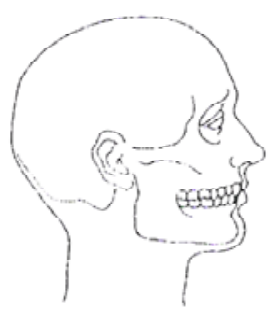

Lado Direito

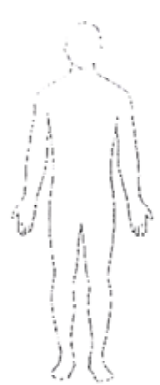

Frente

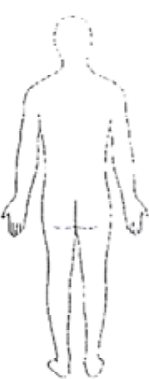

Trás

\begin{tabular}{|l|l|}
\hline \multicolumn{2}{|c|}{ História Médica } \\
\hline Tratamento atual: & Doenças infecciosas-contagiosas: \\
\hline Medicamentos: & Doenças respiratórias: \\
\hline Alergias: & Doenças cárdio-circulatórias: \\
\hline Sistema Sensorial: & Doenças neuropsiquiátricas: \\
\hline Tabagismo - Etilismo - Droga Adicto: & Doenças gastro-intestinais: \\
\hline Doenças músculo-esqueléticas: & Doenças gênito-urinárias: \\
\hline Doenças endócrinas: & Outras: \\
\hline
\end{tabular}

\begin{tabular}{|l|c|c|c|}
\hline \multicolumn{3}{|c|}{ Exame Cervical Funcional } \\
\hline & Dor (local) & Restrição & Sem Restrição \\
\hline Flexão & & & \\
\hline Extensão & & & \\
\hline Rotação D $\left(70^{\circ}\right)$ & & & \\
\hline Rotação $\mathrm{E}\left(70^{\circ}\right)$ & & & \\
\hline Inclinação Lateral D $\left(60^{\circ}\right)$ & & & \\
\hline Inclinação Lateral D $\left(60^{\circ}\right)$ & & & \\
\hline
\end{tabular}

\section{Testes Funcionais}

Teste Muscular (1 min)

Anterior

Lado direito

Lado esquerdo

Teste Articular

Lado direito

Contra-teste lado esqu

Lado esquerdo ( ) não

Contra-teste lado direito
( ) กäo
( ) não
( ) não
( ) direita
( ) direita
( ) direita

Local

Local:

Local:

( ) direita

Alivio

( ) direita

Alivio
Local:

( ) Sim

Local:

( ) $\operatorname{Sim}$
( ) não
( ) Esquerda

( Esquerda Local:

( ) Esquerda Local:

( ) Esquerda Local:

( ) Esquerda Local: 
6. Excursões ("Mova sua mandibula o mais longe possivel para lateral, mesmo se sentir desconforto, e mova sua mandibula para posição normal. Mova sua mandibula novamente")
a. Excursão lateral direita $\mathrm{mm}$
b. Excursão lateral esquerda $\mathrm{mm}$
c. Protrusão $\mathrm{mm}$

Tabela abaixo: Para os itens "a", "b" e "c"

\begin{tabular}{|c|c|c|c|c|c|c|c|}
\hline \multicolumn{9}{|c|}{ DOR MUSCULAR } \\
\hline nenhuma & direito & esquerdo & ambos & nenhuma & direito & esquerdo & ambos \\
\hline 0 & 1 & 2 & 3 & 0 & 1 & 2 & 3 \\
\hline 0 & 1 & 2 & 3 & 0 & 1 & 2 & 3 \\
\hline 0 & 1 & 2 & 3 & 0 & 1 & 2 & 3 \\
\hline
\end{tabular}

d. Desvio de linha média $\mathrm{mm}$

\begin{tabular}{|c|c|c|}
\hline direito & esquerdo & NA \\
\hline 1 & 2 & 8 \\
\hline
\end{tabular}

7. Ruídos articulares nas excursōes

Ruido direito

\begin{tabular}{|l|c|c|c|c|}
\hline & nenhum & estalido & Crepitação grosseira & Crepitação leve \\
\hline Excursão Direita & 0 & 1 & 2 & 3 \\
\hline Excursão Esquerda & 0 & 1 & 2 & 3 \\
\hline Protrusão & 0 & 1 & 2 & 3 \\
\hline
\end{tabular}

Ruído esquerdo

\begin{tabular}{|l|c|c|c|c|}
\hline & nenhum & estalido & Crepitação grosseira & Crepitação leve \\
\hline Excursão Direita & 0 & 1 & 2 & 3 \\
\hline Excursão Esquerda & 0 & 1 & 2 & 3 \\
\hline Protrusão & 0 & 1 & 2 & 3 \\
\hline
\end{tabular}

PALPAÇÃO (Nós gostariamos que você indicasse se você não sente dor ou apenas sente pressão (0), ou dor (1-3). Por favor, classifique o quanto de dor você sente para cada uma das palpaçōes de acordo com a escala)

$$
\begin{aligned}
& 0=\text { sem dor } / \text { somente pressão } \\
& 1=\text { dor leve } \\
& 2=\text { dor moderada } \\
& 3=\text { dor severa }
\end{aligned}
$$

8. Dor muscular extra-oral com palpação

\begin{tabular}{|l|rrrr|rrrr|}
\hline & \multicolumn{4}{|c|}{ DIREITO } & \multicolumn{5}{c|}{ ESQUERDO } \\
\hline a. Temporal (posterior) & 0 & 1 & 2 & 3 & 0 & 1 & 2 & 3 \\
\hline b. Temporal (médio) & 0 & 1 & 2 & 3 & 0 & 1 & 2 & 3 \\
\hline c. Temporal (anterior) & 0 & 1 & 2 & 3 & 0 & 1 & 2 & 3 \\
\hline d. Masseter (superior) & 0 & 1 & 2 & 3 & 0 & 1 & 2 & 3 \\
\hline e. Masseter (médio) & 0 & 1 & 2 & 3 & 0 & 1 & 2 & 3 \\
\hline f. Masseter (inferior) & 0 & 1 & 2 & 3 & 0 & 1 & 2 & 3 \\
\hline g. Região mandibular posterior & 0 & 1 & 2 & 3 & 0 & 1 & 2 & 3 \\
\hline h. Regiäo submandibular & 0 & 1 & 2 & 3 & 0 & 1 & 2 & 3 \\
\hline
\end{tabular}

9. Dor articular com palpação

\begin{tabular}{|l|llll|llll|}
\hline a. Pólo lateral & 0 & 1 & 2 & 3 & 0 & 1 & 2 & 3 \\
\hline b. Ligamento posterior & 0 & 1 & 2 & 3 & 0 & 1 & 2 & 3 \\
\hline
\end{tabular}

Por favor troque as luvas 
10. Dor muscular intra-oral com palpação (Agora eu vou palpar dentro da sua boca, mantenha sua mandibula relaxada)

\begin{tabular}{|l|c|ccc|cccc|}
\hline & \multicolumn{3}{|c|}{ DIREITO } & \multicolumn{4}{c|}{ ESQUERDO } \\
\hline a. Área do pterigóideo lateral & 0 & 1 & 2 & 3 & 0 & 1 & 2 & 3 \\
\hline b. Tendão do temporal & 0 & 1 & 2 & 3 & 0 & 1 & 2 & 3 \\
\hline
\end{tabular}

\begin{tabular}{|l|rrrr|rr|r|r|}
\hline & \multicolumn{3}{|c|}{ DIREITO } & \multicolumn{4}{c|}{ ESQUERDO } \\
\hline Esternocleidomastóideo & 0 & 1 & 2 & 3 & 0 & 1 & 2 & 3 \\
\hline Sub-occipital & 0 & 1 & 2 & 3 & 0 & 1 & 2 & 3 \\
\hline Trapézio & 0 & 1 & 2 & 3 & 0 & 1 & 2 & 3 \\
\hline
\end{tabular}

(Use o desenho abaixo para indicar dores referidas)

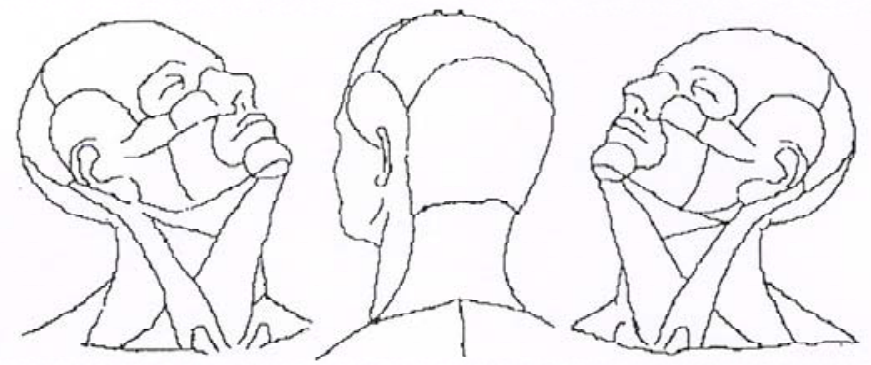

\section{PALPAÇÃO DA CADEIA LINFÁTICA CERVICAL}

Região sublingual:

Região submandibular:

Região júgulo-carotidea alta:

Região júgulo-carotidea média:

Região júgulo-carotidea baixa:

Região supraclavicular:
( ) aparentemente normal

( ) aparentemente normal

( ) aparentemente normal

( ) aparentemente normal

( ) aparentemente normal

( ) aparentemente normal

\section{OROSCOPIA (INSPEÇÃO E PALPAÇÄO)}

\begin{tabular}{|ll}
\hline Lábios: & ( ) aparentemente normal \\
Mucosa jugal: & ( ) aparentemente normal \\
Lingua: & ( ) aparentemente normal \\
Soalho de boca: & ( ) aparentemente normal \\
Palato duro: & ( ) aparentemente normal \\
Palato mole: & ( ) aparentemente normal \\
Gengiva: & ( ) aparentemente normal \\
Area retromolar: & ( ) aparentemente normal \\
Drenagem de glândulas salivares & ( ) aparentemente normal
\end{tabular}
(parótida, submandibular e sublingual): 


\begin{tabular}{|lc|}
\hline \multicolumn{2}{|c|}{ EXAME dOS NERVOS CRANIANOS } \\
\hline (II) Acuidade visual & ( ) aparentemente normal \\
\hline (III, IV, VI) Músculos extra-oculares & ( ) aparentemente normal \\
\hline Pupilas (tamanho, formato, simetria, reação à luz) & ( ) aparentemente normal \\
\hline (V) Motor & ( ) aparentemente normal \\
\hline (V) Sensorial $\left(\mathrm{V}_{1}, \mathrm{~V}_{2}, \mathrm{~V}_{3}\right.$ ) & ( ) aparentemente normal \\
\hline (VII) Motor (músculos faciais) & ( ) aparentemente normal \\
\hline (VIII) Audição & ( ) aparentemente normal \\
\hline (IX, X) Reflexo do engasgo/elevação do palato & ( ) aparentemente normal \\
\hline (XI) Trapézio (elevação dos ombros, rotação da cabeça) & ( ) aparentemente normal \\
\hline (XII) Hipoglosso (volume da lingua/movimento) & ( ) aparentemente normal \\
\hline
\end{tabular}

Hipóteses Diagnóstica (Topográfica, Sindrômica, Etiológica):

\section{RDC:}

I. ( ) Dor miofascial

( ) Dor miofascial com limitação de abertura

II. ( ) Deslocamento do disco com redução

( ) Deslocamento do disco sem redução, com limitação da abertura

( ) Deslocamento do disco sem redução, sem limitação da abertura

III. ( ) Artralgia

( ) Osteoartrite da ATM

( ) Osteoartrose da ATM

tratamento psicológico:

término

Yoga: inicio

término 
APÊNDICE C - Resposta referentes à sensibilidade da fibromucosa da área basal obtidos durante a mensuração da intensidade da força de mordida

\begin{tabular}{|c|c|c|c|c|c|}
\hline \multirow[t]{2}{*}{ Paciente } & \multicolumn{3}{|c|}{ Com Barra } & \multicolumn{2}{|c|}{ Sem Barra } \\
\hline & Ciclo Mastigatório & $\begin{array}{l}\text { Forca de mordida } \\
\text { LE }\end{array}$ & $\begin{array}{l}\text { Forca de } \\
\text { mordida LD }\end{array}$ & $\begin{array}{l}\text { Forca de mordida } \\
\underline{L E}\end{array}$ & $\begin{array}{l}\text { Forca de mordida } \\
L D\end{array}$ \\
\hline & & 1.dor mucosa sup. & 1.dor mucosa sup & $\begin{array}{l}\text { 1.dor mucosa inf } \\
\text { esq }\end{array}$ & $\begin{array}{l}\text { 1.dor mucosa inf } \\
\text { dir }\end{array}$ \\
\hline \multirow[t]{3}{*}{1} & lado direito & \begin{tabular}{|l|} 
deslocou lado \\
oposto
\end{tabular} & 2.dor mucosa sup & $\begin{array}{l}\text { 2.dor mucosa inf } \\
\text { esq }\end{array}$ & $\begin{array}{l}\text { 2.dor mucosa inf } \\
\text { dir }\end{array}$ \\
\hline & & 2.dor mucosa sup. & 3.dor mucosa sup & 3.dor mucosa sup & $\begin{array}{l}\text { 3.dor mucosainf. } \\
\text { Dir }\end{array}$ \\
\hline & & \multicolumn{2}{|c|}{ 3.dor mucosa superior } & & \\
\hline \multirow[t]{4}{*}{2} & $\begin{array}{l}\text { lado direito, depois } \\
\text { equilibrou }\end{array}$ & 1.dor mucosa sup & 1.cansou & $\begin{array}{l}\text { 1. dor mucosa inf. } \\
\text { esq }\end{array}$ & $\begin{array}{l}\text { 1. dor mucosa inf } \\
\text { dir }\end{array}$ \\
\hline & equilibrou & 2.dor mucosa sup & 2.cansou & $\begin{array}{l}\text { 2. dor mucosa inf. } \\
\text { esq }\end{array}$ & $\begin{array}{l}\text { 2. dor mucosa inf. } \\
\text { Dir }\end{array}$ \\
\hline & & 3.dor mucosa sup & 3.soltou prót.sup. & $\begin{array}{l}\text { 3. dor mucsa inf. } \\
\text { Esq }\end{array}$ & $\begin{array}{l}\text { 3. dor mucosa inf. } \\
\text { Dir }\end{array}$ \\
\hline & & deslocou prót.sup & & & \\
\hline \multirow[t]{3}{*}{3} & lado esquerdo & 1.cansou & 1.cansou & $\begin{array}{l}\text { 1. dor mucosa inf. } \\
\text { esq }\end{array}$ & $\begin{array}{l}\text { 1. dor mucosa inf } \\
\text { dir }\end{array}$ \\
\hline & & 2.cansou & 2.cansou & $\begin{array}{l}\text { 2. dor mucosa inf. } \\
\text { esq }\end{array}$ & $\begin{array}{l}\text { 2. dor mucosa inf. } \\
\text { Dir }\end{array}$ \\
\hline & & 3.cansou & 3.cansou & $\begin{array}{l}\text { 3. dor mucsa inf. } \\
\text { Esq }\end{array}$ & $\begin{array}{l}\text { 3. dor mucosa inf. } \\
\text { Dir }\end{array}$ \\
\hline \multirow[t]{3}{*}{4} & lado direito & $\begin{array}{l}\text { 1.dor mucosa inf } \\
\text { esq. }\end{array}$ & 1.cansou & $\begin{array}{l}\text { 1.dor mucosa inf } \\
\text { esq }\end{array}$ & 1.cansou \\
\hline & & 2.cansou & 2.cansou & $\begin{array}{l}\text { 2.dor mucosa inf } \\
\text { esq }\end{array}$ & $\begin{array}{l}\text { 2.dor mucosa inf } \\
\text { dir }\end{array}$ \\
\hline & & $\begin{array}{l}\text { 3.dor mucosa inf } \\
\text { esq. }\end{array}$ & 3.dor mucosa sup. & $\begin{array}{l}\text { 3.dor mucosa inf } \\
\text { esq }\end{array}$ & $\begin{array}{l}\text { 3.dor mucosa inf } \\
\text { dir }\end{array}$ \\
\hline \multirow[t]{4}{*}{5} & lado direito & 1.cansou & 1.cansou & $\begin{array}{l}\text { 1.dor mucosa } \\
\text { sup/inf }\end{array}$ & $\begin{array}{l}\text { 1.dor mucosa inf } \\
\text { dir. }\end{array}$ \\
\hline & & 2.cansou & 2.cansou & $\begin{array}{l}\text { 2.dor mucosa } \\
\text { sup/inf }\end{array}$ & 2.dor mucosa sup \\
\hline & & 3.cansou & 3.cansou & 3.dor mucosa sup & deslocou prót.sup \\
\hline & & & & deslocou prót.sup. & 3.dor mucosa inf \\
\hline \multirow[t]{5}{*}{6} & lado direito & 1.dor superior esq. & 1.soltou prót.sup & & deslocou prót.sup \\
\hline & & 2.dor superior esq. & 2-ndn & & \\
\hline & & 3.dor superior esq. & 3-ndn & $\begin{array}{l}\text { 1.dor mucosa } \\
\text { sup/inf }\end{array}$ & $\begin{array}{l}\text { 1.do mucosa } \\
\text { sup/inf }\end{array}$ \\
\hline & & & & $\begin{array}{l}\text { 2.dor mucosa } \\
\text { sup/inf }\end{array}$ & $\begin{array}{l}\text { 2.dor mucosa } \\
\text { sup/inf }\end{array}$ \\
\hline & & & & $\begin{array}{l}\text { 3.dor mucosa } \\
\text { sup/inf }\end{array}$ & $\begin{array}{l}\text { 3.dor mucosa } \\
\text { sup/inf }\end{array}$ \\
\hline \multirow[t]{4}{*}{7} & laod esquerdo & 1.não doeu & 1. não doeu & & \\
\hline & & 2.não doeu & 2. dor superior & $\begin{array}{l}\text { 1.dor mucosa } \\
\text { inf/sup }\end{array}$ & $\begin{array}{l}\text { 1.dor mucosa inf } \\
\text { dir. }\end{array}$ \\
\hline & & 3.não doeu & 3. não doeu & $\begin{array}{l}\text { 2.dor mucosa } \\
\text { sup/inf }\end{array}$ & $\begin{array}{l}\text { 2.dor mucosa inf } \\
\text { dir. }\end{array}$ \\
\hline & & & & $\begin{array}{l}\text { 3.dor mucosa } \\
\text { sup/inf }\end{array}$ & $\begin{array}{l}\text { 3.dor mucosa inf } \\
\text { dir. }\end{array}$ \\
\hline \multirow[t]{3}{*}{8} & lado direito & $\begin{array}{l}\begin{array}{l}\text { 1.dor mucosa } \\
\text { inf.esq. }\end{array} \\
\end{array}$ & 1.dor mucosa sup & $\begin{array}{l}\text { 1-dor mucosa } \\
\text { inf.esq. }\end{array}$ & $\begin{array}{l}\text { 1-dor mucosa } \\
\text { inf.dir. }\end{array}$ \\
\hline & & \begin{tabular}{|l|} 
2.dor mucosa \\
inf.esq. \\
\end{tabular} & 2.dor mucosa sup & $\begin{array}{l}\text { 2-dor mucosa } \\
\text { inf.esq. }\end{array}$ & $\begin{array}{l}\text { 2-dor mucosa } \\
\text { inf.dir. }\end{array}$ \\
\hline & & $\begin{array}{l}\text { 3.dor mucosa inf } \\
\text { esq. }\end{array}$ & 3.dor mucosa sup. & $\begin{array}{l}\text { 3-dor mucosa inf. } \\
\text { Esq. }\end{array}$ & $\begin{array}{l}\text { 3-dor mucosa } \\
\text { inf.dir. }\end{array}$ \\
\hline
\end{tabular}




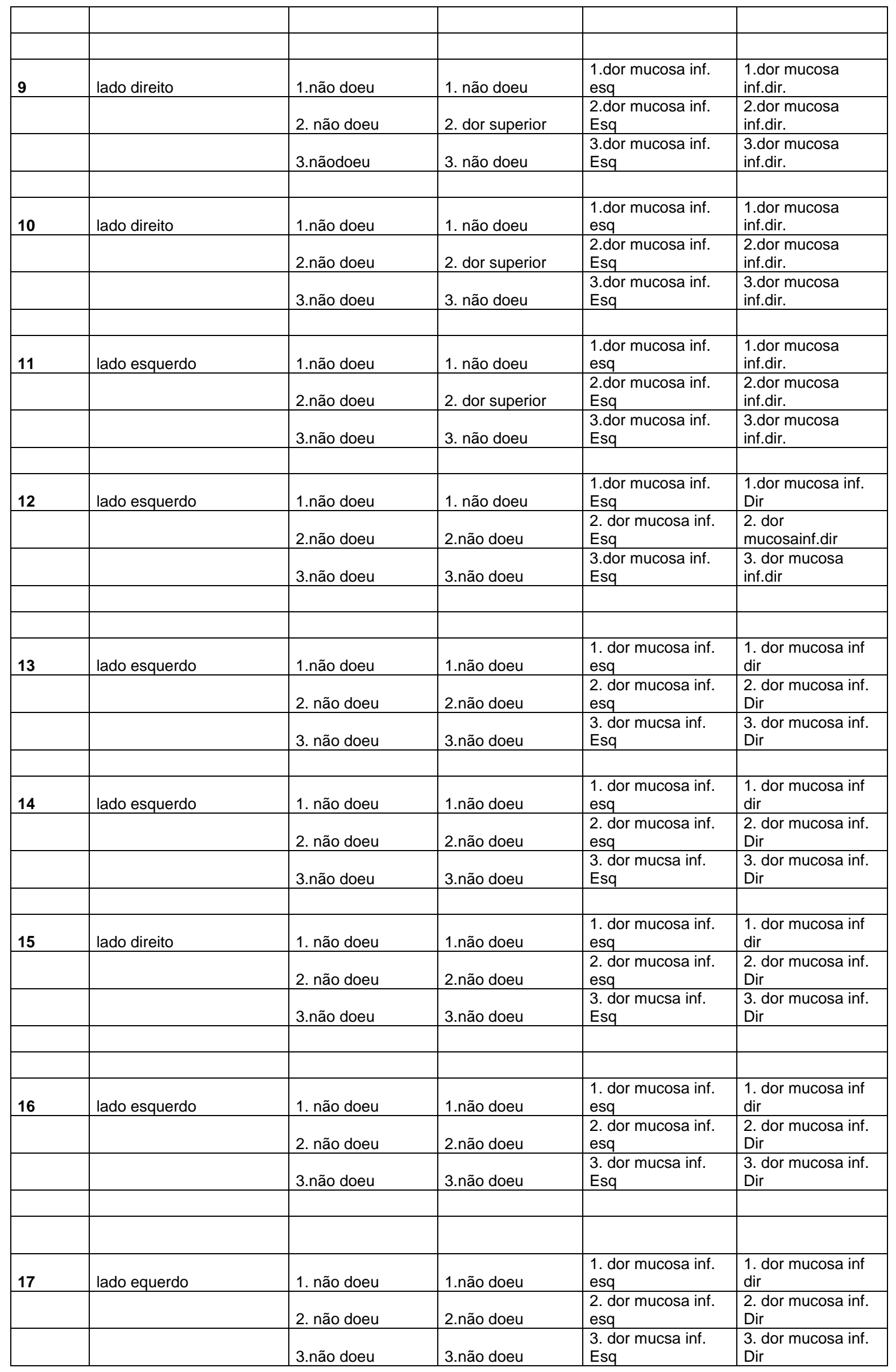




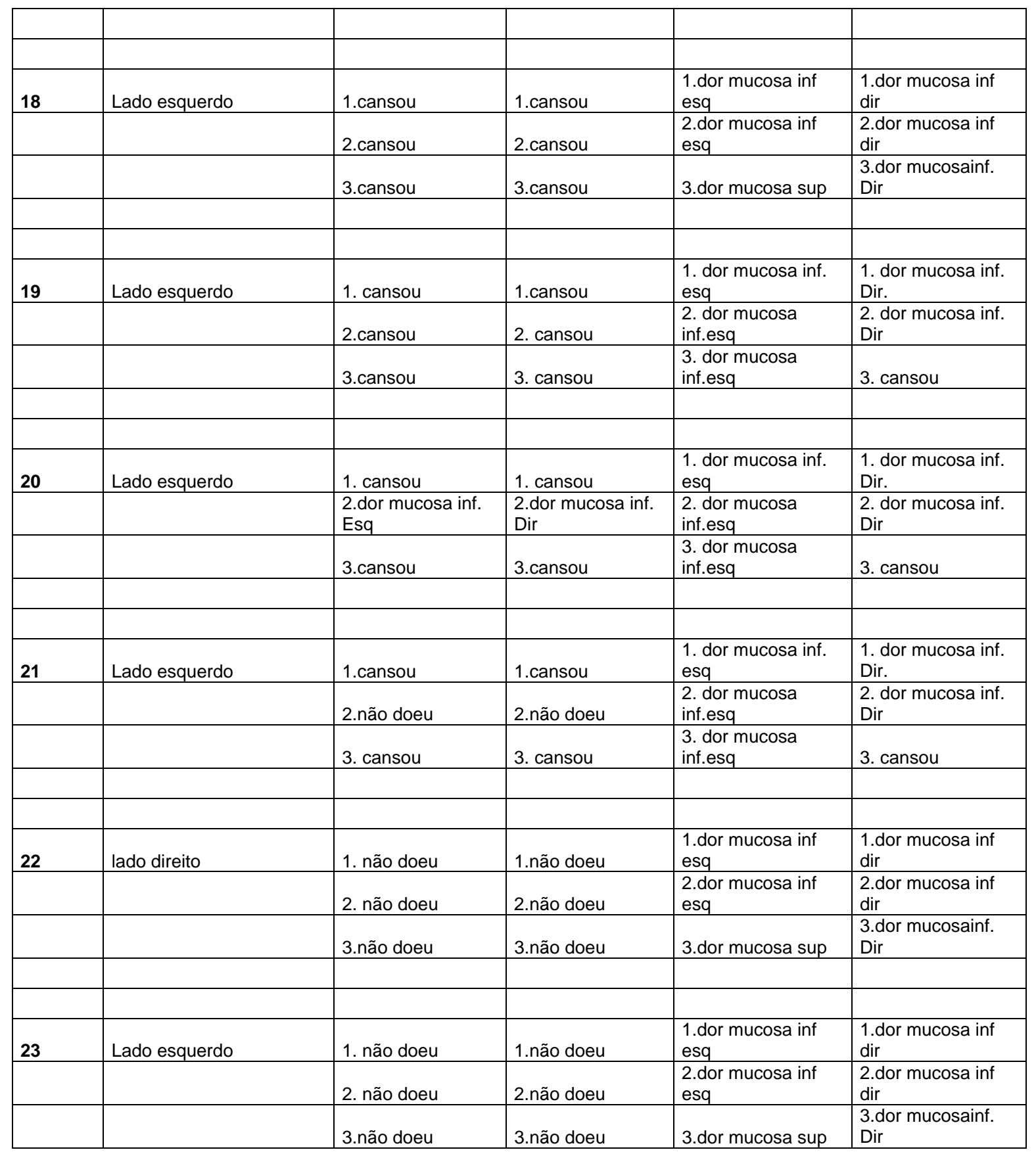


APÊNDICE D - Dados de cada paciente referentes aos três exames dé cada lado com barra e sem barra

\begin{tabular}{|c|c|c|c|c|}
\hline Paciente 1 & $\begin{array}{c}\text { Sem Barra Lado } \\
\text { Esquerdo }\end{array}$ & $\begin{array}{c}\text { Sem Barra Lado } \\
\text { Direito }\end{array}$ & $\begin{array}{c}\text { Com Barra Lado } \\
\text { Esquerdo }\end{array}$ & $\begin{array}{c}\text { Com Barra Lado } \\
\text { Direito }\end{array}$ \\
\hline $1^{\circ}$ exame & 4,60 & 2,70 & 6,00 & 4,45 \\
\hline $2^{\circ}$ exame & 4,05 & 2,60 & 7,15 & 4,00 \\
\hline $3^{\circ}$ exame & 4,35 & 5,00 & 6,85 & 5,50 \\
\hline
\end{tabular}

\begin{tabular}{|c|c|c|c|c|}
\hline Paciente 2 & $\begin{array}{c}\text { Sem Barra Lado } \\
\text { Esquerdo }\end{array}$ & $\begin{array}{c}\text { Sem Barra Lado } \\
\text { Direito }\end{array}$ & $\begin{array}{c}\text { Com Barra Lado } \\
\text { Esquerdo }\end{array}$ & $\begin{array}{c}\text { Com Barra Lado } \\
\text { Direito }\end{array}$ \\
\hline $1^{\circ}$ exame & 1,55 & 2,80 & 9,05 & 7,60 \\
\hline $2^{\circ}$ exame & 1,25 & 1,00 & 4,55 & 6,20 \\
\hline $3^{\circ}$ exame & 1,10 & 1,00 & 3,20 & 7,40 \\
\hline
\end{tabular}

\begin{tabular}{|c|c|c|c|c|}
\hline Paciente 3 & $\begin{array}{c}\text { Sem Barra Lado } \\
\text { Esquerdo }\end{array}$ & $\begin{array}{c}\text { Sem Barra Lado } \\
\text { Direito }\end{array}$ & $\begin{array}{c}\text { Com Barra Lado } \\
\text { Esquerdo }\end{array}$ & $\begin{array}{c}\text { Com Barra Lado } \\
\text { Direito }\end{array}$ \\
\hline $1^{\circ}$ exame & 11,85 & 5,15 & 11,85 & 12,00 \\
\hline $2^{\circ}$ exame & 7,70 & 3,40 & 15,05 & 11,90 \\
\hline $3^{\circ}$ exame & 4,25 & 6,75 & 11,40 & 11,75 \\
\hline
\end{tabular}

\begin{tabular}{|c|c|c|c|c|}
\hline Paciente 4 & $\begin{array}{c}\text { Sem Barra Lado } \\
\text { Esquerdo }\end{array}$ & $\begin{array}{c}\text { Sem Barra Lado } \\
\text { Direito }\end{array}$ & $\begin{array}{c}\text { Com Barra Lado } \\
\text { Esquerdo }\end{array}$ & $\begin{array}{c}\text { Com Barra Lado } \\
\text { Direito }\end{array}$ \\
\hline $1^{\circ}$ exame & 9,75 & 2,55 & 11,85 & 12,00 \\
\hline $2^{\circ}$ exame & 7,00 & 2,60 & 15,05 & 11,90 \\
\hline $3^{\circ}$ exame & 7,65 & 3,15 & 11,40 & 11,75 \\
\hline
\end{tabular}

\begin{tabular}{|c|c|c|c|c|}
\hline Paciente 5 & $\begin{array}{c}\text { Sem Barra Lado } \\
\text { Esquerdo }\end{array}$ & $\begin{array}{c}\text { Sem Barra Lado } \\
\text { Direito }\end{array}$ & $\begin{array}{c}\text { Com Barra Lado } \\
\text { Esquerdo }\end{array}$ & $\begin{array}{c}\text { Com Barra Lado } \\
\text { Direito }\end{array}$ \\
\hline $1^{\circ}$ exame & 7,65 & 6,65 & 15,20 & 12,15 \\
\hline $2^{\circ}$ exame & 4,45 & 2,05 & 11,95 & 10,00 \\
\hline $3^{\circ}$ exame & 2,15 & 1,75 & 8,95 & 10,00 \\
\hline
\end{tabular}




\begin{tabular}{|c|c|c|c|c|}
\hline Paciente 6 & $\begin{array}{c}\text { Sem Barra Lado } \\
\text { Esquerdo }\end{array}$ & $\begin{array}{c}\text { Sem Barra Lado } \\
\text { Direito }\end{array}$ & $\begin{array}{c}\text { Com Barra Lado } \\
\text { Esquerdo }\end{array}$ & $\begin{array}{c}\text { Com Barra Lado } \\
\text { Direito }\end{array}$ \\
\hline $1^{\circ}$ exame & 4,55 & 4,10 & 11,85 & 12,00 \\
\hline $2^{\circ}$ exame & 2,75 & 4,75 & 15,05 & 11,90 \\
\hline $3^{\circ}$ exame & 1,45 & 4,90 & 11,40 & 11,75 \\
\hline
\end{tabular}

\begin{tabular}{|c|c|c|c|c|}
\hline Paciente 7 & $\begin{array}{c}\text { Sem Barra Lado } \\
\text { Esquerdo }\end{array}$ & $\begin{array}{c}\text { Sem Barra Lado } \\
\text { Direito }\end{array}$ & $\begin{array}{c}\text { Com Barra Lado } \\
\text { Esquerdo }\end{array}$ & $\begin{array}{c}\text { Com Barra Lado } \\
\text { Direito }\end{array}$ \\
\hline $1^{\circ}$ exame & 6,55 & 2,55 & 10,20 & 4,50 \\
\hline $2^{\circ}$ exame & 5,55 & 2,50 & $8 ; 5$ & $9 ; 0$ \\
\hline $3^{\circ}$ exame & 5,45 & 2,55 & 8.1 & $9 ; 2$ \\
\hline
\end{tabular}

\begin{tabular}{|c|c|c|c|c|}
\hline Paciente 8 & $\begin{array}{c}\text { Sem Barra Lado } \\
\text { Esquerdo }\end{array}$ & $\begin{array}{c}\text { Sem Barra Lado } \\
\text { Direito }\end{array}$ & $\begin{array}{c}\text { Com Barra Lado } \\
\text { Esquerdo }\end{array}$ & $\begin{array}{c}\text { Com Barra Lado } \\
\text { Direito }\end{array}$ \\
\hline $1^{\circ}$ exame & 6,40 & 8,40 & 12,05 & 12,55 \\
\hline $2^{\circ}$ exame & 5,50 & 5,30 & 10,15 & 10,00 \\
\hline $3^{\circ}$ exame & 6,95 & 6,05 & 9,95 & 8,45 \\
\hline
\end{tabular}

\begin{tabular}{|c|c|c|c|c|}
\hline Paciente 9 & $\begin{array}{c}\text { Sem Barra Lado } \\
\text { Esquerdo }\end{array}$ & $\begin{array}{c}\text { Sem Barra Lado } \\
\text { Direito }\end{array}$ & $\begin{array}{c}\text { Com Barra Lado } \\
\text { Esquerdo }\end{array}$ & $\begin{array}{c}\text { Com Barra Lado } \\
\text { Direito }\end{array}$ \\
\hline $1^{\circ}$ exame & 2,70 & 1,50 & 3,95 & 2,80 \\
\hline $2^{\circ}$ exame & 1,30 & 1,60 & 2,90 & 1,15 \\
\hline $3^{\circ}$ exame & 2,40 & 1,90 & 1,60 & 1,65 \\
\hline
\end{tabular}




\begin{tabular}{|c|c|c|c|c|}
\hline Paciente 10 & $\begin{array}{c}\text { Sem Barra Lado } \\
\text { Esquerdo }\end{array}$ & $\begin{array}{c}\text { Sem Barra Lado } \\
\text { Direito }\end{array}$ & $\begin{array}{c}\text { Com Barra Lado } \\
\text { Esquerdo }\end{array}$ & $\begin{array}{c}\text { Com Barra Lado } \\
\text { Direito }\end{array}$ \\
\hline $1^{\circ}$ exame & 6,30 & 9,80 & 21,40 & 23,10 \\
\hline $2^{\circ}$ exame & 8,90 & 12,65 & 30,85 & 17,95 \\
\hline $3^{\circ}$ exame & 10,0 & 13,75 & 17,00 & 19,45 \\
\hline
\end{tabular}

\begin{tabular}{|c|c|c|c|c|}
\hline Paciente 11 & $\begin{array}{c}\text { Sem Barra Lado } \\
\text { Esquerdo }\end{array}$ & $\begin{array}{c}\text { Sem Barra Lado } \\
\text { Direito }\end{array}$ & $\begin{array}{c}\text { Com Barra Lado } \\
\text { Esquerdo }\end{array}$ & $\begin{array}{c}\text { Com Barra Lado } \\
\text { Direito }\end{array}$ \\
\hline $1^{\circ}$ exame & 2,30 & 4,60 & 11,15 & 9,70 \\
\hline $2^{\circ}$ exame & 2,10 & 5,5 & 9,95 & 9,35 \\
\hline $3^{\circ}$ exame & 1,80 & 1,80 & 3,15 & 9,65 \\
\hline
\end{tabular}

\begin{tabular}{|c|c|c|c|c|}
\hline Paciente 12 & $\begin{array}{c}\text { Sem Barra Lado } \\
\text { Esquerdo }\end{array}$ & $\begin{array}{c}\text { Sem Barra Lado } \\
\text { Direito }\end{array}$ & $\begin{array}{c}\text { Com Barra Lado } \\
\text { Esquerdo }\end{array}$ & $\begin{array}{c}\text { Com Barra Lado } \\
\text { Direito }\end{array}$ \\
\hline $1^{\circ}$ exame & 2,95 & 1,50 & 5,90 & 4,45 \\
\hline $2^{\circ}$ exame & 1,80 & 1,65 & 7,15 & 4,00 \\
\hline $3^{\circ}$ exame & 1,60 & 2,20 & 6,85 & 5,50 \\
\hline
\end{tabular}

\begin{tabular}{|c|c|c|c|c|}
\hline Paciente 13 & $\begin{array}{c}\text { Sem Barra Lado } \\
\text { Esquerdo }\end{array}$ & $\begin{array}{c}\text { Sem Barra Lado } \\
\text { Direito }\end{array}$ & $\begin{array}{c}\text { Com Barra Lado } \\
\text { Esquerdo }\end{array}$ & $\begin{array}{c}\text { Com Barra Lado } \\
\text { Direito }\end{array}$ \\
\hline $1^{\circ}$ exame & 5,90 & 4,45 & 8,15 & 4,75 \\
\hline $2^{\circ}$ exame & 7,15 & 4,00 & 7,80 & 5,55 \\
\hline $3^{\circ}$ exame & 6,85 & 5,50 & 6,80 & 7,10 \\
\hline
\end{tabular}

\begin{tabular}{|c|c|c|c|c|}
\hline Paciente 14 & $\begin{array}{c}\text { Sem Barra Lado } \\
\text { Esquerdo }\end{array}$ & $\begin{array}{c}\text { Sem Barra Lado } \\
\text { Direito }\end{array}$ & $\begin{array}{c}\text { Com Barra Lado } \\
\text { Esquerdo }\end{array}$ & $\begin{array}{c}\text { Com Barra Lado } \\
\text { Direito }\end{array}$ \\
\hline $1^{\circ}$ exame & 7,95 & 5,05 & 11,85 & 12,00 \\
\hline $2^{\circ}$ exame & 8,70 & 3,65 & 15,05 & 11,90 \\
\hline $3^{\circ}$ exame & 8,00 & 6,40 & 11,40 & 11,75 \\
\hline
\end{tabular}




\begin{tabular}{|c|c|c|c|c|}
\hline Paciente 15 & $\begin{array}{c}\text { Sem Barra Lado } \\
\text { Esquerdo }\end{array}$ & $\begin{array}{c}\text { Sem Barra Lado } \\
\text { Direito }\end{array}$ & $\begin{array}{c}\text { Com Barra Lado } \\
\text { Esquerdo }\end{array}$ & $\begin{array}{c}\text { Com Barra Lado } \\
\text { Direito }\end{array}$ \\
\hline $1^{\circ}$ exame & 7,30 & 1,85 & 11,15 & 9,70 \\
\hline $2^{\circ}$ exame & 6,30 & 6,20 & 9,95 & 9,35 \\
\hline $3^{\circ}$ exame & 6,95 & 2,10 & 3,15 & 9,65 \\
\hline
\end{tabular}

\begin{tabular}{|c|c|c|c|c|}
\hline Paciente 16 & $\begin{array}{c}\text { Sem Barra Lado } \\
\text { Esquerdo }\end{array}$ & $\begin{array}{c}\text { Sem Barra Lado } \\
\text { Direito }\end{array}$ & $\begin{array}{c}\text { Com Barra Lado } \\
\text { Esquerdo }\end{array}$ & $\begin{array}{c}\text { Com Barra Lado } \\
\text { Direito }\end{array}$ \\
\hline $1^{\circ}$ exame & 4,60 & 2,70 & 5,90 & 4,45 \\
\hline $2^{\circ}$ exame & 4,05 & 2,60 & 7,15 & 4,00 \\
\hline $3^{\circ}$ exame & 4,35 & 5,00 & 6,85 & 5,50 \\
\hline
\end{tabular}

\begin{tabular}{|c|c|c|c|c|}
\hline Paciente 17 & $\begin{array}{c}\text { Sem Barra Lado } \\
\text { Esquerdo }\end{array}$ & $\begin{array}{c}\text { Sem Barra Lado } \\
\text { Direito }\end{array}$ & $\begin{array}{c}\text { Com Barra Lado } \\
\text { Esquerdo }\end{array}$ & $\begin{array}{c}\text { Com Barra Lado } \\
\text { Direito }\end{array}$ \\
\hline $1^{\circ}$ exame & 4,60 & 2,70 & 6,30 & 3,55 \\
\hline $2^{\circ}$ exame & 4,05 & 2,60 & 6,00 & 3,65 \\
\hline & 4,35 & 5,00 & 9,35 & 1,95 \\
\hline
\end{tabular}

\begin{tabular}{|c|c|c|c|c|}
\hline Paciente 18 & $\begin{array}{c}\text { Sem Barra Lado } \\
\text { Esquerdo }\end{array}$ & $\begin{array}{c}\text { Sem Barra Lado } \\
\text { Direito }\end{array}$ & $\begin{array}{c}\text { Com Barra Lado } \\
\text { Esquerdo }\end{array}$ & $\begin{array}{c}\text { Com Barra Lado } \\
\text { Direito }\end{array}$ \\
\hline $1^{\circ}$ exame & 2,95 & 5,45 & 7,00 & 9,60 \\
\hline $2^{\circ}$ exame & 4,10 & 4,70 & 4,35 & 10,0 \\
\hline $3^{\circ}$ exame & 6,50 & 2,75 & 6,65 & 9,30 \\
\hline
\end{tabular}




\begin{tabular}{|c|c|c|c|c|}
\hline Paciente 19 & $\begin{array}{c}\text { Sem Barra Lado } \\
\text { Esquerdo }\end{array}$ & $\begin{array}{c}\text { Sem Barra Lado } \\
\text { Direito }\end{array}$ & $\begin{array}{c}\text { Com Barra Lado } \\
\text { Esquerdo }\end{array}$ & $\begin{array}{c}\text { Com Barra Lado } \\
\text { Direito }\end{array}$ \\
\hline $1^{\circ}$ exame & 3,70 & 10,65 & 18,05 & 13,55 \\
\hline $2^{\circ}$ exame & 4,35 & 8,35 & 16,35 & 14,55 \\
\hline $3^{\circ}$ exame & 5,65 & 6,50 & 12,70 & 14,00 \\
\hline
\end{tabular}

\begin{tabular}{|c|c|c|c|c|}
\hline Paciente 20 & $\begin{array}{c}\text { Sem Barra Lado } \\
\text { Esquerdo }\end{array}$ & $\begin{array}{c}\text { Sem Barra Lado } \\
\text { Direito }\end{array}$ & $\begin{array}{c}\text { Com Barra Lado } \\
\text { Esquerdo }\end{array}$ & $\begin{array}{c}\text { Com Barra Lado } \\
\text { Direito }\end{array}$ \\
\hline $1^{\circ}$ exame & 11,65 & 6,50 & 14,75 & 3,60 \\
\hline $2^{\circ}$ exame & 5,35 & 6,00 & 10,00 & 4,90 \\
\hline $3^{\circ}$ exame & 7,15 & 4,50 & 2,95 & 4,35 \\
\hline
\end{tabular}

\begin{tabular}{|c|c|c|c|c|}
\hline Paciente 21 & $\begin{array}{c}\text { Sem Barra Lado } \\
\text { Esquerdo }\end{array}$ & $\begin{array}{c}\text { Sem Barra Lado } \\
\text { Direito }\end{array}$ & $\begin{array}{c}\text { Com Barra Lado } \\
\text { Esquerdo }\end{array}$ & $\begin{array}{c}\text { Com Barra Lado } \\
\text { Direito }\end{array}$ \\
\hline $1^{\circ}$ exame & 6,65 & 2,80 & 9,85 & 5,80 \\
\hline $2^{\circ}$ exame & 5,80 & 6,25 & 6,70 & 5,05 \\
\hline $3^{\circ}$ exame & 2,85 & 3,85 & 6,20 & 8,75 \\
\hline
\end{tabular}

\begin{tabular}{|c|c|c|c|c|}
\hline Paciente 22 & $\begin{array}{c}\text { Sem Barra Lado } \\
\text { Esquerdo }\end{array}$ & $\begin{array}{c}\text { Sem Barra Lado } \\
\text { Direito }\end{array}$ & $\begin{array}{c}\text { Com Barra Lado } \\
\text { Esquerdo }\end{array}$ & $\begin{array}{c}\text { Com Barra Lado } \\
\text { Direito }\end{array}$ \\
\hline $1^{\circ}$ exame & 6,35 & 6,75 & 6,30 & 3,55 \\
\hline $2^{\circ}$ exame & 3,80 & 9,05 & 6,00 & 3,65 \\
\hline $3^{\circ}$ exame & 4,25 & 6,45 & 9,35 & 1,95 \\
\hline
\end{tabular}

\begin{tabular}{|c|c|c|c|c|}
\hline Paciente 23 & $\begin{array}{c}\text { Sem Barra Lado } \\
\text { Esquerdo }\end{array}$ & $\begin{array}{c}\text { Sem Barra Lado } \\
\text { Direito }\end{array}$ & $\begin{array}{c}\text { Com Barra Lado } \\
\text { Esquerdo }\end{array}$ & $\begin{array}{c}\text { Com Barra Lado } \\
\text { Direito }\end{array}$ \\
\hline $1^{\circ}$ exame & 6,75 & 6,10 & 11,15 & 9,70 \\
\hline $2^{\circ}$ exame & 6,25 & 8,75 & 9,95 & 9,35 \\
\hline $3^{\circ}$ exame & 1,35 & 5,70 & 3,15 & 9,65 \\
\hline
\end{tabular}


ANEXO A - Parecer do Comitê de Ética em Pesquisa

\title{
Faculdade de Odontologia
} Universidade de Sáo Paulo

\section{PARECER DE APROVAÇĀO}

Protocolo $102 / 05$

\begin{abstract}
Com base em parecer de relator, o Comitê de Ética em Pesquisa. APROVOU o protocolo de pesquisa "Estudo comparativo da intensidade da força de mordida de próteses totais convencionais e overdentures inferiores retidas por sistema barra/clip sobre implante", de responsabilidade do Pesquisador Ricardo Soeiro Rodrigues, sob orientação do Professor Doutor Vyto Kiausinis.

Tendo em vista a legislação vigente, devem ser encaminhados a este Comitê relatórios anuais referentes ao andamento da pesquisa e ao término cópia do trabalho em "cd". Qualquer emenda do projeto original deve ser apresentada a este CEP para apreciação, de forma clara e sucinta, identificando a parte do protocolo a ser modificada e suas justificativas
\end{abstract}

São Paulo, 03 de agosto de 2005

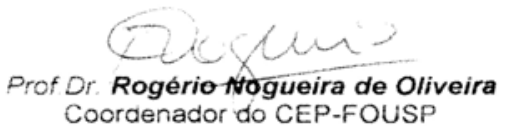

Coordenador do CEP-FOUSP 